\title{
THE-RIVERSIDE-LIBRARY FOR-YOUNG.PEOPLE
}

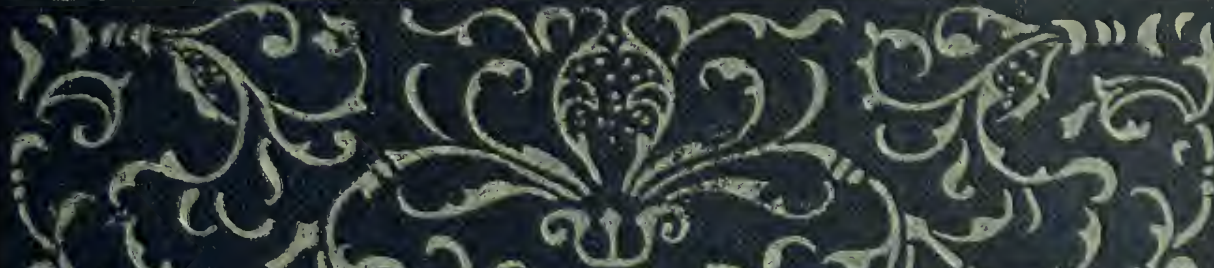

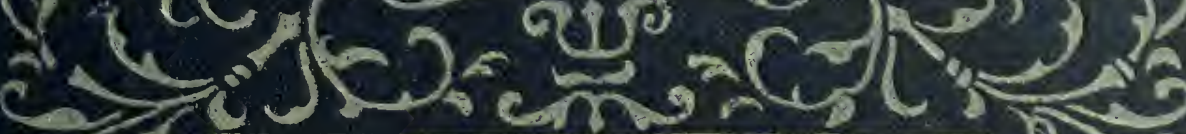

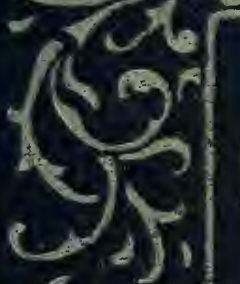

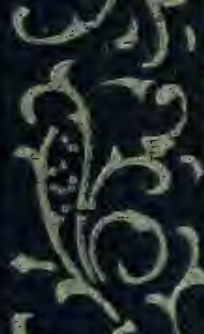

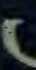

(ब) $\sqrt{22}$

aro

FRAIL CHILDREN OF THE AIR

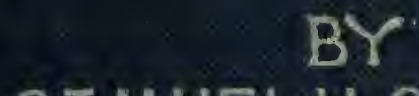

SATMUEL.H.SCUDDER

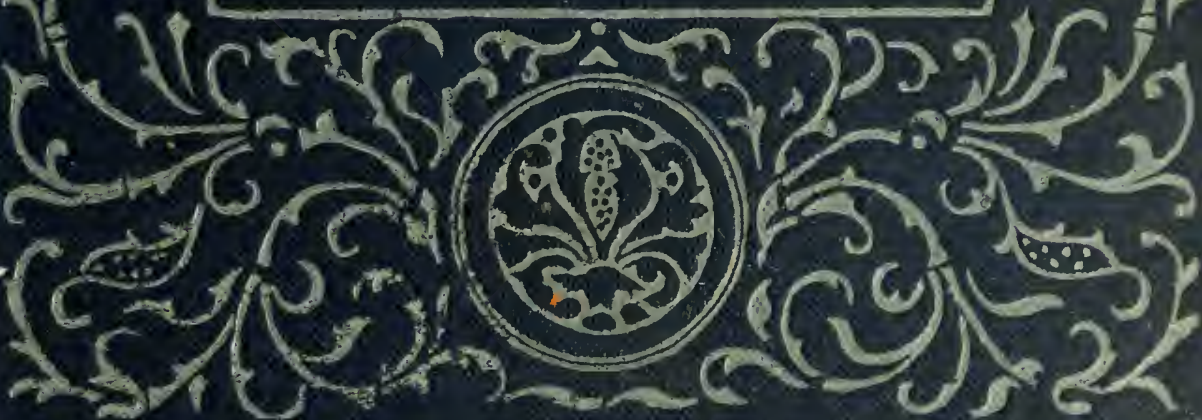

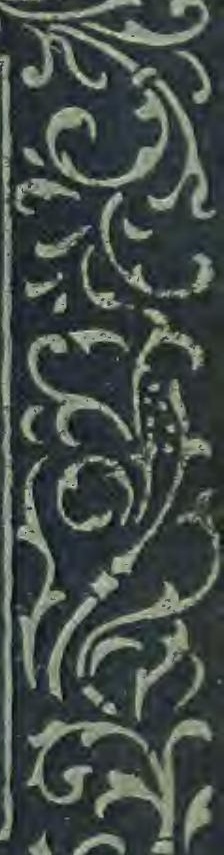



$1 /$

J. C. Bridw -1! 






Number 15 FRAIL CHILDREN OF THE AIR By SAMUEL HUBBARD SCUDDER $\overbrace{}^{2}$ 



\section{FRAIL CHILDREN OF THE AIR}

QL

544

$5425 \geq$ EXCURSIONS INTO THE IVORLD

ENT

OF BUTTERFLIES

SAMUEL HUBBARD SCUDDER

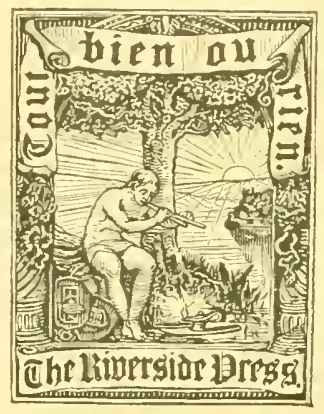

BOSTON AND NEW YORK

HOUGHTON, MIFFLIN AND COMPANY

Che limberside prest, cambrione

I 897

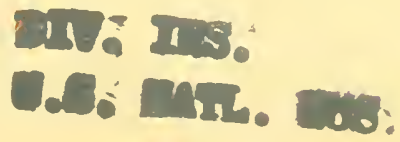


Copyright, 1895,

BY SAMUEL HUBBARD SCUDDER.

All rights reserved.



The Riverside Press, Cambridge, Mass., U. S. A.

Electrotyped and Printed by H. O. Houghton \& Company. 


\section{.5436 \\ Insects}

\section{NOTE}

The following papers are a small selection, for the general reader, of those published in the anthor's "Butterflies of the Eastern United States and Camada," — a work so costly as to reach relatively few, and one which was mainly addressed to the specialist.

As far as possible, these papers have been divested of technical details and in many cases revised or extended, to bring them up to date. Each is wholly independent of the others; but though they do not pretend to form a consistent whole, it is believed that the perusal of these fragments will show, as well as a more elaborate treatise, that there is as much to be learned from the study of the lives and structure of our own every-day butterflies as can be gleaned in any other branch of natural history.

'To gain for our butterflies a deeper interest and closer attention on the part of the observing public is the simple object of the present volume.

Cambridge, Mass., April 13, 1895. 



\section{CONTENTS}

PAGE

Explanation of Plates . . . . . . . . vii

I. Butterflifs in DISGUISE; A STUDY OF MIMICRY 1

II. The STRUgGLE FOR EXISTENCE IN THE GENUS BASILARCHIA . . . . . . 22

III. Decertive DeVices AMONG CATERPILLARS • 38

IV. Butrerfles as botanists . . . . 47

V. The Names OF BUtTerflies . . . . 56

VI. COLOR-RELATIONS OF CHRYSALIDS TO THEIR SURROUNDINGS . . . . . . 63

VII. The IVhite Mountains of New Hampshire AS A HONE FOR BUTTERFLIES . . . 71

VIII. Butterfly sounds . . . . . . 88

IX. Nests and other structures Made BY CATERPILLARS 100

X. Postures of Butterflies At REst AND Asleep 108

XI. The eggs of butterfles . • . • 114

XII. Psychological peculiarities in our Butter-

FLIES . . . . . . . 120

XIII. Social caterpillars . . . . . 127 ,

XIV. The Fixity OF HABIT IN BUtTFrflies * 。135

XV. How butterfles pass the wintei . . 139

XVI. The oldest butterfly inhabitants of New

ENGLAND. . . . . . . 145

XVII. Protective Coloring in Caterpillars . 154



XIX. The PRocession OF THE SEASONS . . . 178 
XX. The Ways of butterfles . . . . 181

XXI. Butterflies at Night and at SEA . . 187

XXII. Some singular things about caterpillars . 194

XXIII. Where did the bUtTERfles COMmon to the Old and the New World originate? 206

XXIV. ANTIGENY; OR SEXUAL DIVERSITY IN BUTTERFLIES . . . . . . . 216

XXY. Lethargy IN Caterpillars . . . . 226

XXVI. A BUDGET OF CURIOUS FACTS ABOUT CHIXSALIDS . . . . . . . . 2\%2

XXVII. Digoneutisu in BUtTerfles . . . . 242 XXVIII. Periodicity in the appearance of ButterFLIES . . . . . . . . 253

XXIX. Color preferences of butterflies, and the ORIGIN OF THEIR COLOR . . . . . 256

XXX. The friends and associates of Caterpillars 263 XXXI. Butterfles OF THE PAST . . . . 267 INDEX TO NAMES OF INSECTS . . . . . . . 277 


\section{EXPLANATION OF PLATES.}

OPPOSITE PAGE

Plate 1. - Basilarchia Aithemiss . . . . . . . . 32

Fig. 1, Egg magnified ; Fig. 2, A spray of willow with caterpillars of different ages feeding upon it, two of the youngest on their perches on a detached leaf. The egg, of natural size, is shown at $a$, a bunch of riffraff at $b$, and the hibernaculum at $c$. Fig. 3, Chrysalis.

The butterfly is shown on the next plate.

Plate 2. - Butterfies of the White Mountains .

Fig. 1, Pieris oleracea. Fig. 2, Basilarchia arthemis. Fig. 3 , Polygonia faunus.

Plate 3. - Nests of Butterfly Caterpillars .

Fig. 1, Nest of Thanaos juvenalis on scrub-oak. Fig. 2, Nest of young Thanaos persins on poplar. Figs. 35), Nests of Euphoeades troilus at successive stages of growth on spice-bush. Fig. 6, Nest of Epargyreus tityrus on Gleditschia. Fig. 7, Nest of Aglais milberti, when full grown, on nettle. Fig. \&, Nest of Vanessa huntera on Gnaphalimm, formed of the petals entangled in web.

Plate 4. - EGGS of Butterfies

Fig. 1, Pontia protodice. Fig. 2, Pholisora catullus. Fig. 3 , Bunch of eggrs of Laertias philenor on a tendril of Aristolochia. Fig. 4, Inverted column of eggs of Polygonia interrogationis. Fig. 5, Epargyreus tityrus. Fig. 6, Cereyonis nephele. Fig. 7 , Speyeria idalia. Fig. 8, Anthocharis genutia. Fig. 9, Brenthis myrina. Fig. 10, Anosia plexippus. Fig. 11, Erora laeta. Fig. 12, Eurymus philodice. Fig. 1:3, Rusticus sendderi. Fig. 14, Strymon titus.

All the illustrations are magnified, excepting Fig. 3, which is slightly reduced. 
Plate 5. - The oldest New England Butrerfies.

Fig. 1, Brenthis montinus. Figs. 2--, Egg, caterpillar. chrysalis, and imago of Oeneis semidea.

The early stages are more or less enlarged.

Plate 6. - Scent-scales or Androronia

Fig. 1, From surface of fore-wing of Argymis atlantis. Fig. 2, From fold of hind-wings of Laertias philenor. Fig. :), From surface of fore-wing of Oeneis jutta. Fig. 4 , From surface of fore-wing of Cyaniris pseudargiolns. Fig. 5, Ponch on hind-wing of Anosia plexippus, concealing antroconia. Fig. 6, From surface of fore wing of Pieris oleracea. Fig. 7, Portion of one of the veins of fore-wing of Speyeria idalia. showing tips of feathered androconia mingled with the ordinary scales. Fig. 8, Part of surface of fore-wing of Callidryas eubule, showing partially erect andronia.

All the drawings are greatly magnified.

Plate $\boldsymbol{7}$. - Butterflies Comon to Two Worlds . . 208

Fig. 1, Vanessa cardui. Fig. 2, Envanessa antiopa. Fig. 3, Vanessa atalanta.

Plate 8. - A polygoneutic and polymorphic ButterFLY, IPHICLIDES AJAX . . . . . . . . . 248

Fig. 1, The spring brood (marcellus). Fig. 2, The summer brood (ajax).

Plate 9. - Coloradan fossil Butterflies

Fig. 1, Prolibythea vagabunda. Fig. 2, Barbarothea florissanti. Fig. 3, Jupiteria charon. Fig. 4, Prodryas persephone. Fig. 5, Lithopsyche styx. Fig. 6, Apanthesis lence.

Plate 1, Figs. 2, 3; Plate 2, Fig. 2; Plate 5, Figs. 3, 4; and Plate 8, Fig. 1, are reproduced by the anthor's kind permission from Edwards's "Butterflies of North America." 


\section{FRAIL CHILDREN OF THE AIR}

BUTTERFLIES IN DISGUISE; A STUDY OF MIMICRY

Every observer, even the most casual, has at some time had his attention arrested by the strange resemblance of some creature to the object upon which it rested; to this form of imitation the term "mimicry" was applied as long ago as 1815 by Kirby and Spence, in the introductory letter to their treatise on entomology. "You would declare," say they, "upon beholding some insects, that they had robbed the trees of their leaves to form for themselves artificial wings, so exactly do they resemble them in their form, substance, and vascular structure; some representing green leaves; and other's those that are dry and withered. Nay, sometimes this mimicry is so exquisite that you would mistake the whole insect for a portion of the branching spray of a tree."

It is not a little curious that it was on the very 
eve of the publication of the "Origin of Species," at the meeting of the British Association for the Advancement of Science, in 1859, that the first attempt was made to collect facts of this nature, and to inquire into the laws which regulate them. At this meeting the late Mr. Andrew Murray read a paper upon the "Disguises of Nature," in which he showed that the most perfect imitation of inanimate objects occurs, not rarely or exceptionally, but in some groups so commonly that the want of it might be regarderl as the exception, and that the concealment of the animal was the plain purpose of the disguise. He confesses, however, that he cannot tell what law has set in motion such endless provision of protection, and can only suggest that it may be found in some force analogous to the great law of attraction; that "like draws to like, or like begets like."

The theory of natural selection, immediately afterward proposed by Darwin, was the key to this puzzle. Its use for this purpose by Bates, in 1862, was one of the earliest independent contributions to the theory from new observations. Buried in the depths of a special systematic paper, there were presented by Bates some of the most striking instances that are known of such 
protective resemblance, in which the animals imitate, not the objects on or near which they live, nor such other ereatures as are in themselves frightful or predaceous, but butterflies quite like themselves, to all external appearance as harmless and as much in need of protection as they. He pointed out, moreover, that there is a special group of butterflies (Heliconinae), of vivid coloring and slow and easy flight, which are the constant subjects of mimicry, while the greater portion of the mimicking butterflies he observed belonged to a very different group (Pierinae), normally white and tolerably unifor'm in color, but which had so changed their livery and even the form of their wings as closely to resemble the objects they minicked in brilliancy of color and variegation, and even in mode of flight. Some, says he, "show a minute and palpably intentional likeness which is perfectly staggering:" Indeed, the likeness proved so close that even after he became aware of the mimicry his practiced eye was often deceived. Or" if he wandered to a new locality, where occurred a new set of Ithomyiae (the most numerously represented among the mimicked genera), the Leptalides (the mimickers) would vary with them so as to preserve the mockery band for band and spot 
for spot. Now his field observations showed him that the mimicking species belonged to a group of butterflies very subject to attack by birds and other foes, while the group which they mimicked had an offensive odor and apparently a taste obnoxious to insectivorous animals, so as to be exempt practically from their attacks. This was shown partly by their exceptional abundance, which did not seem to accord with slow and easy flight and conspicuous coloring, features that naturally would render them an easy prey to their enemies. That these butterflies were truly distasteful to birds has been shown again and again. Thus Belt says, in his "Naturalist in Nicaragua":-

"I had an opportunity of proving in Brazil that some birds, if not all, reject the Heliconii butterflies, which are closely resembled by butterflies of other families and by moths. I observed a pair of birds that were bringing butterflies and dragonflies to their young, and although the Heliconii swarmed in the neighborhood, and are of weak flight, so as to be easily caught, the birds never brought one to their nest. I had a still better means of testing both these and other insects that are mimicked in Nicaragua. The tame, white-faced monkey I have already mentioned was extremely fond of insects, 
and would greedily munch up any beetle or butterffy given to him, and I used to bring him any insects that I found imitated by others, to see whether they were distasteful or not. I found he would never eat the Heliconii. He was too polite not to take them when they were offered to him, and would sometimes smell them, but invariably rolled them up in his hand, and dropped them quietly again after a few minutes. A large species of spider (Nephila) also used to drop them out of its web when I put them into it. Another spider that frequented flowers seemed to be fond of them, and I have already mentioned a wasp that caught them to store its nest with. There could be no doubt, however, from the monkey's actions, that they were distasteful to him."

Bates very naturally argued that if these offensive properties gave the Ithomyiae such exemption from attack as enabled them to swarm in spite of lazy habits and brilliant coloring, then other butterflies living in the same places would gain a certain amount of freedom from attack if their flight and coloring so nearly resembled those of the offensive species as actually to deceive insect-eating animals, even though they were themselves in no way distasteful.

The fact of a resemblance so close that it is to 
all appearances a "palpably intentional likeness" is impossible to question. But how explain it? How could a butterfly change its appearance to such a degree, its wings from a uniform color to a banded, strealed, and spotted pattern, and at the same time lengthen their form and extend the antennae? "Can the Ethiopian change his skin or the leopard his spots?"

The answer, as Bates clearly saw, was to be looked for in the same direction as when accounting for the assumption by animals of the color of their surroundings. Both are produced in the same way, and have the same cause and end. It is only by keeping in view this tolerably obvious truth that we can explain all the freaks of mimicry. "The specific, mimetic analogies," says Bates, "are adaptations, - phenomena of precisely the same nature as those in which insects . . are assimilated in superficial appearance to the vegetable or inorganic substance on which or amongst which they live."

To gain an idea, then, of the processes by which the "staggering" examples of mimicry are produced, we must look first at the simplest forms of protective resemblance. Go to the seashore and observe the grasshoppers among the beach grass. 
They fly up at your approach, whiz off a rod or so, and alight. Can you see them? They are colored so nearly like the sands they live upon that detection of one at rest is almost impossible. On yonder giassy bluff, a stone's throw away, you will find none of them, but other kinds equally, or almost equally, lost to sight by their harmony with their surroundings. What chance of life for either if they suddenly changed places? They would be so conspicnous that every passing bird or other insectivolous creature would sight them. Of course these protective colors have been gained by slow steps. Every grasshopper that found its preferred food among the sands was liable to be eaten. In the long run just those would be eaten which were most easily seen. One which varied in coloring in never so small a degree, so as to be less easily seen than his brother, would live to perpetuate his kind, and his brother come to an untimely end; the progeny would show the fortunate variation, and be more likely to be spared to transmit in increased volume the probability of the happy coloring. Given, then, a brood of grasshopper's that find their preferred food in sandy spots, and unless other and more powerful forces act upon them it must result, from their liability to be eaten by 
creatures fond of grasshoppers, that in time they will resemble in coloring the sand on which they live; it is impossible that they should not. Any creature not specially protected by nauseousness, or habit, or special device of some sort, must in the very nature of things, if it is to live at all, have some other protection, and that afforded by color and pattern is by far the most common. The world is made up of eaters and eaten, of devices to catch and devices to avoid being caught.

We may apply the same reasoning to two kinds of butterflies subject naturally to the same class of enemies; that is, living in the same region and flying at the same time. If one has the slightest advantage over the other in the fight for life, by being, for instance, distasteful to one class of common enemies, so that these forbear to attack it after experiment or by instinct (the result of ancestral experiments), and there be among the less favored flock, here and there, an individual which, under circumstances favoring it, such as distance or shadow, may more often than its fellows be mistaken by the enemy for one of its distasteful neighbors through its possession of a little more than usual of a certain tint on a part of the wing, a little larger spot here, or more of the sem- 
blance of a band there, - how small soever this difference may be, it must, by the very laws of natural selection, be cherished, perpetuated, increased, by slow but sure steps. Nor is there any limit to its increase except its absolute deception of the enemy. So long as there is the slightest advantage in variation in a definite possible direction, the struggle for existence will compel that variation. Knowing what we now know of the laws of life, mimicry of favored races might even have been predicted.

It is to be presumed that the actual colors found in a mimicking butterfly are, with rare exceptions, such as existed somewhere in the ancestral form. In the case of our own mimicking Basilarchia, for example, whose orange ground tint is so totally at variance with the general color of the other normal members of the group, it will be observed that all the normal species possess some orange. Without this as a precedent fact, such perfect mimicry might perhaps never have arisen. Individuals among the normal speeies vary somewhat in this particular, so that it is easy to suppose that some of the original $B$. archippus, with more orange than usual, may have escaped capture, on occasion, from this cause. From such a small beginning, 
such as one may now see every year in B. astyanax, sprang doubtless the whole story, and at last we find a butterfly which has for a ground color of both surfaces of the wings an orange which is the exact counterpart of that of Anosia plexippus; by reason of which, in all probability, it enjoys a freedon from molestation comparable to that attributed to plexippus, so that it ventures more into the open country than its allies, and thus gains a wider pasturage and surer subsistence.

It wonld seem, then, to be plain that all cases of protective coloring and mimetic form come under one and the same law, and have been produced by the same means (the survival of the best mocker), whether the subject initated be animal, regetable, or mineral. The actual outcome is, incleed, vastly more surprising in some cases than in others, in some "perfectly staggering," as Bates says; yet though there be to all appearances a " palpably intentional likeness," there is found to be no intention in the case so far as mocker and mocked are concerned, but the result of a natural selection against which neither could even strive, and of which neither was ever conscious. ${ }^{1}$ The process

1 "Imitation" and "mimicry" both imply intention ; but the limits of our langnage compel ns to use figurative speech; we have no word to express meonscious mimicry. 
has been a long one, so that in the case of parastatic mimicry, as that form which involves the copying of one's fellows might be termed (or, if one prefers an English term, neighborly minicry), we may readily presume far less difference between mocker and mocked when the mimicry between. them first began than now exists between the mocked and the normal relatives of the mocker. It is argued, indeed, with great show of reason, that as the resemblance grew stronger the birds became more sharp-sighted, which reflected again on the mimicry, and that thus the final departure from the normal type was intensified; but this assumption is not necessary.

So far we have referred only to the first illustrations of mimiery given by Bates, those which present the simplest, though not the least striking forms, involving as they do the widest departure of mimetic butterflies from their normal type. Let us glance briefly at some other points.

A new element enters when we find that neighborly mimiery is sometimes confined to a single sex of a butterfly; that is to say, one sex is of the normal color of its allies, while the opposite sex departs widely therefrom, and is found to resemble closely another and a nauseous butterfly of the 
same region. Now, as mimicry is clearly only a protective device, or rather outcome, we should naturally inquire whether either sex was more in need than the other of protection from those foes against which mimicry could avail anything. Plainly, it would be the female, since, were she lost before oviposition, just so many eggs would be lost with her; and besides this, her heavier, more sluggish flight - a necessity from her burden of eggs - makes her an easier prey to insectivorous creatures against which mimicry is aimed. Accordingly, we find many instances in which the female is mimetic and the male normal. Probably they are far more numerous than we imagine, and many of the exceedingly common differences between the sexes, which since Darwin's day we have been wont to set down to sexual selection, doubtless are to be attributed to something of this nature. But there is no known case of parastatic mimicry confined to the male sex. On the other hand, some of the most vivid and striking examples of mimicry are to be found confined to the females. There is one example brought forward by Trimen which is the most surprising yet published, where not only have two kinds of African swallow-tail butterflies, one with, the other with- 
out tails, long supposed to be widely distinct species, been proved to be male and female, the female departing from the type to mimic a Enploeid butterfly, but the male is found to have no less than three distinct wives, each mimicking a different kind of Euploeid characteristic of the region inhabited by mocker and mocked, and each very different from the husband; while an allied male, formerly thought to be the same as the preceding, keeps a similar harem, similarly mimetic of species of Euploeinae prevailing in its districts, and, besides, has in one place at least a concubine which is not at all mimetic. Surely the play of mimicry can go little farther.

But in all this arises a new difficulty. How is it that mimetic qualities, which in a given locality breed so true, are inherited by one sex only? Why do the males escape? Here the question is not, Why are the females mimetic? but rather, Why are the males not mimetic? To this no satisfactory answer has yet been given. It has been attributed to sexual selection, the females being supposed to be of a conservative frame of mind, and admitting no variation in their consorts; but this it would be difficult to prove, or, it seems to me, to render very probable. 
This, however, is the view of it taken by Belt, who remarks that " it is supported by the-fact that many of the males of the mimetic Leptalides have the upper half of the lower wing of a pure white, whilst all the rest of the wings is barred and spotted with black, red, or yellow, like the species they mimic. The females have not this white patch, and the males usually conceal it by covering it with the upper wing, so that I camnot imagine its being of any other use to them than as an attraction in courtship, when they exhibit it to the females, and thus gratify their deep-seated preference for the normal color of the order [tribe] to which the Leptalides belong."

Still another difficulty besets the subject, - a difficulty in part recognized by Bates. It has been the subject of much discussion, but on the principles supported above is far more easily disposed of. Bates found not only that the distasteful Heliconoid butterflies were mimicked by those which were in evident need of protection, from the fact of their being greedily eaten by insectivorous animals, but that there were cases of mimicry quite as close among the Heliconoid butterflies themselves. Many instances of the same lind have since been recognized in other parts of the world. 
Here both mocked and mockers were protected by nauseousness, and it was by no means clear to him: how any advantage, the fundamental cause of variation of this kind, was to be gained by such imitation. The resemblance was so close that, according to his own words, "species belonging" to distinct genera have been confounded, owing to their being almost identical in colors and markings; in fact, many of them can scarcely be listinguished except by their generic characters." Bates himself was inclined to look upon these, not as cases of parastatic mimiery, but as due " to the similar adaptation of all to the same local, probably inorganic conditions."

But this vague explanation has not been satisfactory to others, and Wallace and Meldola, and particularly Fritz Müller, have followed the matter, and shown that, if the mimicked species possesses the slightest arlvantage in the mere point of numbers over the mimicking, this advantage is sufficient to produce the mimicry concerned. It is highly probable, from the experiments of Fritz Müller and the observations of Belt, that the Heliconoid butterflies are simply distasteful, not poisonous, to insectivorous animals. Miiller has even figured a consiclerable number of 
examples of a single species found by him (in this instance belonging to the Acraeinae, a closely allied nauseous group) in which the wings had evidently been seized by insectivorous birds, for they show great gaps in their wings, such as a bill would make upon them. By such seizures many of the distasteful butterflies doubtless perish, and Meldola shows very clearly by mathematical analysis that a resemblance between two species so close that the experimental seizures would be divided between them in the ratio of their numbers gives an advantage decidedly in favor of the scarcer species. Or, as Wallace puts it, "if two species, both equally distasteful, closely resemble each other, then the number of individuals sacrificed is divided between them in the proportion of the squares of their respective numbers." If the rarer species is only one tenth as numerous, it will benefit in the proportion of one hundred to one.

Exactly the same argument can be applied to examples of mimicry between two species where neither is distasteful. These cases, though less conspicuous, are probably more numerous than those of which we have been speaking; for, on the principles that we have laid down, any advan- 
tage which one species has over another will be attacked by that other in every possible way; and if there be elements in the structure or mark. ings which admit of a closer resemblance between the two, and this resemblance will lessen the disadvantage under which the weaker species labors, then in the very nature of things that resemblance must follow, unless other opposing elements intervene. For here, at least, the relative abundance of the species concerned is an essential element. It has been thought by some to be also an essential element of all mimicry; but not only is there no sufficient reason for holding such a view, excepting in cases like those last quoted, but it has been asserted by no less keen an observer than Fritz Müller himself, and agreed to by others, that the mimicked species is not always more abundant than its counterfeit; indeed, the mimicking and the mimicked species have been found to vary in their relative numbers in different localities, sometimes the one, sometimes the other, preponderating. But with regard to mimicry of one distasteful butterfly by another, there may also enter another element; for it is hardly to be believed that all distasteful butterflies are equally objectionable to all birds, 
and it is obvious that the more distasteful the butterfly is to its rapacious foes, by so much more has it the advantage in the struggle for life; so that mimicry of one distasteful butterfly by another less distasteful is scarcely more surprising than the mimicry of a nauseous butterfly by one that has not this quality.

Only one further difficulty remains, and this is that, in a few instances, an insect has been found differing so peculiarly from its congeners as to leave no doubt in the mind that it differs in the direction of mimicry when no exact prototype can be found. For example, the butterfly of one of the Nymphalinae, with normal dark colors and a definite pattern, will vary altogether from that patter'n and coloring, to take on the Jivery peculiar to the Euploeinae, a group very extensively imitated, when there is found in the regions inhabited by this supposed mimicking species no Euploeid which it in any way specially resembles. In this case but two explanations have been offered: one that the mimicked butterfly has not yet been found, another that it has for some cause become extinct. But with the extinction of the mimicked form we should expect speedy extinction of the mimicking, and it 


\section{A STUDY OF MIMICRY}

woull seem more probable that these were cases of general mimiery in process of formation toward some specific type. At any rate, we need to know more definitely about these instances before we can properly discuss them. They have never been collated.

In support of the general theory of mimicry, it may be said that eases are far more common in the tropics than in temperate regions, even relatively; and so, too, are insectivorous animals. The accounts of travelers in the tropies constantly mention the attacks of birds upon butterflies, while instances of butterflies being seen pursued by birds are vastly more rare in the temperate regions. I have never seen one. In the tropies, moreover, the birds are aided by a great number of other insectivorous animals, such as lizards. In our own country, therefore, we should not look for many instances of mimicry of any decided type. The most striking is unquestionably that of Basilarchia archippus, which mimies Anosia plexippus, and the closely related case of Basilarchia eros and Tasitia berenice, the last two butterflies largely supplanting the first two on the peninsula of Florida. In both these instances the mimicry is enjoyed by both sexes. A third 
case is found in the less close but still striking mimicry of our Red-spotted Purple (Basilarchia astyanax) by the female of Semnopsyche diana, an instance the more remarkable as the mimicked species belongs to the same genus as our two other mimicking forms.

When we take a general view of mimicry as exhibited by one butterfly for another, how strange it seems; and what an interesting illustration it is of the adaptability and pliancy of natural forces, that for the evident protection of one species in the struggle for existence so exact and beautiful a resemblance should be brought about! Consider for a moment that the subjects of mimicry are at the final stage of life; they have already passed through nearly all the dangers to which the species as a species is subjected, — so rudely subjected that they are indeed but a centesimal, or even less, rarely or never more, of those brought into the world with them. During the early period of their life they were exposed to vastly more dangers than they can now experience. At times they were absolutely helpless, without the power of movement. They are now endowed with powers of flight sufficient to thwart the purpose of many a foe; yet it is in 
just this period that these special and extraordinary provisions for their safety and for the accomplishment, so far as the species is concernerl, of the end of their life are given them. All this has been brought about for the sole purpose of prolonging their aerial life for the exceedingly few days which are necessary for pairing and the deposition of eggs. The more we contemplate so strange and perfect a provision, and the means by which it is accomplished, the more are we impressed with the capabilities of natural selection, and begin to comprehend how powerful an element it has been in the development of the varied world of beauty about us. 


\section{II.}

THE STRUGGLE FOR EXISTENCE IN THE GENUS BASILARCHIA

THE power of reproduction conceded, the universal instinct for self-preservation is the fundamental and controlling principle by which the perpetuation of any kind of animal is successfully reached. The uncontrollable maternal instinct of self-sacrifice existing in some creatures alone overmasters it, and this exists only in the higher animals, which, compared with the great mass, are but few in number ; and is then in most cases called into play only when the creature's life-work is nearly finished. No such instinct occurs among butterflies, nor is in any way likely to be found, so that "self-preservation" and "perpetuation of the species" are here, at least through all but the closing days of life, practically equivalent terms. The "struggle for existence" in the species and in the individual are largely convertible terms.

This struggle is the perpetual inheritance of the individual. The individual inherits alike its struc- 
ture and its habits of life, which latter are very largely, perhaps almost absolutely, dependent on its structure; its tastes and its propensities; its fears and its devices to circumvent its enemies; all its instincts, which are to a great extent, possibly wholly, the entailment of ancestral habits; its very attitudes, whether at rest or in motion. Its advantages and its disadvantages are thus alike its legacy; so too the peculiar means it employs to disembarrass itself of these disadvantages. This is especially true of the insect in its earlier stages, where freedom to change the immediate surroundings is exceedingly limited or altogether impossible, except so far as there is foresight, or an instinct marvelously akin to foresight, on the part of the creature in an antecedent stage.

It is of mole than usual interest to study the meaus of self-preservation in the genus Basilarchia, since there is hardly another genus of our butterflies where throughout its entire life the insect is apparently so exposed to its enemies. They are all, of their kind, conspicuons objects even to our dull eyes, and more than that they are, with the exception of the chrysalis, always found in unusually conspicuous situations. How then do they manage to escape their keen-sighted foes, the hirds; or 
their wakeful, indefatigable, persistent enemies among the insect tribes, — ichneumons, ants, wasps, flies, mites, and spiders?

Take first the egg-stage. Every one who has attempted to rear butterflies knows what immense destruction falls to the lot of any species at this stage of its life. Ants and spiders look on eggs as delicacies made for their delectation, and there is a whole group of tiny Hymenoptera, almost too small to breathe, one would think, mere specks, which live solely upon insects' eggs, piercing them with their egg-darts, their progeny living imprisoned and feeding on the contents until they have run the cycle of their changes. Some attack whole batches of eggs, laying one egg in each, so that one parasite may destroy the entire brood of one butterfly; others lay their all in one or two eggs, and it is to this class that those belong which sting the eggs of Basilarchia. How does Basilarchia escape this danger? In the first place, the mother rarely lays more than one egg in one spot or even on one bush, though as many as a dozen or two may occasionally be found, where the butterfly's numbers are great and they are growing as it were imprudent. Then it must be remembered that these parasitic flies must be guided less by vision than by touch; and 
again, that most insect eggrs are laid on the broader parts of the leaf on which the young will feed; it is here that the parasite will range in quest of prey; but the eggs of Basilarchia are rarely found except at the extreme tips of leaves, and in addition the leaves of the food-plants concerned are all acuminate, some to an excessive extent, as in some of the poplars and birches. When the parasite has, however, found an egg, it may well be inquired whether she would not be deceived by it. It differs from the eggs of all our other butterflies in that it is besprinkled with little flexible filaments, for all the world like the hairs of some leaves. Or if the clothing of the egg's did not deceive, she might even then find it difficult of attack, for minute as these parasites are, less than half a millimetre long, their bodies would extend across at least three of the polygonal cells which regularly stud the surface of the egg, and which send forth these little filaments at every angle, so that poor bewildered Madame must struggle through a weary chaparral before she can attain the barren grounds at the summit and find a spot to readily insert her sting. Yet that she succeeds is only too evident to the collector ; the larger part of the eggs obtained in the open field which have fallen into my hands have been parasitized. 
This is its but too partial defense against its special enemies. But how about those wandering buccaneers, the ants, mites, and spiders? These labor under the same visual defects as the direct parasites, or sometimes greater ones; and the position of the egg, remote from their usual hunting-ground, must serve as no inconsiderable protection; how great, there are hardly means of measurement. Their greatest protection from these savages, which cannot fly but must wander ceaselessly about on foot in search of prey with satanic energy, is undoubtedly in the fewness of their number on one plant. The spider that finds two eggs of a Basilarchia in one day must be an excellent hunter.

Escaped at last from these dangers, which only last at the most ten days, the caterpillar crawls forth from its prison and begins its active life. It is a scrawny, juiceless looking thing, all covered with warts, and less than any other newly born caterpillar would seem a tempting morsel even to an ichneumon or a spider. Yet both make havoc with it at this time. To a wandering ichneumon contact with an empty egg-shell would probably mean, as a result of its inherited wisdom, that some nice young caterpillar was abont, and the neighborhood would be all the more thoroughly 
ransacked. Caterpillars devouring their egg-shells, and so not leaving this " scent" behind them, would oftenest escape, and by degrees this habit would bo perpetuated and fixed; and so it is here; almost invariably the caterpillar hastens to destroy its former prison walls, which it devours to the very base, too closely glued to the leaf to be eaten: probably it breathes more freely when that is done.

But where does it now find itself? Its food at its very feet, - yes; but in the most exposed position possible. Atop the extreme tip of one of the outmost leaves of a spray that projects most freely into the sun and air, just where it can most easily be seen by the passer by ; this seems to be the case nine times out of ten. It is, however, probably the safest place from the prowling spiders; but surely not from its flying enemies. What does it do? Retreat down the leaf? That would be only to exchange one danger for another, and on its way to a presumed place of safety it would be more sure of detection, because a moving object in nature is always most easily noticed. No, it eats the nearest bit of leaf down to but not inchuding the midrib, first on one side and then on the other, and then retires to near the tip of the midrib, to digest it; subsequent meals it takes in the same way, moving 
with excessive deliberation along its narrow path and retiring always to the same spot. On this perch it cannot be seen from below, and from the sides and above seems almost or wholly a part of the denuded midrib to which it clings; more particularly when the leaves are in motion by the wind, as they usually are on the trees on which it feeds, particularly in the case of the aspen.

That this mode of life is on the whole an advantage to it is rendered probable from the fact that there are two cases known, in which it is followed very closely by caterpillar's of the moth (Notodonta) feeding on the very same plant as species of butterflies with this habit (one in Europe and one in America); while the caterpillars of Basilarchia employ a further device, the actual import of which has been a puzzle. Very soon after birth, when it has eaten but a very few swaths down the leaf, the little fellow constructs a small and loose packet from minute bits of leaf and other rejectamenta, loosely fastened to one another and to the midrib, close to but scarcely touching the eaten edge of the leaf; and as fast as the leaf is eaten, it removes this packet (continually added to until it becomes about as big as a small pea) farther and farther down the midrib away from its perch, always keeping it near the 
eaten edge. It should be noted that it is so loosely attached, the bits of leaf at all possible angles, that it is moved by the least breath. Meanwhile the caterpillar has been growing larger and more conspicuous and is thus in greater peril from its enemies. There are two possible services that this odd packet may render. A spider wandering over the leaf and observing its motion may seize it and thinking it has a prize, hurry away with it and leave its architect unharmed. This seems to me rather a strained suggestion, for a wandering spider would probably proceed to investigate it on the spot. Another explanation seems more probable. It should be remembered that the leaves preferred by these creatures as food are mostly such as are easily shaken by the wind, and as the caterpillar moves with the leaf and with all the surrounding leaves (in a continual fluttering in the case of the trembling aspen, and to a less degree in the other foodplants), this of itself is a protection to it, as it would more readily escape observation as an object distinct from the leaves, all being in motion together; but on the more stable leaves, like the willow and especially the Rosaceae and the oaks, the motion in a feeble wind would not be sufficient to be serviceable, and here at least the packet 
comes into play. An object in motion among others at rest is a most noticeable thing, a fact well recognized among animals, as a host of them show when they fear being seen. This packet attached by loose silken threads moves, as stated, with a breath of wind and so would distract attention from its architect near by, who has taken pains to place it at the farthest remove from his perch, while still (to avoid undesirable steps) on his daily track. If this be really its object, it is surely one of the ordest devices in nature.

The species of Basilarchia all pass the winter while in the caterpillar state and but partly grown. The caterpillar has moulted at least once (devouring its cast-off clothing, by the way, doubtless that it may not attract attention) and has to prepare against the inclement season. This it does in a very shrewd way, which is all the more remarkable because no trace or semblance of it is seen in caterpillars of the broods that attain their entire growth in the same season. When the proper time approaches, warned thereto possibly by the dryness of its food, or by the cooler nights, the caterpillar constructs a little nest, sometimes from the still unfinished leaf on which it was born, sometimes from one which it prepares specially at 
greater pains; this is done by eating away or biting off the unnecessary parts, and leaving on either side of the base of the leaf little flaps just large enough, when drawn together, bottom side up and meeting above, to form a cylinder into which it can squeeze; a projecting shelf is also left beyond the opening, on which it may stand when ready to crawl in, and upon which it may back out in the spring; the whole of the inside and the upper surface of the shelf are then plastered over with a dense coating of brown silk and the flaps drawn together; more than that, with strangest foresight, the petiole of the leaf is thoroughly fastened to the stem by numberless threads passed carefully and tightly around both; into this cylinder it then crawls head foremost, completely filling the cavity, closing the beveled himder opening with the sloping tuberculate and sharpened terminal segments, sure to find itself there when the long night of winter is passed. No, not quite sure, for a wasp or some other predaceous insect will sometimes tear this fine castle open and destroy its single occupant. Whether it is an additional safeguard or not, it is an instructive fact that, at least where the winters are most severe, nearly all these hibernacula are made out of leaves so near the 
ground that the snow covers them with its warming mantle; and what is more, in certain cases they so closely resemble the winter buds and bursting leaves of the new year that they must sometimes deceive their prowling foes of the early spring.

Shortly after it again appears in the spring and has fed on the tender buds and just opening leaves, it moults again, usually upon the shelf of its hibernaculum, but no longer devours its skin, as it quits the immediate neighborhoor. It now changes its livery as well and is a most extraordinary looking object, withal very conspicuous. Dark and light green and cream color strive for the mastery and leave it streaked and blotched, so that it bears no inconsiderable resemblance, in color at least, to the droppings of some birds, a circumstance which doubtless serves it as some sort of protection. Its body is humped and the bosses bear tubercles which give it a somewhat repulsive aspect; especially a pair a little behind the head are raised aloft, thickly studded with prominences, the effect of which is heightened by the creature's habit of arching this part of the body, bending its head to the ground and raising aloft its hinder part, also studded with roughened 


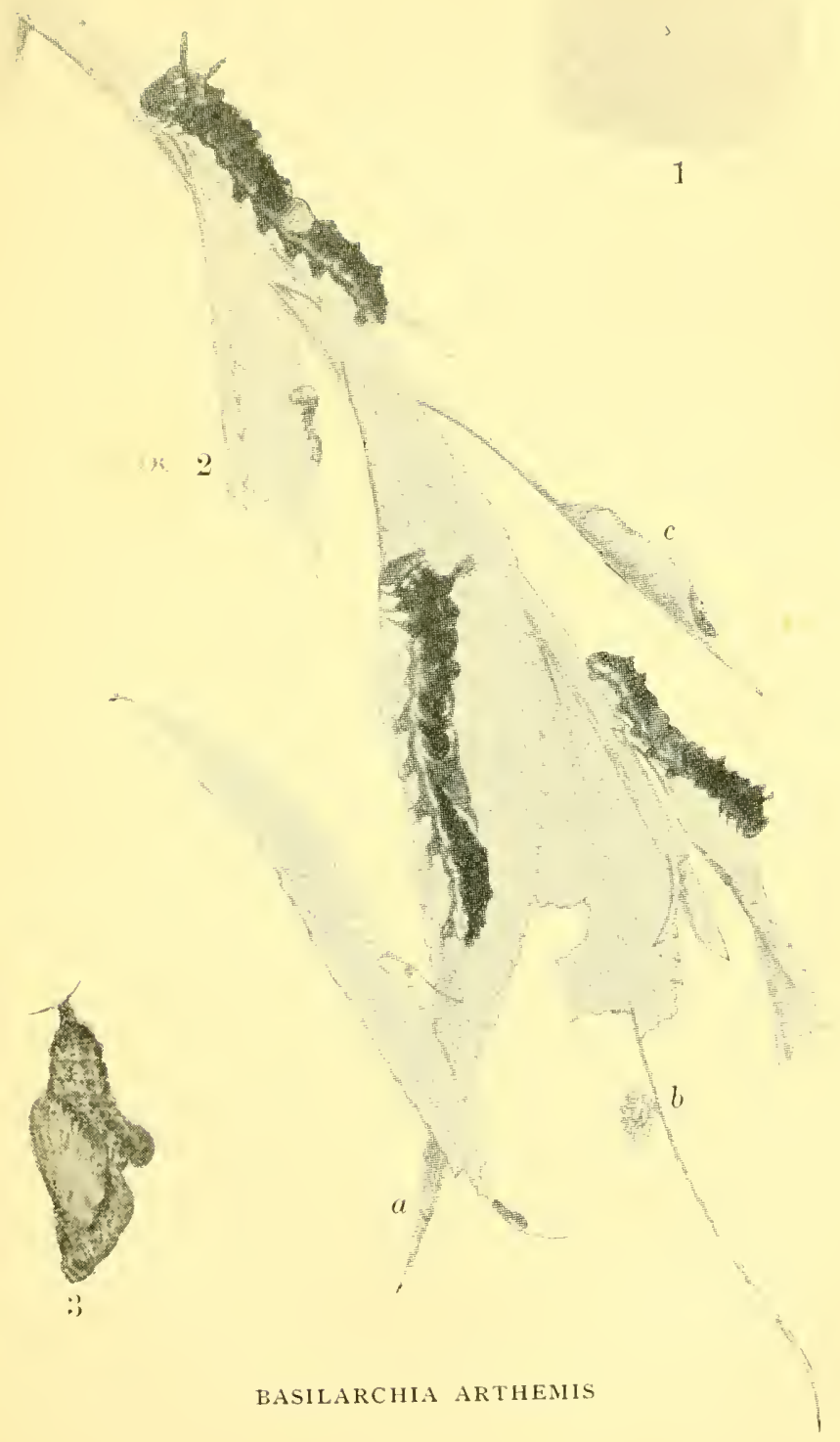



processes. Altogether it is a rather hideous beast. Then too, if disturbed, it raises the front half of its body from the groumd and uses it as a kind of whiplash, throwing it to one side and the other with great violence. When it walks, it moves with a slow and cautions tread, its head trembling as if it had the palsy. All this is donbtless to inspire fear to such enemies as might be tempted to attack it, but to how much avail we can hardly tell. It is certainly attacked in considerable numbers by a parasitic hymenopteron, the young of which live within on the juices of the body and escape from the chrysalis when that is formed.

The chrysalis, helpless thing, probably hangs quite exposed upon the stem of the plant which has given the caterpillar nourishment. We know it almost entirely from those raised in confinement. It has an oddly shaped form, with a great projection on the back like a Roman nose, and is of a dark green or greenish brown color varied with cream color, and smooth as if varnished. This makes it appear like a hanging lump of bird dung, and so again must often prevent its being picked off and devoured by some hungry bird. 
When one that has at last escaped all the perils of its youth finally reaches its full development, it is even more conspicuous and exposed than before. Although now upon the wing and no doubt often able to escape a pursuer by some quick movement, its natural flight is not swift, and its ordinary movements on the wing are a few quick flutters followed by a sailing motion which is most favorable to capture. Its colors differ of course in the different kinds, and they may in this particular be divided into two classes. One effects a deep rich black-blue or blackish purple, and is variegated with light blue and white, the latter partly in the form of bands, on some forming a broad bow across both wings, rendering them most conspicuous and striking objects. They are, too, of a pretty large size, and as they fly mostly in the neighborhood of copses or along shaded roadsides or forest roads, they seem to render themselves by the contrasting background as conspicuous as possible. Another class is of an orange brown color of greater or less depth, while the veins are black, and a black stripe, sometimes accompanied by white dots, crosses the wings. These fly in more open places, more fully exposed to the sum, and are scarcely less conspicuous than their 
fellows. All these butterflies live a considerable time, and indeed the eggs do not mature in the bodies of the females until they have been a fortnight on the wing; and then they do not lay all their eggs at once, or even within a few days, but prolong the operation over many days or even several weeks. To deposit all her eggs therefore, which is the province of course of the female, she must fly amid all the dangers her conspicuous colors offer for about a month, a considerably longer time than the average of butterflies. Previous to egg-laying at least, much of her time is spent upon the ground in company with her fellows, often in great flocks, engrossed in sucking up moisture from the damp earth, from decaying fruits, or the droppings of beasts; and so must become a conspicuous and easy prey to her enemies.

What then is to become of this saving remnant of the tribe? How escape from the dangers which it seems to invite? For the individual there would seem to be nothing but chance; but the number of eggs laid under the most farorable circumstances or chances is very considerable; and if only a pair of these finally reaches maturity and are able to fulfill their functions, the number of individuals of the species is maintained. It would 
seem, however, as if even this chance were small and as if still further protection were needed. And one further protection seems to be afforded in some species in a peculiarity of their life history. Apparently the species of Basilarchia are, at least in New England, normally single brooded; but in not infrequent cases, doubtless more frequent in southern than in northern parts, a second or supplementary brood is formed in one season; as the butterfly lays eggs for some time, and all the females are not born at once, the earliest progeny of the earliest females may not infrequently be able to mature in the same season in time for the production of a second brood. This would seem to be a provision on the part of nature to give the species a better chance. That they need it is perhaps evidenced by the fact that the black-veined orange species, which are almost universally more numerous in individuals than the others, have, in regions where one brood is the normal condition of their fellows, always two broods.

But this is not the only advantage the blackveined orange species have, so that we cannot fairly ascribe their greater numbers to this alone. Their very colors are an advantage to them, for in them they mimic species of another group, the 
Euploeinae, which possess a taste and perhaps an odor offensive to birds and other insectivorous animals; the mimiery is very striking indeed, and is the more remarkable from the fact that the northern species resembles the only species of Euploeinae found in the region it inhabits, while the southern species as well as the sonthernmost examples of the northern species resemble another which is more common in the region they inhabit. It is indeed possible that one of the normally colored species of Basilarchia, one that has least conspicuously contrasted colors, though resplendent with blue and green, is specially protected by the various other devices we have recounted; for certainly it is itself mimicked by one sex of a butterfly of another very distinct group, viz., Semnopsyche diana. 


\section{III.}

\section{DECEPTIVE DEVICES ANONG CATERPILLARS}

The life of a caterpillar is full of perils from birth to maturity. Though often formidable to look at, it is nevertheless soft skimed. Though it may have a choice place of concealment or even a well constructed nest, it must roam at large while seeking food; and there are several periods of its life when, to undergo its eedysis, it must remain an entire day or even more, motionless and helpless and generally quite exposed. Its main purpose in life, next to feeding, is not to be seen.

One of the simplest devices to escape notice is that of confining all activities (which include with these gluttons scarcely anything but feeding) to the night-time and retiring to some concealment during the day. This is a very common occurrence with the Satyrimae and Argynnimi in particular, the Argynnini with their dusky clothing retiring to the surface of the ground where they are least liable to be seen, the satyrids remaining 
perhaps upon the stems or blades of grass or selge which form their food and anong which they are concealed by their striped attire. Or the retirement may be to the under surface of a leaf, a very common practice, which is exemplified in our own fauna by the habit, among others, of such diverse butterflies as our Green Comma (Polygonia faunus), Buckeye (Junonia coenia), and the Blue Swallow-tail (Laertias philenor).

A very common mode of concealment, however, is the construction of a special nest for the purpose, within which they remain at all times when not feeding, and oftentimes even the greater part of their entire lives, feeding as they may do upon the nest itself until they have eaten themselves out of house and home. A good instance of this last propensity is found among the species of Vanessa, all of which construct more or less open nests, but devour the contents and the structure itself of the same. Others forming open nests are some of the species of Polygonia, while more complete webconcealments are made by the caterpillars of the American Tortoise-shell (Aglais milberti) and some of the Melitaeini. The mere partial curling of a leaf so as to conceal the sides of the creature lying thereon answers the purpose of the Tiger 
Swallow-tail (Jasoniades glaueus), while its neighbor the Green-clouded Swallow-tail (Euphoeades troilus) turns the leaf completely over so that the opposite edges touch. But the group which above all others contains caterpillars living in concealment is the Hesperidae, the higher Hesperini making an oval inclosure by strong strands of silk comnecting the edges of leaves at wide intervals, while the Pamphilini construct burrow-like nests by sewing together the edges of neighboring blades of grass; hardly an instance is known where one of them lives openly.

Butterfly caterpillars which live exposed have many of them special modes of guarding against danger, some falling to the ground and curling up at the slightest shock or alarm, such as many of the Melitaeini in their later stages. Others fail with greater deliberation, first attaching a thread to the leaf from which they drop, such as the Snout butterfly (Hypatus bachmanii) and the Coral Hair-streak (Strymon titus). Others assume a sphinx-lilie attitude which they may retain for a long time, as is the case with the Painted Beauty (Vanessa huntera) in its earlier life, and in this they are sometimes aided by the presence of a special knobbed process on the hunched por- 
tions, as in the species of Basilarehia. Others when disturbed strike with their mandibles the leaf upon which they are resting, as the Red Admiral (Vanessa atalanta) and Harris's butterfly (Cinclidia harrisii) are known to do. Or they may move their heads from side to side, catching their mandibles in the roughnesses of the leaf, and so produce a grating sound, - a very common trick of the higher Hesperilae. A curious allied habit is found in the Blue Swallow-tail (Laertias philenor), which repeatedly taps alternately with its front legs upon the leaf when disturbed, - a habit I have seen in no other caterpillar. The Monarch (Anosia plexippus) again, which, when eating, keeps its anterior flexible filaments constantly in motion forward and backward, moves them with still greater violence when it is in a state of alarm, and this must serve as a very considerable protection to it.

Nearly all caterpillars, whether of butterflies or moths, will, when disturbed, throw their heads violently around from side to side in a threatening, angry manner, the head with its hard incasement and biting jaws being the most offensive weapon in the control of the caterpillar. But it is a very curious sight to see how, as impelled by one im- 
pulse, the young eaterpillars of some of the Nymphalidae, such as the Mourning Cloak (Euvanessa antiopa), the American Tortoise-shell (Aglais milberti), and Harris's butterfly (Cinclidia harrisii), will move their heads by simultaneous jerks to one side and the other, like a regiment of soldier's shifting arms. This community of action must be a very considerable safeguard, and indeed I am inclined to regard the mere presence of caterpillars in considerable numbers feeding in company as in itself protective, partly because it is most common in the highest family and never found in the lowest, so that the habit would seem to have grown and become intensified by its protective qualities. Some certainly of the caterpillars which thus feed in company will not be touched by chickens. I have several times thrown twigs covered with the caterpillar's of the Mourning Cloak (Euvanessa antiopa) into a chicken yard only to the alarm of the chickens, they either paying no attention to the caterpillars as they crawled away, or regarding them with evident horror, never once offering to touch them; of course this may be due simply to their spinous elothing. But besides the spined caterpillars which are presumably protected by such community of action, such as the Mourning Cloali 
(Euvanessa antiopa), the American Tortoise-shell (Aglais milberti), the Compton Tortoise (Eugonia j-album), and the Melitaeini in their earlier stages, we have, even in our own famma, instances of naked caterpillars which enjoy the same means of protection, such as the Tawny Emperor (Chlorippe elyton) and the Blue Swallow-tail (Laertias philenor), especially in their earlier stages.

The greatest danger to caterpillars would seem to be when they are in motion, as they are then more readily detected by insectivorous creatures. To guard against such danger, many caterpillars, as all the Satyrinae, are excessively slow in their movements. Most caterpillars remain absolutely still during all times when they are not actually eating or on their way to their feeding spots, but some have the habit, in passing to and from their feeding grounds, of moving with the utmost rapidity, hurrying as if their safety depended upon it, as doubtless it does. Such are all the Argynnini, and I have noticed a similar habit in the Gray Comma (Polygonia progne). Others, again, among the slow movers have a very peculiar trick, which I do not remember to have seen mentioned by others; it is a sort of rocking motion, not from side to side but forward and backward, moving 
forward by little starts; they seem to glide by little jerks in a very slow and measured way. The caterpillars in which I have noticed this habit are the Blue-eyed Grayling (Cercyonis alope), the Orange Sulphur (Eurymus eurytheme), and the Green-clonded Swallow-tail (Euphoeades troilus); it is most conspicuous in the last.

Perhaps of all our caterpillars there are none which have so many means of defense in habit or protective device as the species of Basilarchia, and this altogether in addition to their coloring. Attention has already been drawn to this. It may be well, however, to summarize here some of the more peculiar ways by which it protects itself. In the first place it moves about with little starts, much as the Green-clouded Swallow-tail (Euphoeades troilus) and the others we have mentioned, its head all the while trembling as if it had the palsy; then, when disturbed, it will throw the front half of its body about like a whip, lashing its sides with great violence and fury, an operation which must most effectually drive away many of its smaller foes at least. These points refer to its active movements, but besides we have its curious habit of living upon the extremity of the uneaten midrib of the leaf upon which it is feeding; its construc- 
tion of a pellet of riffraff, movalble with every breath of wind, apparently to distract attention from its presence; its habit of retiring after feering (when a leaf no longer serves its purpose) to the twig of the plant upon which it feeds, where it is less easily observed; and its construction of a complex hibernaculum in which it passes the winter, to secure which from falling to the ground it securely enwraps the twig of the leaf of which it is made with silken cords to the stem.

Doubtless if the behavior of our other caterpillars had been followed more closely, many would show devices as complicated, various, and interesting as those of Basilarchia. I have not attempted to go outside our own fauna, but here much more information is needed. We should not fail, however, to mention the almost universal habit of caterpillars of eating their cast skins, so as to remove from their immediate vicinity any traces of their presence, a habit the more marked because I believe it is not shared by any of those caterpillars which live in company, where the numbers are so great that escape from observation would be impossible, and safety lies only in their numbers. Nor have I alluded to the special protection afforded to many of the Lycaeninae by the presence of their 
friendly ants, nor to the osmateria or stench-throwers of the Papilioninae, by which they are specially protected, since in both these instances these have their seat in physiological processes, which are of a widely different nature from the mere habits under discussion. 


\section{IV.}

BUTTERFLIES AS BOTANISTS

KNowLEDGE of the food plants of the caterpillars of butterflies is of prime importance to one who wishes to study their life histories; for although some species are polyphagous, others are the most particular creatures in the world and will starve to death if they are not supplied with just what they want. That this is not always the easiest thing to learn may be inferred from the frequent mishaps with the most experienced. And it is no wonder they are sometimes at fault or at a loss, for the one hundred butterflies of the easter'n United States and Canada, whose food plants are known, choose their food from more than one third of the families of plants mentioned in Gray's Manual of our botany.

Fifty-two families are represented; of these, thirty-two nourish only members of a single one of the four families of butterflies, and as a general rule are therefore of minor significance. Excep- 
tion must here be made, however, to four or five of these; for instance, the Violaceae, which almost exclusively supply our Argynnini with food; the Grossulaceae, on which no less than six of our Nymphalinae and especially the Vanessini have been found; the Cyperaceae, on which several, very likely many, of the Satyrids flourish; the Aquifoliaceae, on which several of our Lycaeninae, both Theclini and Lycaenini, feed; and finally the Lauraceae, a favorite food plant of the Papilioninae.

Twelve families of plants have been found to be the food of butterflies of two (and not more than two) families of our butterflies, but in most of these cases they are only known as the food of single species in each family and so assume small importance. Yet among them are others in which the case is different. Thus the Rutaceae are known to serve as the food of about as many different species of Papilioninae as the Lauraceae, and they are said also to be among the food plants of Chrysophanus; the Betulaceae are a common food of several species of Nymphalinae and nourish also Jasoniades; while of the utmost importance are the grasses and sedges, upon which nearly all our Satyrinae and Pamphilini live,- 
a good fourth of our butterfly fauma, even omitting the many Pamphilini which doubtless feed upon grasses but which are not yet known in their early life.

The families of plants fed upon by all four families of butterflies are three in number, and with the Rosaceae just mentioned and the Gramineae, the greatest supporter of caterpillar life, must be looked on as the favorite food of butterflies in their early stages. These are the Cupuliferae and especially the oaks which nomish eight species, mostly Lycaenidae and Hesperidlae; the Salicaceae, the food of eleven species, five of them Nymphalidae, the others equally divided among' the remaining families; and the Leguminosae, . which vie for preëminence with the Gramineae, for twenty-three of our species are found upon it; of these, nine are Hesperidae (and perhaps exelusively Hesperini), seven are Lyeaenidae, five Papilionidae (exclusively Pierinae and indeed Rhodocerini), and two Nymphalidae.

More than one third of our butterfly fauna is made up of the lowest, least known, and most inconspienous family, the Hesperidae, our members of one tribe of which feed almost exclusively on Leguminosae (a few on Salieaceae, Cupuli- 
ferae, etc.), of the other on Gramineae and Carices, and of course very decidedly affect the general result when all butterflies are considered. It is entirely owing to them that these two families take the first place, though they are by no means insignificant in their relation to the other families of butterflies. For leaving the Hesperidae out of consideration, the Rosaceae easily assume the first place and hold it alone, while the Leguminosae and Gramineae still retain such importance as to hold the second place, and indeed the highest position there with the Salicaceae, Compositae, and Violaceae, followed hard by the Cupuliferae, Ericaceae, Grossulaceae, and Cruciferae. These, then, are the preferred food of the caterpillars of our eastern American butterflies.

Two facts brought out from this study of the food plants of our caterpillars are more striking when brought into contrast: the narrow choice of very many species which feed upon a single species or genus of plants and the very large number of families of plants which are brought under contribution to feed the entire body of our caterpillars. The fact that considerably more than half of the families of plants are sought by only a single family of butterflies, and indeed 
usually by but a single species of butterfly, is only what one who has reared butterflies might expect, since he must often have found that under no consideration would a given caterpillar feed upon anything whatever but its own pet food plant. This is more striking because of the polyphagous nature of others, such as Jasoniades glaucus, which feeds upon plants belonging to no less than fifteen different families.

In many, perhaps the majority of instances the plants upon which allied species or genera of caterpillars feed, themselves belong to allied families of the botanical systems; and Fritz Müller brings forward some curious instances in which a knowledge of the habits of butterflies would have led, had they been followed, to an earlier recognition of the affinities of certain plants. Thus he says (Nature, xxx. 240) :-

"The caterpillars of Mechanitis, Dircenna, Ceratinia, and Ithomia feed on different species of Solanaceae (Solanum, Cyphomandra, Bassovia, Cestrum), those of the allied genus Thyridia on Brunfelsia. Now this latter genus of plants had been placed unanimously among the Scrophularineae, till quite recently it was transferred by Bentham and Hooker to the Solanaceae. Thus it appears that butterflies had recognized the true affinity of Brunfelsia long before botanists dirl so. 
"'There is yet another and more curious instance of our butterflies confirming the arrangement of plants in Bentham and Hooker's 'Genera Plantarum.' Ageronia and Didonis were formerly widely separated by lepidopterists, being even considered as constituting dis. tinct families, but now they are to be found beside one another among the Nymphalinae, and the structure of their caterpillar's leaves no doubt about their close affinity. The caterpillars of Ageronia feed on Dalechampia, those of Didonis on Tragia. Now these two Euphorbiaceous genera were widely separated by Endlicher, who placed the former among the Euphorbieae, the latter among the Acalypheae; Bentham and Hooker, on the contrary, place them close together in the same sub-tribe of Plukenetieae, and thus their close affinity which had been duly appreciated by butterflies has finally been recognized by botanists also."

The narrow choice of certain species is perhaps indicated in our own fauma by what we know of the fool plant of the Pearl Crescent (Phyciodes tharos). So far as we know it feeds only upon a single species of Aster ; "and if your butterfly selects only that," said the late Dr. Gray when I told him of this, "it is a better botanist than most of us." Only one other plant has been alleged as its food and that probably by mistake. This special Aster the female selected ont of many 
furnished it by Mr. Mead whereon to lay her eggs, and no one has yet reared it upon anything but Aster novae-angliae. Considering the difficulty that botanists have with the species of this group, such restriction of choice, if really true, certainly indicates some keen perception on the part of the butterfly.

Now with exceedingly rare exceptions the eggs of butterflies are laid upon the very plant upon which the eaterpillar will feed. In certain instances where the plants are abundant, as in the case of grasses, the butterfly may lay upon an object in the near vicinity, and this has also happened in a few instances in the case of butterflies which are rather particular in their choice. Thus I once saw a European Satyrid lay an egg on a dead blade of grass lying loose upon the ground, have seen one of our species of Brenthis lay egg's upon grass in the vicinity of violets, and found the eg'g of a Pamphilid upon a thistle growing among grasses. These exceptions seem only to prove the general rule that the eggs of butterflies are laid directly upon the food plant of the young.

This is an act of instinct, one will say. But is this any real explanation? WV wish to know how 
the instinct acts. A parent butterfly that in its early life has been nourished upon willow has no means in the winged condition of tasting the willow to recognize it, its organs for obtaining food being suited only for liquid nourishment.

Nor can it be by the color of the object. It is true that butterflies are attracted by flowers through their means of vision. Interesting stories are told of their being deceived by painted or artificial flowers. But in these cases there is no reason to suppose that it is anything but the tint in mass that attracts them to the spot. Pray how does the green of one plant differ from that of all others? Anatomy and experiment both seem to teach that butterflies have no power of vision for any such discrimination as is required of them in selecting special food plants for their young; which yet they discover in an unerring manner.

There remains apparently nothing but smell. That their sense of smell is exceptionally acute is plain from facts coming from a quite different somree, which are given in another place, under Aromatic Butterflies. The production of odor implies the recognition of odor, and inasmuch as the organs through which the odor is known in many cases to be emitted exist in a very much 
larger number of butterflies than have been recognized by our senses as odorous, it would seem a warrantable conclusion that, although we cannot perceive their odor, they nevertheless produce odors recognizable by their mates. Now we know in a similar way that many plants are odorous quite apart from their flowers; and if one, with this idea in mind, will but watch the movements of a mother butterfly seeking a spot whereon to lay her eggs, he will not fail to recognize that many of these actions seem particularly in keeping with the notion that she is at work scenting the various plants that bear a general resemblance in their aspect to the one which she seeks; many, indeed, which have no such general appearance, settling or' half settling in a dozen different places in the near vicinity of the plant, reaching it by nearer and nearer approaches, and finally settling with satisfaction at the desired spot. To such an observer it will seem tolerably clear that it is to the sense of smell that butterflies owe their recognition of botanical species. 


\section{V.}

THE NAMES OF BUTTERFLIES

WHEN in the preparation of my "Butterflies of the Eastern United States and Canada" I found myself compelled by my study of the famna to make use of a scientific terminology very different from that then in ordinary use, it seemed as if it might be desirable that at least our commoner species should have English names, which might in time become settled and then endure through all possible variations of scientific terminology. I noticed that in all the popular British works upon butterflies, an English name was almost invariably given, and that the names adopted by different authors dirl not always agree. It appeared, therefore, to be probable that many of them were manufactured for the occasion. Some were extremely pretty, other's appeared forced. I had noticed, further, that for the similar convenience of agriculturists an English name, often bungling and difficult to remember, a translation perhaps of an awk- 
ward scientific name, was given to insects treated of in economical reports; and, further, that Gosse, an Englishman who eame to this commtry in his youth and wrote very interestingly of our animals, almost invariably applied a name, apparently of his own coining, to the butterflies with which he here came in contact. I therefore made an attempt to introdnce such names into our nomenclature, where they had not already been given, endeavoring to adopt from the English such generic terms as fritillary, hair-streak, etc., for similar butterflies of our own country, and to coin appropriate names where required. I published a list of this sort in the first volume of "Psyche," which strangely enough met with most violent opposition, an opposition which appeared to me to be entirely umeasonable and certainly out of all proportion to the arljudged crime.

Accordingly in my "Butterflies of the Eastern United States" I again attempted to collate all the names that I could find that har been given to our different butterfies, and to select from among them that one which seemed most worthy of permanence, as my contribution toward a popular terminology. Of course in this case precedence is of no consequence, and local names applicable to another 
continent can scarcely be used. But I have not hesitated to devise names for such as have not already received them, in the hope that they may sometime be favorably received. Exception was made to my first list on the ground that such names should have a real popular value and origin; and this objection is unquestionably valid. But that attempt and the later one are only efforts at the introduction of names which may hereafter become as strictly popular, in a technical sense, as those which have been given to certain common butterflies in other parts of the world. They must once have been named by some one, and the practice is common among ornithologists; only recently $\mathrm{Mr}$. Sclater was complimented in the columms of "Nature" for his success and good judgment in this matter. I have further support in the fact that one finds among the early authors on the continent of Europe many attempts of this same kind, where common names have been applied which may or may not have come down to us at the present time. Thus taking up the other day the old work of Sepp on Dutch butterflies, I found such names as "konings-mantel" (a curious variation from the German tranermantel) given to antiopa, "distelvink" to cardui, "nommer-vlin- 
der" to atalanta, and to others not found in this country such odd names as "de eike page" and "hooi-beestje." I should be sorry if old Sepp had not taken this liberty. This is my warrant ard my only warrant for attempting to introduce such names. It seems to me that they will possibly serve a useful purpose, and certainly they can do no one any harm. They can be simply ignored. They will only survive if fitted to do so.

One examining for the first time the scientific terminology of butterflies would be interested at seeing how largely the names, and especially the early ones, had been bestowed by anthors who had received a classical education, and how extensively the Greek mythology figured in the nomenclature of these creatures.. The many forms of the name of Venus in particular would strike one. Much of this is certainly due to the example set by the first great nomenclator of zoölogy, Linné, who applied also the names of Greek heroes in the Trojan war to a very large number of swallow-tail butterflies, and his example has been followed by lepidopterologists down to the present day. A few notable exceptions will be found in later times when names of old Scandinavian mythical heroes were introduced into the nomenclature of European butter- 
flies; and in our own country Harris, when he found so large a number of skippers ummamed, bethought himself of a new device, which was the use of the names of Indian chiefs of greater or less historic fame which have come down to us, and his example, first followed by Edwards and myself, has been taken up by nearly all subsequent writers, so that the bulk of the specific names of our Pamphilini are now drawn from those of the dusky red aborigines of our country.

As to the very word "butterfly" itself, there has been much written, but, strangely, as it seems to me, the persons best qualified by their philological learning are least assured concerning the derivation of the name. Skeat and Murray are not known as entomologists. "It has amused many to devise guesses to explain the name," says Skeat. Mr. Frederick Clarkson, in the "Canadian Entomologist" (xvii. 44 ), thinks there is good reason to believe that the root-meaning of the word " lates back to early Egyptian history, and as a hieroglyphic it is synonymous as representing the qualities of completeness and perfection which characterize the soul." All of which I in my ignorance judge to be humbug. One distrusts much of the reason. ing drawn from hieroglyphs, for it would seem in 
general that almost any meaning can be drawn from them by dilettanteism if only sufficient ingenuity is put in. An English writer, Sara Coleridge, has stremmously upheld the idea that a butterfly was simply a better sort of fly, laughing to scom the common notion, which seems to me, as I think it must to all entomologists, to be unquestionably the correct one, that the word is simply an expressive name given to the commonest form of butterfly that is found in Europe, where the name arose, namely, the butterflies of the genus Eurymus, which are ordinarily of much the same kind of yellow that one firds on the buttercup, whence the name of both. One feels the greater confidence in this because the term is applied in so many different languages in much the same way. In AngloSaxon, it is buttor-fleoge, which is simply butterfly ; while some of the variations of this term in other languages are the Dutch botervlieg, earlier botervlieghe, the German butterfliege, and the earlier German form, buttervogel. ${ }^{1}$ Other variations of the same name appear in the poetical quotations

${ }^{1}$ Compare our own ladybird for Coccinella, as in the common distich, which ran differently in my childhood from what is set down in the books. I was tanght to say:-

"Ladybird, ladybird, fly away home,

Your house is on fire and your children will roam." 
from different languages which $I$ made use of in my "Butterflies of the Eastern United States." Murray in his New English dictionary gives various extracts showing the early use of this name, the earliest in the Anglo-Saxon being as far back as 1000 by Aelfric. Chancer gives it in another form : "Swich talkyng is nat worth a boterflye." 


\section{VI.}

COLOR-RELATIONS OF CHRYSALIDS TC THEIR SURROUNDINGS

Ir has long been known that there is in many instances considerable variation in the color of the chrysalids of certain butterflies, and that in not a few instances we find a dimorphism more or less accentuated. The most frequent difference that has been noticed has been the prevalence on the one hand of green tints, on the other of dark gray or brown. Now when we recall that the commonest places chosen by caterpillars of butterflies for pupation are either amongst the foliage of the plant on which they have fed, or on the other hand pendent from, or attached to, the twigs or trunks of trees with their gray bark, or to stones whose general color is dark gray or brown, we notice that we have here general tints of much the same con. trast. When we further observe that the green color prevails in the chrysalids of those species which commonly transform upon the leaves of their 
food plant, and brown or gray in those which seem to prefer the background of bark or rock or dead wood, we are struck at once with the protection which such resemblance must afford to chrysalids in general. And this conclusion would be very much strengthened were we to review the various minuter peculiarities of coloring and of sculpture which one may easily find. One of the most curious of these is noted by Fritz Müller, who says that the appendages on the chrysalids of Eneides, which hang horizontally on the under side of leaves, resemble the fungi which attack insects and which are found in precisely similar places. Another instance would be found in the sharp angularities of many chrysalids among the Nymphalidae, combined with their frequent brilliancy by reflected colors, golden or nacreous, which, in combination, would be strikingly similar to the metallic gleam of angular minerals in the rocks which form their natural background.

This last circumstance, to which attention has been specially called by a very painstaking experimental entomologist of England, Professor E. B. Poulton, led him to a careful inquiry into the cause and extent of the special color-relations existing between the chrysalids of butterflies and their 
surrounding surfaces. He has been able to obtain almost at will chrysalids of different colors, according to the tints with which he has surromuled them, and so has opened a new field of experimental inquiry which may yield important, as it already has interesting results. By carefully selecting the time at which his experiments were made he has been able to determine that in all the species experimented upon it was only necessary to confine attention to that period in the later larval life of the insect, when it has ceased feeding and remains motionless, together with the early portion of the next period, after spiming the silken pads and shrouds for the pupal attachments until it has thrown off the larval skin. It had already been pointed out by Meldola that it was impossible to suppose the moist skin of the freshly formed pupa photographically sensitive to the color of the surrounding surfaces, and this has been male per. fectly evident from the experiments of Poulton, which show that the color is determined before the assumption of the pupal state, since experiments made later than the time mentioned produced absolutely no results. Neither was Poulton successful, as he seems to have expected to be, in preventing the influence of surrounding objects 
from reaching the nervous centres through the ocalli of the caterpillar. All his successful experiments came when applied to that period of the transformation to which we have referred.

Most of the experiments were made upon three species, the Small Tortoise-shell (Aglais urticae), the Large Cabbage White (Mancipium brassicae), and the Small Cabbage White (Pieris rapae). The experiments consisted in preparing for the creatures during their changes artificial surrounding's of different colors : green, orange, black, white, and gilt. Over seven hundred chrysalids in all were experimented upon, and it was found that with Aglais urticae green and orange surroundings caused no effect on the pupal colors, black produced as a rule dark chrysalids, while white produced light colored ones, many of the last being brilliantly golden; this suggested the use of gilt surroundings, which were far more efficient than white in producing chrysalids of a distinctly golden color, more so even than often occurs in a state of nature. The influence of black was curiously shown by the fact that when the caterpillars changed to chrysalids upon light surfaces, those which underwent their transformations in close proximity to one another were darker than those which were more 
isolated, the color of each being affected by that part of the surroundings which were mate up of the dark bodies of its neighbors. In endeavoring to discover whether the sensitiveness of the chrysalids to their surroundings was due to the general surface of the skin as a whole or only to that of one portion, experiments were made by confining the chrysalids in tubes, part of which were colored black and part gilt, and the two parts separated by a diaphragm only permitting the pendent body to pass through; by reversing the conditions and making experiments with a large number of chrysalids, it became plainly evident that the color influence acted on some element of the larval skin, and that the larger the area of the skin exposed to any one color the more the chrysalids followed its influence. The nature of the effects produced is thus deseribed by Poulton :

"The coloring matter of the dark pupae is contained in a thin superficial layer of the cuticle; below this is a thicker layer divided into exceedingly delicate lamellae, between which fluids are present, and the latter form the thin plates which, by causing interference of light, produce the brilliant metallic appearance. The thinner upper layer, being dark, acts as a screen in the dark pupae. Precisely the same metallic appearances are 
caused by the films of air between the thin plates of glass which are formed on the surface of bottles long exposed to earth and moisture. Both have the same spectroscopic characters and the same transmitted colors (complementary to those seen by reflection). The brilliancy of the cuticle can be preserved in spirit for any length of time; it disappear's on drying, but can be renewed on wetting (this had been previously known), and the colors are seen to change during the process of drying and when the cuticle is pressed, for the films are thus made thimmer. 'The same lamellated layer' exists in non-metallic pupae of other species, and is used as a reflector for transparent coloring-matter contained in its outer lamellae. Thus the structure which rendered possible the brilliant effects due to interference probably existed long before these special effects were obtained, and was used for a different purpose."

It has long been known that many of the chrysalids of the Vanessini which yield parasitic Ichneumonidae in place of their proper inhabitants are frequently gilded; which is to be explained, in Poulton's view, by the abnormal state of the caterpillar, which prevents the formation of pigment in the chrysalis. In this instance the gilded appearance is preservative not of the creature itself, but of one of its foes, and does not appear a very wise provision of Nature. 
These experiments were made prineipally with the Small Tortoise-shell (Aglais urticae); other's upon the different species of Pierinae were quite similar, the influence of black surroundings being to produce dark chrysilids, and the greater the il lumination the darker the chrysalids, this last result being the reverse of that obtained with the Vanessini ; white produced light colored chrysalids, and the greater the illumination the lighter the chrysalids; dark red produced dark, deep orange very light green chrysalids; pale yellow and yellowish green surroundings produced rather darker chrysalids than the orange; and bluish green much darker, while dark blue produced still darker ehrysalids.

There is thus seen to be a certain difference between different sorts of chrysalids as to the effect of the color of their surroundings, some being decidedly affected by color's which have no influence upon others. Probably a careful study of the natural conditions under which pupation takes place may lead to better comprehension of a fact at present not clearly explainable; and may bring other instances into harmony, as where, according to Fritz Müller, a Brazilian Swallow-tail, evander, is said to have both brown and green chrysalids with no intermediate forms, and both produced under 


\section{identical circumstances. Our own Zebra Swallow-} tail (Iphiclides ajax), in which a similar dimorphism seems to be equally distinct, would serve as a good subject for experiment.

In concluding his account of his experiments on the Pierinae, Mr. Poulton observes:-

"It must be remarked that the effect of the colored surroundings upon the dark pigment is, perhaps, the least important part of the changes produced, for there are other consequences which seem to be much deeper in significance and far more difficult to understand. The black pigment patches and minute black dots are cuticular and superficial, while the ground colors are subcuticular and deep-seated; and in the most brightly colored pupae they are mixed colors due to the existence of different pigmentary (and probably chlorophylloid) borlies present in the different elements and at different depths of the subcuticular tissues of the same pupa. In other pupae no trace of such colors can be seen. Hence we see in these most complex and varied effects of the stimulus provided by the reflected light, which deepen into their permanent pupal condition very many hour's after the stimulus has ceased to act, the strongest evidence for the existence of a chain of physiological processes almost unparalleled in intricacy and difficulty, while a theory of comparatively simple and direct photochemical changes induced by the stimulus itself without the intervention of such a physiological circle seems entirely inadequate as an explanation of the facts." 


\section{VII.}

THE WHITE MOUNTAINS OF NEW HAMPSHIRE, AS A HOME FOR BUTTERFLIES

There is no spot in New England where an aurelian can obtain such successful results in a brief time as in the high valleys of the White Mountain region. Not only are many butterflies which elsewhere are rare, or abundant only in very restricted localities, to be obtained here, but they occur in the greatest profusion, more than making amends for the less favorable weather which is apt to interfere with collecting in mountainous localities. From the latter part of May until late in September one is always rewarded for a few days' collecting.

Perhaps it is because my visits have mainly been to that spot that I have found "The Glen" the most favorable region. Here, in a valley running north and south, at an elevation of about 2000 feet, following in one direction the valley of the Peabody, and in the other that of the Ellis, in a 
densely wooded region with high mountains on either side sloping down to the narrow valley, with considerable clearings in the river bottom, where cultivated patches, pastures, swampy tracts, hillsides overgrown with shrubbery, and damp and shaded forest roads are to be met with, nearly all the conditions for abundant insect-life are to be found at their best. More than this, a wagon road, eight miles in length, winding half way through the primeval forest, where it forms a broad lane which the butterflies covet, half way over the rough ledges and sedgy plateaus of the treeless upper region of our lighest mountain, where flowers are blooming all through the season to captivate the tired traveler, - this road to the highest summit affords a ready means of learning at what altitude the valley species ascend, and what kinds inhabit the inhospitable higher levels of the mountains.

Let us speak first of those which belong in the valleys, where the vegetation is so profuse and diversified; and restrict our remarks principally to those which are commonest here, and met with more rarely elsewhere, - those which have, so far as New England is concerned, their maximum development in this district. 
It is the region par excellence of that striking butterfly, the Banded Purple (Basilarchia arthemis). When the stage, with its city freight, winding its way over the hilly roads with the first rush of travel, leaves most of the farms behind it and enters the heart of the forest, flock after flock of these showy butterflies arise from the damp spots in the road where, sometimes by hundreds, they are assembled to suck the moisture from the earth, and then flutter about the stage in fascinating bewilderment, settling again to the feast in a hesitating way as soon as the disturbance is past. Indeed, they sometimes become a very nuisance, dozens of them when seeking a shelter entering the open doors and windows of the farm-houses, and fluttering about the windows in a vain and distracting attempt to escape when there is any movement within.

In the early season, when the buds are just beginning to burst, the young caterpillar may be found emerging from its hibernaculum deftly fastened near the tips of black-birch sprigs everywhere growing by the roadside; in July, the bristling globular egg attached to the extreme tip of the pointed leaf of the same, and later the leaves eaten in peculiar fashion, reveal where to look for the 
grotesque party-colored caterpillar, scarcely to be distinguished from that of its congener, the Viceroy (B. archippus). The latter is also common (though less common than in southern New England), prefers the willow and the poplar, and may be found feeding even up to the extreme limit of forest vegetation on the mountain side.

This, too, is the New England metropolis for that high-spirited butterfly, the Green Comma (Polygonia faunus). Unlike arthemis, it is never found in flocks, but only by threes and fours at most, keeping up a constant warfare with one another ; but it is still so common along the roads, and particularly in the more open spots, or where the roads enter bits of forest or cross a mountain brook, that, notwithstanding its wary activity, one may even capture in favorable times a hundred in a day; once I must have seen five hundred in a single railway ride of six miles in the forest on the western side of Mt. Washington between Fabyan's and the base of the mountain. Its caterpillar also party-colored, but bristling with spines - may be found both on the black birches and the willows. Where both these plants are found in such abundance, search would seem to be vain; but if it is confined to such sprays of the smaller plants as 
project forward toward the road, - such spots indeed as the butterflies select to alight upon, - the patient search will be rewarded. Another Polygonia, far rarer, the Hoary Comma (P. gracilis), I had until 1887 taken only here and on the opposite side of Mt. Washington, perhaps a couple of dozen in all in as many years; and it is almost its only known locality in New England, though it doubtless occurs in many other elevated regions farorable for P. faunus. In 1887 it was tolerably common, and was found to occupy a distinctly lower zone, below 2500 feet. The Gray Comma (P. progne) is also common, belongs properly to the same zone, and I have taken its larva here on the wild gooseberry. The Compton Tortoise (Eugonia j.-album) is another butterfly common in certain seasons at least, and I should consider this its favorite New England ground, were it not that one night it flew by hundreds into Sankaty lighthouse on Nantucket, where in several summer's' residence on the island I never saw it at any other time. The Mourning Cloak (Euvanessa antiopa) is also common enough at the White Mountains, but not much more so than elsewhere. One may generally see a dozen on à good day in early June, - seedy-looking individuals which 
have survived the winter. The American Tortoise-shell (Aglais milberti) is also common in the lower country, feeding in swarms upon the nettles; and this concludes the series of Nymphalini which need be mentioned.

The Mountain Silver-spot (Argymnis atlantis) occurs here in the utmost profusion, as nowhere else in New England. One may easily take humdreds in a single day, the sandalwood-scented males largely predominating. The Silver-bordered Fritillary (Brenthis myrina) and the Meadow Fritillary (B. bellona) are abundant in the restricted meadow-lands, and in about equal numbers, though B. myrina is far more common in central New England. But the region is one of the best for most of our Melitaeini. The Tawny Crescent (Phyciodes batesii) occurs here early in June, and this is its only known New England locality. The Pearl Crescent (P. tharos) swarms (as it also does elsewhere), and here is the best place to search for those very local species, Harris's butterfly (Cinclidia harrisii) and the Baltimore (Euphydryas phaeton). They can best be obtained in the larval state, for they may always be taken in large numbers very early in the spring in such conveniently accessible spots as the immediate borders of the 
Glen road, harrisii feeding in large companies on Diplopappus and phaton scarcely more dispersed on Lonicera.

I have never paid special attention to the Theclini in this region, nor had them force themselves on my notice; so that I am inclined to think none of them particularly abundant, or more so than elsewhere. Nor are any of the Lycaenini exceptionally common, excepting Cyaniris, which is certainly far commoner, especially the Early Spring Azure (C. pseudargiolus lucia), than anywhere else in New England, abundant as it often is. The roads seem at times blue with them, and they swarm at all moist spots, occurring also to the very edge of the forest line, and enchanting the early pedestrian at every step. They are also one of the earliest risers, and are the first to be seen when the clouds break after a rain. Of the Chrysophanini, the American Copper (Heodes hypophlaeas) is of course abundant, as everywhere, and the Wanderer (Feniseca tarquinius) may always be found in its time at the proper places; there is one isolated copse, with alder (everywhere growing in profusion), just north of the Glen House, where I never fail to see it fluttering about when in season. 
Among the Pierinae, the Clouded Sulphur (Eurymus philodice) and the Cabbage butterfly (Pieris rapae) are of course abundant enough. I shall be surprised if the Pink Edge (E. interior) does not some day turn up here, having escaped the net only because no one takes so common an insect as its congener, which it resembles too much on the wing to be readily distinguished from it; and I have taken it above timber. The only interesting form of this group found here is the Gray-veined White (Pieris oleracea). Though nowhere nearly so common as thirty years ago, when I first collected at the mountains, when one might see fifty at a time in an open field, it is not yet quite exterminated by the invading Cabbage butterfly ( $P$. rapae), and in the very first of the season, when a dozen or so may be taken in a day, is as common as that species; but with the advanced season it appears quite lost among the swarms of the latter. Probably it will always hold out in this, its New England stronghold.

None of the swallow-tails are preëminently abundant, with the single exception of the Tiger Swallow-tail (Jasoniades glancus). But this is indeed an exception. Early in June of any year one may take a dozen or twenty with a.single sweep 
of the net at moist places by the roardside, or if cautious enough pick up with the fingers one specimen after another till he wearies of the task. It never fails to be abumdant, and its great size and social habits make it appear the commonest butterfly of the region. The males appear to vastly outnumber the females.

The skippers may be dismissed with a few words, as most of them may be found equally abundant elsewhere; but this is certainly the best place I know for obtaining the Dreamy Dusky-wing (Thanaos icelus), and is probably the best for securing those rarer forms, the Arctic Skipper (Pamphila mandan) and Pepper and Salt (Amblyscirtes samoset), though they are never very abundant, while the Roadside Skipper (A. vialis) is always to be met with early in June.

These are the more interesting of the valley butterflies of the White Mountains, found in much greater abundance than elsewhere; but they form a small part of those which abound here, and the real interest centres in noting to what height any of them may be found. For this the open heads of the great ravines which seem to gnaw at the very vitals of the great mountain masses, with the wagon road up Mt. Washington on one side and the 
broad railway-cutting at the other, forming as they do highways for butterfly as well as man, are the most interesting and instructive spots. Prominent among those which may be found, and which probably or certainly pass their lives in any part of the forest region, however elevated, where there are open spaces, are the Viceroy (Basilarchia archippus), alleady mentioned in this way, the Poly. gonias, the Compton Tortoise (Eugonia j.-album), and the Spring Azure (Cyaniris pseudargiolus). Not infrequently, these fly even far above these natural limits, and have been taken or seen upon the highest points. Indeed, many insects are the veriest Appalachians, seeming to take a delight in exploring the summits. This is truer of some other insects than of butterflies, and perhaps they are borne upward by the wind-currents; for in the first week of Jume I have found the great snow-patches at the very summit of Mt. Washington fairly peppered with numerous small insects, especially Coleoptera, Diptera, Hymenoptera, and Homoptera, prominent among which were thousands upon thousands of delicate-winged plant-lice. Besides these among the larger insects an Acanthosoma, perhaps A. nebulosa, swarmed on the hotel piazza, and every pool of water by the roadside was 

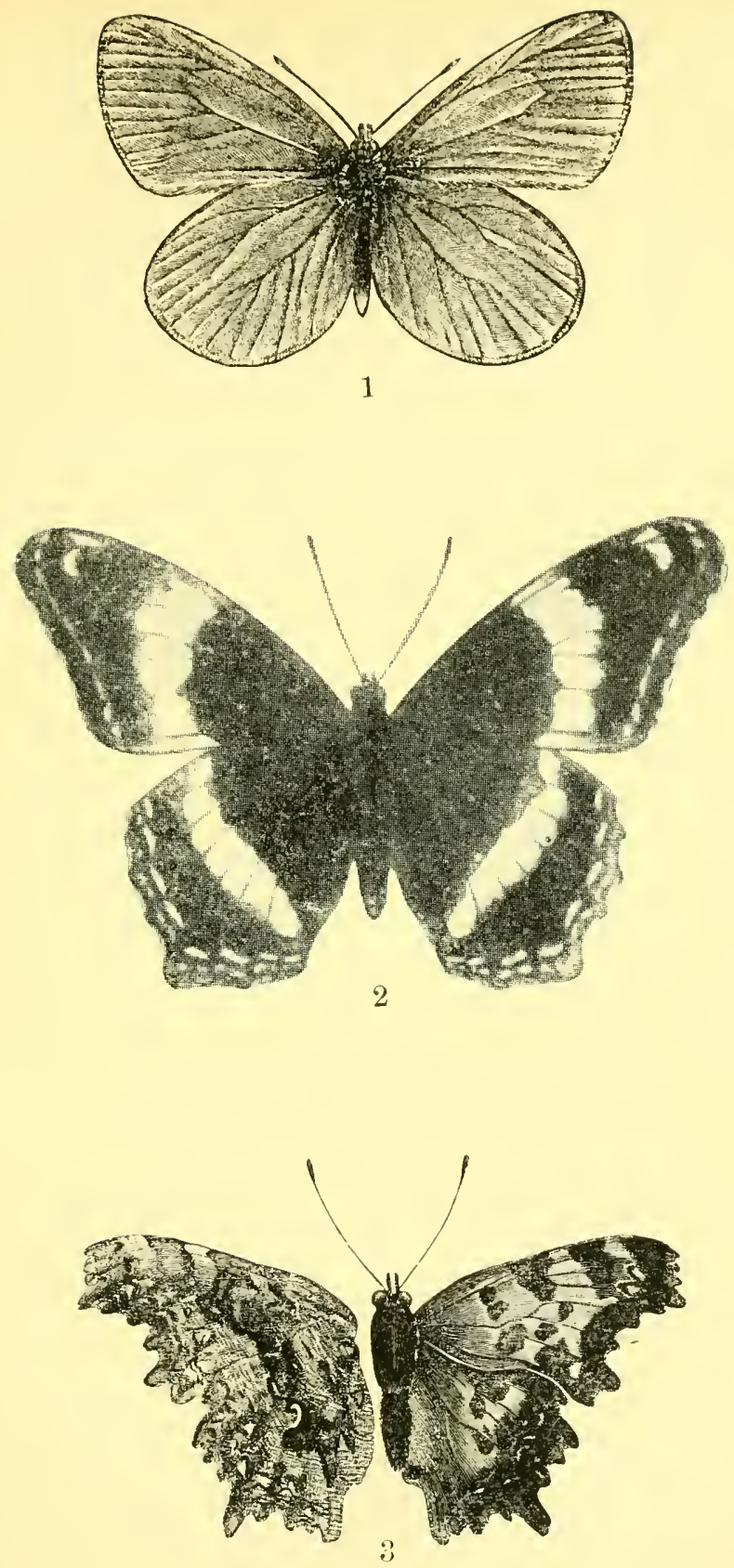

WHITE MOUNTAIN BUTTERFLIES 

the grave of comtless Bibio femoratus. Of the butterflies alone which I have found upon the very highest summits are (besides two species immediately to be mentioned, characteristic of the monntain top) the following: Basilarehia archippus, B. arthemis, Polygonia interrogationis, P. famms, P. gracilis, Eugonia j.-album, Euvanessa antiopa, Aglais milberti, Argynnis atlantis, Brenthis myrina, B. bellona, Phyciodes tharos, Incisalia niphon, Cyaniris pseudargiolus, Pieris rapae, Jasoniades glancus, Thanaos icelus, and Limochores taumas, - in all, twenty species.

It will require still a good deal of field-work to determine how far up the mountain side these forms habitually breed: for, as given, the list is merely that of stragglers of an inquisitive turn of mind.

It is far more interesting, perhaps the most interesting point in the geographical distribution of New England butterflies, to find that there are two butterflies living exclusively on these inclement mountain heights. One of them, the White Mountain butterfly (Oeneis semidea), is known elsewhere only on the summits of the highest peaks of the Rocky Mountains in Colorado, where it does not appear, apparently, below an elevation of about 
12,000 feet, above which, and up to 14,000 feet, it has been taken on Mt. Lincoln, Sierra Blanca, the Argentine Pass, Pike's Peak, and Twin Lakes. It is, however, regarded by some as only a variety of a species found farther north. In any case it is either a distinct species or well on the road to it; and so far as its interest in this connection goes, it matters little in which light it be viewed. The other species, the Dappled Fritillary (Brenthis montimus), will, in my judgment, certainly be found beyond the great range of the White Mountains, whence only it is so far known. I should look for it confidently above the forest line in the Adirondacks, and on Kitaadn, as well as other elevated and barren heights. It has been reported as seen on Black Mountain near Thornton, N. H., which is wooded to the summit; but an actual capture would be necessary to establish such a fact. It, too, is regarded by some as merely a variety of another species found farther north, and this northern species occurs as near as southern Labrador and Anticosti, and ranges across the country to Great Slave Lake. It is, however, separable from it, and whether to be looked on as a distinct species or merely as a variety is a pure matter of individual idiosyncrasy. The question is similar to the pre- 
ceding, but at present receives no side-light from the west.

One will hardly fail to notice that while the forest line at the White Mountains is tolerably well marked (at a height of about 4000 or 4500 feet), it is always succeeded above by a considerable area, where the dwarfed spruce or "scr'ub," struggling upward with ever diminishing height, conceals the gray rocks in a covering of uniform green, excepting on the unstable surfaces of the steeper slopes, - an area which is strongly contrasted with the barren gray broken rocks above, which lie piled in vast heaps exposed to full view, except where a patch of sedge furnishes a small and barren pasture upon some more favored platean. The sides of these mountains, where they rise to their highest culmination, are thus divisible into a forest and an alpine region, and the latter into a lower, or scrub, and an upper, or rocky, district. These two subdivisions of the alpine region correspond fairly well with the areas occupied by the two mountain butterflies just mentioned. There is no doubt that occasional individuals of the White Mountain butterfly (Oeneis semidea) will be found far within the limits of the lower alpine region; for the fierce blasts of wind which sweep around these lofty ele- 
vations must sometimes hul these feeble flutterers far down toward the wooded valleys, as I have myself seen; and there is no doubt that they can find their food plant all through the lower alpine region; nevertheless, the contrast between the occasional and unwilling visitor below and the swarms which in their season crowd the upper plateaus is very marked and significant. The localities where I have found them most abundant are the successive sedgy plateaus which flank the upper part of the earriage road on Mt. Washington, and especially the broad area between the sixth and seventh mile-posts, where the road takes a side turn, and which I call Semidea Platean. So, too, one may find an aspiring Brenthis above the limits of the lower alpine region; but it is very rarely seen there, and the violets on which the caterpillar probably feeds will scarcely ever be found in any abundance within the upper alpine area. It seems fairly deducible from these facts that even the limited area of the barren heights above the White Mountain forests is divisible into two districts, each of which claims a butterfly as its own; so that in ascending Mt. Washington, we pass, as it were, from New Hampshire to northern Labrador ; for on leaving the New Hampshire forests and forest famma behind 
us, we come first upon insects (there are other's besides B. montinus) recalling those of the northern shores of the Gulf of St. Lawrence and the eoast of Labrador opposite Newfoundland; and when we have attained the summit a butterfly greets us which represents the famna of Atlantic Labrador and Greenland.

Interesting as this is, how very meagre such a showing appears by the sicle of our knowledge of the butterfly fammas of the Swiss and Colorado alps, where the mountaius rise to so much greater heights, and the mountainous area is so vastly more extended! In the Swiss mountains, where the alpine area is limited above as well as below, and the melting of the eternal snows keeps the whole region above the trees one of the choicest pasturages for cattle that the earth affords, the whole aspect of the butterfly world is different. A host of species in infinite numbers crowd about the blossoms, the springs, the very edges of the glaciers. Forms wholly unknown in the valleys below, or allied to but easily distinguished from them, meet one at every step. A species of Oeneis, very many of Erebia, several Brenthis, a number of Melitaeini, a host of Lyeaenini, with species of Eurymus, Parnassius, and several Hes- 
peridae, show how varied and striking the fama is. Besides these a great many of the valley forms often accompany them, among which will be found our old friends antiopa, cardui and atalanta, so rarely seen with us above the forest. In the cordilleras of Colorado, where the snow-fields are far less important, and glaciers are practically unknown, we have a condition of things between the mountains of Switzerland and New Hampshire. The number of distinct forms is considerable, but by no means so large as in Switzerland. A couple of species of Oeneis are found here, with several Erebias, and a Brenthis or two; some Melitaeini also occur, most of which are also found some distance below the timber-line, which is here vastly higher than at the White Mountains, being at about 10,000 feet. The Lycaenini are abundant, and one finds a characteristic Eurymus, Parnassius (also found at lower levels), and one or two Hesperidae of the same group as occurs on the Swiss Alps. Indeed, the agreement of the typical alpine forms of Colorado and Switzerland is striking, and in strange contrast to the poverty of New Hampshire; the more so, as a large number of the additional generic types are not those characteristic of high latitudes. 
What the higher levels of the White Mountains would be as a home for butterflies, if a thousand or two more feet were added to their elevation and snow crowned the higher summits, it might be hard to say, but it would certainly be still very different from the fauna of the Swiss or the Colorado alps. Many of the generic forms which are common to them scarcely oceur in eastern America; so that the difference between the three alpine faunas we have mentioned accentuates the distinction which exists between eastern America and Europe, and the agreement found between western America and Europe. 


\section{VIII.}

BUTTERFLY SOUNDS

IT has long been known that some South American butterflies during their flight give utterance to peculiar clicking sounds, but it is far less known that such noises are made by our own butterflies; we shall hope to show that it is not improbably a common feature in the life of butterflies. The first account of the noises made by butterflies (belonging to the genus Ageronia) appears to be that given by Darwin in his celebrated "Journal," who states that "several times when a pair, probably male and female, were chasing each other in an irregular course, they passed within a few yards of me; and I distinctly heard a clicking noise, similar to that produced by a toothed wheel passing under a spring catch. The noise was continned at short intervals, and could be distinguished at about twenty yards' distance." But the most interesting account we have seen of these sounds is that given by $\mathrm{Mr}$. 
Bigg-Wither. 'This butterfly, which he and his friends christened the "whip butterfly," is said by him to settle upon the boles of trees, head downward and wings outsprearl, closely embracing the bark. "In this position, which is more common to moths than to butterflies, it remains undetected by the casual observer, as it resembles merely a patch of lichen. If approached, however, it will give warning of its disapprobation by sharply shutting and opening its wings once or twice (more generally twice) in quick succession, producing by this sudden contact the whip-like snap from which we gave it its name." One notices exactly this movement in many of our temperate Vanessini, when half alarmed. "Frequently, too, it makes the same sound when on the wing. The sumugua [a bird with a sharp beak and abnormally big mouth] is very partial to this butterfly, and is at once attracted by the whip-like crack, forsaking its branch on which perhaps it has been perching for half an hour without having given the smallest sign of life, and darting after the 'whip-cracker' with great eagerness." Mr. Walker states that when these butterflies are approached after alighting they start off at great speed, "making at the same 
time a loud and most singular snapping or crackling noise, which I can best compare to the sound of a slight electric spark, at intervals of one to five seconds. This somd is particularly distinct when the male is chasing the female, and I have heard it at a distance of at least ten yards. I think it is produced by both sexes." Wallace observed the same thing at Para, and believed that it was produced in some way by the contact of two insects, as he only heard it when two insects were chasing or frolicking with each other, and it seems to be the general belief that the sound is common to both sexes, which Mr. Van Volxem positively asserts.

But, as stated above, these sounds are emitted also by butterflies of the temperate regions. Thus Mr. Swinton, who has written a good deal upon this subject, states that the Small Tortoiseshell (Aglais urticae), about to hibernate and in a drowsy condition, was induced by him to depress and shut the wings successively, and " each time she testily performed this action I heard distinctly, as the fore wings were brought forward, when only the extreme basal portion of the wings was in contact, a sound soft and refreshing, like evening footsteps on the pavement, or 
grating sand-paper." The same thing has been observed long since by the Rev. Mr. Green in the European Peacock butterfly (Hamadryas io), who accidentally disturbed a colony of hibernating butterflies and heard a faint hissing noise issue from the cavity in which they were concealed, while the wings were slowly depressed and elevated; the noise resembled "that made by blowing slowly with moderate force through the closed teeth." The late Mr. Hewitson of England also observed the same thing in Hamadryas io, but compares the sound of the wings when rubbed together to the friction of sand-paper. Mr. A. H. Jones noted the same thing in a hibernating Mourning Cloak (Euvanessa antiopa), which produced a grating sound, and I have myself not only heard this butterfly make the noise while fanning its wings as it rested upon a window sill, but have artificially produced the same sound by rubbing the wings of a dead specimen together.

Other butterflies, but tropical species, are also stated to produce such sounds. Thus Distant gives the observation of a Captain Godfery as noticing that one of a pair of a species of Thanmantis (a genus allied to the great blue Morphos of South America), while flying around its mate, 
"produced a most curious crackling or rustling noise," which "was evidently emitted at the creature's will, and was distinctly andible within two or three yards of the insect." Fritz Müller, who adds his testimony to the clicking sound emitted by Ageronia, states that quite another butterfly, a species of Eunica, equally produces the noise, and he also heard a sound, even louder than that made by Ageronia, "produced by two small brown butterflies which I did not suceed in catching."

The sounds made by butterflies of the temperate zone and compared by nearly all observers to that of the abrasion of one rough surface upon another, more or less faint, would hardly seem at first sight to be entirely analogous to the clicking sounds made by their more noisy brethren of the tropies, but it is not impossible that they should be. Experiments made after death upon the Green Comma (Polygonia famms) show that they must be capable of producing the same somnds as the Mourning Cloak (Euvanessa antiopa); and in this connection, an instance which occurred to me one summer on the top of Mt. Washington has a direct bearing; for while walking on the carriage road, I started up a pair of the former, 
unobserved, just at my feet. I instantly stopped motionless to see whether they would settle again, when one of them, which had flown to a short distance, turned and flew rapidly back straight at my face, turning only when within three or four inches of my nose, and then suddenly whisking off with a distinct "click" at turning.

All the instances thus far given relate to the family Nymphalidae, and therefore the following instance recorded by Rev. A. E. Eaton of England is of unusual interest. He states that he heard Parnassius apollo make a rustling noise by "slowly flapping her wings" while clinging to a flower, "and scraping the hinder pair with her four posterior legs, which were thrust backwards simultaneously each time that the wings opened;" it continued to do this even after the front wings were firmly held, but stopped when the hind wings were seized.

The only persons who seem to have endeavored to discover the cause of these sounds are the late Mr. Doubleday and Messrs. Swinton and Hampson. Mr. Donbleday examined the species of the genus Ageronia in the British Museum in vain for any sufficient cause drawn from the external structure of the animal. He found certain peculiarities, 
one of them a cavity on the under side of the upper wing near the region of the costal nervure, and another in the swollen part of the costal nervure of the same wing, both of them parts not covered by the hind wings in flight. He rightly disclaims any attempt to discover "a connection between either of these peculiarities in structure and the sound produced by the insect." Mr. Swinton, however, in several places has attempted to show that the base of the anal veins of the front wing in the stridulous Vanessini and in Ageronia has a certain structure comparable to a file or lima, parallel indentations or slight striae being seen across its surface under a strong magnifying power. But this explanation can in no way answer, becanse an exactly similar feature may be found in all the other veins of all these butterflies, there being nothing distinctive in the veins themselves, either in the front or hind wing, in the regions which naturally overlap. When one examines, however, the Vanessini of the temperate regions, he will discover that the hind wings are in many cases furnished not only with scales but with long, pointed bristles, and I at first thought that these bristles might be the cause of the sounds, although they seemed to be just as abundant in other parts 
of the wing as in those which were naturally covered by the opposite wing. But this peculiarity is not found at all in Ageronia.

If, however, one will examine the surfaces brought into contact between the two wings in the insects known to produce audible sound, he will note that nearly all the scales on the under surface of the front wing and those on the upper surface of the hind wing next the base, that is, in just those portions of the wing which overlap each other, are much smaller and more erect than in any other part of the wing, even than those in the immediate vicinity; and by experiment can show that when these portions of the wing are rubbed together a rustling noise is produced, while in other butterflies, such as Brenthis, not nearly so much contrast appears. In Ageronia these scales have also a more or less conical shape, as if to intensify the sound produced by their rubbing, but of course one could not initate by clumsy motion of the hand any possible "click" from this source.

Mr. G. F. Hampson, however, by dissection of Ageronia, has probably discovered the precise instrumentation by which the "click" is effected. At the base of the inner margin of the fore wing he finds a pair of curved horny hooks with enlarged 
extremities, so placed that when the fore wing is moved up and down they play upon a pair of somewhat similar processes attached to the thorax; these being abruptly released from contact when the wing reaches a certain angle, would be likely to produce a snapping sound or "click."

Many observers have noted the peculiar movements of the wings of butterflies which are not accompanied by audible sounds, especially in the family Lycaenidae, where the hinder wings alone, erect when the insect is at rest, are rubberl together in a curious way, giving them "the appearance of revolving disks," as Mr. Wallace calls it; and many observers have attempted to discover whether any sound followed this motion, but none have succeeded in doing so. Yet any other explanation of the intent of the movement would seem to be almost out of place, inasmuch as it is invariably made by certain species, including many of our own native kinds, directly upon alighting, and at a time when there may well be no butterflies in sight.

This movement of the hind wings has been repeatedly seen and remarked upon by observer:s in all parts of the world. Swinton thonght he had found the source of the possible sound that may 
result (none is perceptible to human ears) in the structure of the lowest vein of the front wing. He examined Callophrys rubi, and states that the vein is bare and "crossed at uniform distances by pronomeed striae, which indicate internal diaphragms and constrict into a series of bead-like formations." This statement has been accepted without examination by some entomologists, yet it is not true. The vein is never bare of scales except when they have been rubbed off, and the markings seen by Swinton are either the threads of the inclosed tracheae or the lines of pockets for the attachment of the abraded scales. But what one does find (in all Lycaeninae, apparently, certainly in all of our species) is that in the lowest interspace of the front wing, next the inner margin, there is a patch of scales of a different character and setting from any other scales on the under surface. The patch does not reach the base of the wing, nor extend much if any beyond the basal third of the wing, but occupies the whole width of the interspace, and is found in male and female alike, just as the wing movement is shared by both sexes; the scales are slenderer than those about them, subfusifor'm and bluntly pointed, and very often erect or nearly erect; but they have one other important quality 
which it seems to me signalizes their use, in that in the midst of scales more lightly attached and easily removed than are those of any other butterflies, it is impossible to remove one of these withont breaking the wing; they are firmly set bristle-scales, and on the opposing part of the hind wings, in the marginal interspace, is a similar patch, not so characteristic, of rounded pavementlike scales. If any noise is produced by the movement of the wings, it must be by the agency of these two opposing fields.

Special movements of some sort are made by a majority of butterflies; as for instance in most of our Argynnimi and other Nymphalinae, which gently wave their wings upward and downward upon alighting, as if panting from their exertions. A marked instance of this is seen in the Red Admiral (Vanessa atalanta). Still more striking instances are the quivering movements of the male settled beside the female; or of a butterfly eagerly sucking a flower when another alights beside it, and is thus warned to "keep its distance." These motions I am inclined to regard as movements for the sake of producing sound, though the sounds are inaudible to our ears. It is probable that this is on account of their faintness. There is a limit to 
human perceptibility of sounds from their shrillness and also from their feebleness. It is known, but perhaps not well known, that there are a certain number of saltatorial Orthoptera which can be seen to stridulate but whose sounds are inaudible to our ears. From the fact that certain butterflies produce sound during certain movements, we can hardly fail to believe that other butterflies making the same motion also produce sound, although inaudible to our ears.

Nor are the sounds made by these friends of our's altogether limited to the butterfly state, a large number of caterpillars making sounds by striking their hearls against the leaf upon which they are resting, or by swinging the head from side to side, catching the mandibles in the roughnesses of the leaf or upon the silken strands which they have spun upon it, to produce a scraping sound to drive away intruders; and Schild states that the chrysalis of the Green Hair-streak (Callophrys rubi) when disturbed produces by its movements a slight sharp chirp, or, as Kleeman called it in 1774, a clicking noise. But though I have seen many chrysalids of Nymphalidae in excessively active motion, I have never observed any sound from this source. 


\section{IX.}

NESTS AND OTHER STRUCTURES MADE BY CATERPILLARS

There is considerable difference among the caterpillars of butterflies as to the amount of silk they spin. Some, and this is especially true of the Lycaenidae, and next of the Pierinae, spin very little and have apparently little use for it, being able to make their way about without weaving a carpet whereon to cling, though they ordinarily do spin some. Others seem unable to take a single step without laboriously spimning a thread wherever they would go, fastening it upon this side and that, and without it will venture nowhere. As a general rule nests of any sort are constructed only by the last-named, i. e. by those most dependent upon a hold on silken strands to make their way. Yet there is one notable exception in a Mexican Pierid which constructs a web nearly as close as parchment.

Nests, which are almost solely for purposes of 


\section{NESTS MADE BY CATERPILLARS 101}

concalment, are very generally made by those caterpillars of butterflies which are gregarious, but there is one kind made by New England social caterpillars which has no such purpose and which is perhaps too simple to be properly called a nest. This is the web made, particularly in earlier life, by the caterpillars of the Mourning Cloak (Euvanessa antiopa), which move about much from place to place, spinning wherever they go, so that at last the line of movement, by successive strands thrown across every angle a twig makes with the larger stem, forms a sort of veil of silk over which they crawl with extreme rapidity, but without which their movements are greatly retarded.

Some caterpillars have a favorite place of repose to which they come after every meal and which they carpet with silk for greater comfort. Of such are some of the swallow-tails, and it would seem as if the nest they constructed were at first an accidental result of this habit, perfected by its protective adaptation. These caterpillar's rest upon the middle of the upper surface of a leaf, upon the floor of which they have stretched a silken carpet from side to side, each strand shorter than the last, so as to make the edges curl toward each other 
and sometimes to meèt, and thus to form an open nest.

The most common form of nest, however, is that in which different parts of the same leaf or adjacent parts of different leaves are fastened together by silken strands. The simplest and weakest of these are made by the caterpillars of the Green Comma (Polygonia faunus) and the Red Admiral (Vanessa atalanta), which fasten together very weakly the opposite edges of a single large leaf so as just to make them meet; but the threads are so slight that they are ruptured with the slightest effort. The caterpillar within, having thus secured a shelter, seems loth to leave it and makes its meals from its own dwelling, until, having literally eaten itself out of house and home, it is forced to venture forth and construct another.

Another form of nest made from a single leaf is constructed by all the higher skippers, Hesperini, in early life, and by many of them throughont life, by folding over a little piece of leaf, and fastening the erge to the opposite surface by a few loose strands of silk; to effect this they first bite a little channel into the leaf at just such a place as to leave a fragment of leaf neither too large nor too small to serve as a roof when they shall have 
turned it over; often they have to cut two channels in order to procure a flap sufficiently small for their purposes; and it is curious to watch one of these tender creatures, just as soon as it has devoured its egg-shell, struggling with a tough oak leaf to build for itself a house. These nests are much more firmly made, the silken fastenings being composed of many strands, often very tough. On' leaving one nest to construct a larger, the caterpillar always, I believe, first bites off the threads of the old nest and gives the flap a chance to resume its position, which, however, it rarely fully does. When older, many of these same skippers find a single leaf of their food-plant too small to conceal them, and so they draw several leaves together just as they grow upon the plant, and, retaining them in the desired place by silken bands, live within the leafy bower. This mode of construction is adopted almost from the first by the Pamphilini which feed on grasses, the proximity of adjoining blarles near the base affording a good chance to attach them together, while a cluster of blarles furnishes a similar chance to construct the somewhat tubular nest they require when they have grown large and fat.

A nest composed of several leaves is not made 
by many other of our butterflies. The Red Admiral (Vanessa atalanta), however, especially when it is more than half grown, finds it easier to attach neighboring leaves of the thickly growing nettle than to find one sufficiently free to use it only; so that fully one half of the nests of the larger caterpillars are made from a number of leaves ; the nest is always roomy, capable of housing several caterpillars, though never containing more than one.

The nesting habits of the Red Admiral are shared by the other species of Vanessa, with certain slight variations. In early life the Painted Lady (V. cardui) tries to make the stiff and crenulate edges of thistle-leaves meet together, but with indifferent suceess, and so fills in the interstices with an exceedingly thin web, in no way concealing it from sight. In after-life it forms an oval nest of the size of a pigeon's egg, by fastening adjoining leaves together very slightly, and filling all the nintertices with a similar flimsy web, upon which it fasten; or into which it weaves, bits of eaten leaf or parts of the inflorescence of the plant, still imperfectly colcealing it from sight; and sometimes it hangs itslf up for chrysalis within the same narrow, and by this time very filthy, apart- 

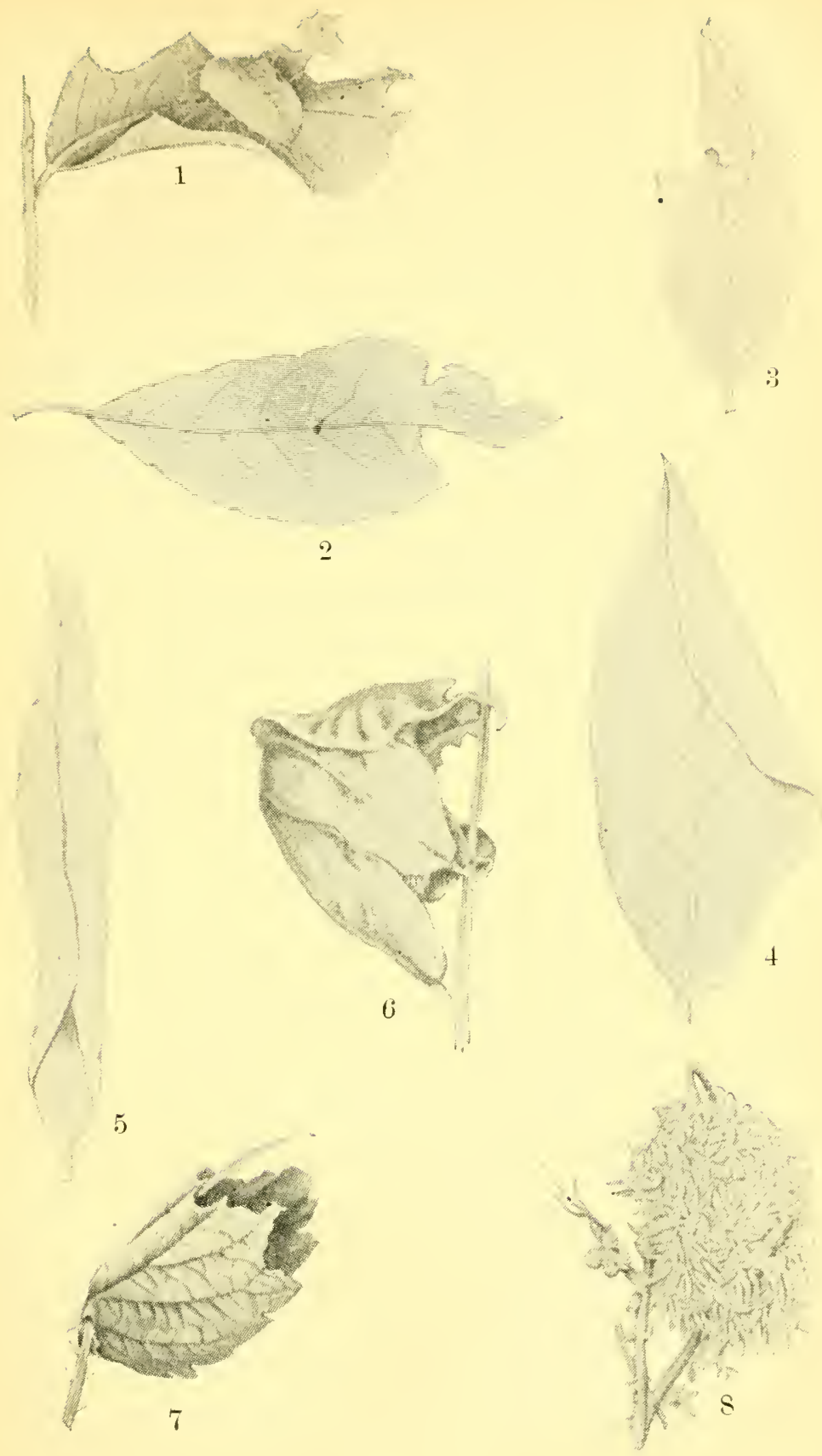

ment. The Painted Beauty (V. huntera) makes a similar but rounder nest on the everlasting, and conceals itself very effectually by completely covering the more compact but still very slight web, with the inflorescence of the plant.

Another class of nests is that made by some of our Melitaeini (Cinclidia and Euphydryas), which, living in company, cover at first a few leaves, then the whole head of the plant, and eventually, sometimes, the whole plant in a tolerably firm web, within which the company feed, until the whole becomes a nasty mess of half-eaten and drying leaves, and all sorts of frass, including their own excrement and cast-off pellicles, everywhere tangled with web. Within such a nest they hibernate, but not until they have strengthened it with denser web and drawn the leaves of the head more tightly, so that it becomes a mere bunch which one may cover with his hand, and which contracts the more, apparently as winter approaches. In the spring they evidently have had enough of this sort of communal life, and live thereafter in the open air.

But perhaps the most interesting nest of all is that made by the caterpillar of the Viceroy. 'This caterpillar hibernates when partly grown, and 
provides for the occasion a winter residence, which is occupied only during the cold season. For this purpose it eats the sides of a willow-leaf nearly to the midrib, for about one third the distance from the tip, ordinarily selecting for the purpose a leaf naar the end of a twig; the opposite edges of the rest of this leaf it brings together, and not only fastens them firmly with silk but covers this nest outside and inside with a carpet of light-brown glossy silk, so that the leaf is nearly hidden; nor is this all: it travels back and forth on the leafstalk and around the twig, spinning its silk as it goes, until the leaf is firmly attached to the stalk, and in spite of frost and wind will easily hang until spring. Following the projecting midrib, the caterpillar creeps into this dark cell, head foremost, and closes the opening with its hinder segments, ail abristle with spines and warts. The other species of the same genus, the red-spotted and the banded purple, have the same habits; the latter feeds on birches, and if we examine these trees in early spring, when all sorts of ichneumon flies are just beginning to wander about in search of prey, we can hardly fail to be struck by the deceptive resemblance these hibernacula of the banded purple bear to the opening buds and curving ter- 


\section{MAD BY CATERPILLARS}

minal shoots of the very twig on which they occur; the color of the soft down of the buds and the enveloping silk of the hibernacula is as similar as are their forms, and this mimetic resemblance is doubtless as effective as it in interesting. 


\section{$\mathrm{X}$}

POSTURES OF BUTTERFLIES AT REST AND ASLEEF

Butterfuies, as a general rule; are very dainty about alighting after flight, appearing to regard the position they shall take with some concern, hesitating more or less about the place they choose; sometimes they hover about a spot or approach and leave it many times before pitching; at others two or three quivers of the wing are all that indicate their daintiness. Moths, on the contrary, usually come plump to a stop and settle, much as if they had been thrown at the spot; while among the butterflies, those that in this respect resemble the moths the most closely are the lowest family, the skippers, and some Nymphalidae which are protected by their colors when alight.

Alighted only for a brief rest, or to sun themselves, or to suck the juices of some flower, butterflies usually keep the wings more or less spread wide open; though in feeding, especially if it be 
in companies, or at rest for a longer time, or, as it were, for observation, the wings are usually closed tightly back to back; among the Pamphilini, however, there is a very prevalent custom which oddly combines these two, the hind wings being held horizontal, the fore wings perpendicular or a little oblique; this gives them a curiously disjointed look, the purpose of which is not easy to see; perhaps a comparative study of the attitudes in males and females, or in those species in which the males have and those where they have not a discal stigma, may lead to some result.

The need of feeding with erect wings is plain enough in certain instances, as where crowds mingle along the edge of a muddy rut in the road; and that the same posture is almost invariably assumed at complete rest, as for the night, ${ }^{1}$ is also easily explained, since that presents the least exposed surface, and one which far more than the upper side of the wings, sometimes very completely, resembles in tint and often in texture or markings the background chosen for rest.

No creatures seem to be more sensitive than

1 Some Hesperini, which rest by day with outspread wings, sleep with roofed wings like moths, and very likely all of them do; we know little of their sleeping attitudes. 
butterflies to warmth and sumshine. $\mathrm{W}^{\mathrm{e}}$ have alluded in another place to the diurnal movements of even hibernating butterflies; and one is amused at watching with what precision a Melitaeid, for example, or a Polygonia, sidles around on alighting, to expose the broadest possible surface to the sum. Startle one of the latter, but not sufficiently to make it leave the spot, and with what a snap the wings close, and, in place of the burning colors which seem to have imbibed the sun's warmth, your butterfly, with the dead leaf or dusty color of its under-surface brought to view, has become nearly invisible.

Butterflies are not much given to walking, but in the use of their legs they have many little peculiarities which generally mark whole groups. Thus the Satyrids always walk by a series of nervous twitches in a very bungling fashion unknown, I believe, outside of this group. Many Theclini never remain on the surface of the leaf or twig on which they have pitched facing in the direction in which they have alighted, but turn part way around to face another way, and that with no reference to the sun; they do the same when the sun is wholly obscured.

At sleep, the wings are packed away into the 
smallest compass, as already stated; with the exception of some Hesperini, ${ }^{1}$ the wings are held erect back to back, the fore wings slid down between the hind pair, so that only the latter and the apex and front edge of the former are visible. There is, however, more variety in the method of treating the antennae; some, like the Satyrinae, sleeping with these wide spread, others tucking them between the wings, others bringing them together beside the front edge of the wings; sometimes only the stalks of the antennae lie between the wings, the clubs appearing beyond as if crowded out by the tight shutting of the wings. In all cases where the antennae are brought together this is the final action of the butterfly before complete repose; at first the antennae remain without, looking in different directions like sentinels; and it is only gradually that they are brought to the position of complete rest.

The moralist tells us, and his warning is seconded by the psychologist, that as every repetition of an action makes it easier than before, so any propensity indulged in wears ruts, as it were, in

1 Wittfeld, however, says that the southern Euphoeades palamedes sleeps with spread wings, and I have seen a European Thais do the same in confinement. 
our character, and habits become fixed; it is easier to travel given roads than others, and, what is fullest of portent, our propensities are plainly bequeathed to our descendants. The lives of frivolous butterflies admonish us in like fashion. Observe how wonderfully alike are the actions of butterflies of the same group, i. e., descendants of the same stock; their habits have become ingrained by repetition through the ages; habits which it were almost certain destruction not to obey, since in nearly every one some protective meaning may be found; habits which run so through groups that the keen observer may foretell the apparently untrammeled actions of creatures he has never seen alive, with as great a percentage of accuracy as the best-informed "clerk of the weather" may predict the action of the morrow's winds.

The behavior of butterflies, then, has clearly its story to tell of the past and its relationships, and we shall not be likely to reach the fairest conchnsions regarding the phylogeny of butterflies until we have given these their full valne. $U_{p}$ to the present no proper investigation has been made in this direction; only a few of the most patent of the tricks and ways of butterflies have been 
noted; a wide and open field lies before the inquirer, and it is for his use that I have tried now and then to bring together a few facts concerning the postures and behavior of butterflies in different circumstances. Thes are, however, still too few whereon to base any general statements likely to require no important modification on future investigation, and I leave them for the present barren of result, in the hope of enticing some one to enter a promising field, and perchance relieve these facts of their present stupidity. 


\section{XI.}

\section{THE EGGS OF BUTTERFLIES}

The eggs of butterflies, except those of the gigantic Ornithopteras, are no larger than a pin's hear, yet when examined under a lens, which is of course required to see the structure of such minute objects, we may look far before discovering anything more graceful in form or delicate in sculpture; indeed, chancing to study some of our forms during a winter spent in Egypt, I was greatly struck by their singular resemblance to the traceried domes of the famous Cairo mosques. They are composed of a thin, elastic, and usually transparent pellicle — so elastic that they will bound like a rubber ball when falling on a hard surface; where not transparent they are made opaque by crosslines or ribs, by a general reticulation, or in some lower forms (Pamphilini) by a uniform density of the whole integument. They are always circular in cross-section, and in general are flattened on the surface of rest; by their form they may be 

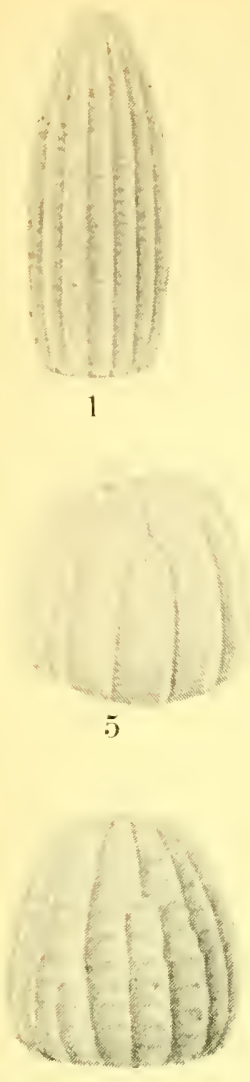

7

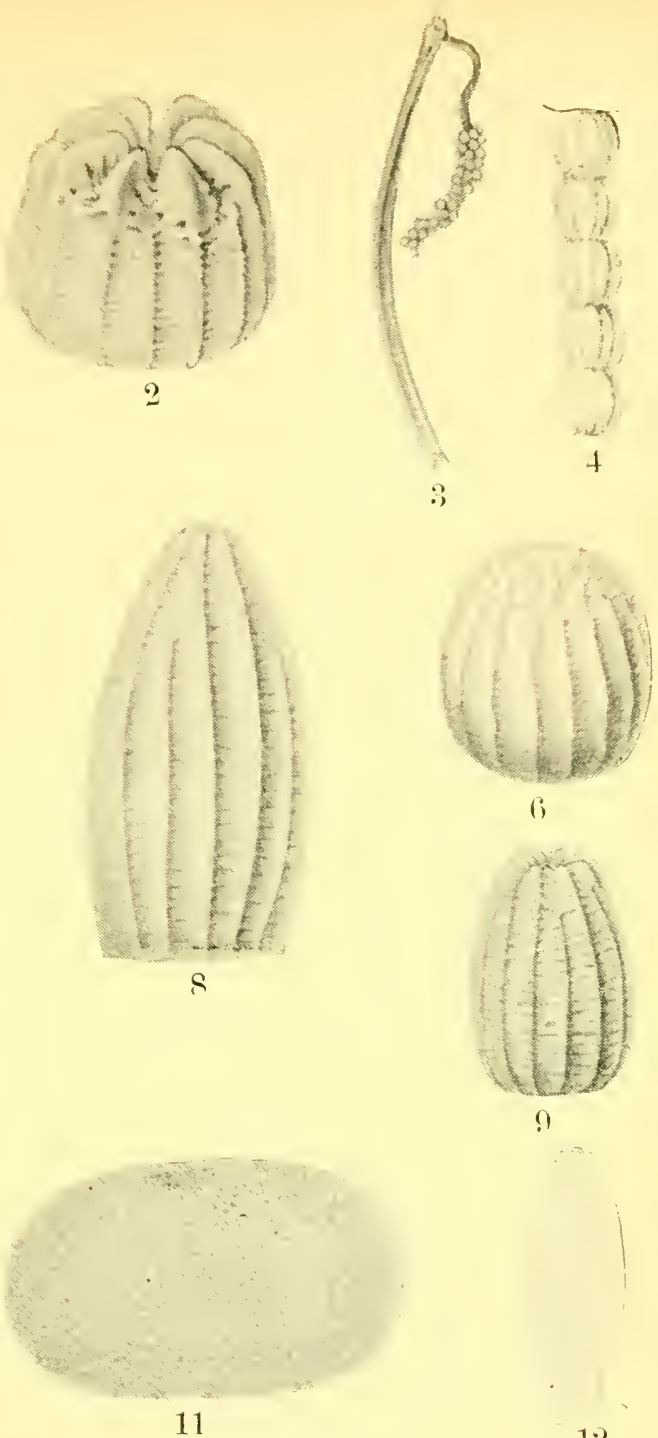

12 

divided into four classes: (1) barrel-shaped, (2) spherisal, (3) tiarate or turbau-shaped, and ( 4 ) hemispherical; or, if we consider their surface sculpture, into three groups: (a) ribbed, (b) reticulate, and (c) smooth. These divisions rum into each other to a greater or less degree, and nearly all possible combinations are found. With rare exceptions nearly allied forms closely resemble each other, and the degree of resemblance is in general an excellent test of affinity. Not only can species and genera be distinguished by oölogical character's, but many of the larger gromps, even as far as the broadest natural divisions of butterflies, may not infrequently be defined in terms of the egg, so that it even beeomes a valuable aid to classification.

The barrel-shaped form is sometimes very much attenuated at both ends, so as better to be deseribed as spindle-shaped, and it is nearly always broader at the base than at the summit, so as to merit the ter'm pyramidal, sometimes mueh broader, as in Speyeria. The truncate top is also very frequently rounded and its edge inconspicnous, and it then rums into the spherical or hemispherical class; but the true barrel-shaped group is always higher than broad. The Nymphalidae and Pierinae al- 
most always belong to this group, and they are always vertically ribbed to some extent, but the ribs always terminate short of the centre of the summit, either gently or abruptly. Sometimes these ribs are coarse and irregular, rumning in zigzag lines from base to summit, so that the egg might almost be regarded as coarsely reticulate; in others the ribs are excessively compressed, mere films, placed edgewise to the body of the egg, glistening in the sunshine like dew-drops, and increasing in size to the summit, where they often form a sort of crown; or they may die ont on the lower half of the egg, or fade into a weaker reticulation; or, above, may terminate at the edge of a sancerlike depression which forms the cap of the egg; but everywhere, with more or less distinctness, between these buttressing ribs, the surface of the egg is broken into quadrangular cells by delicate crossridges, which often increase in stoutness toward the main ribs, and in their turn buttress them.

The spherical forms include particularly the Papilioninae, some Satyrinae and the Hesperini, unless these last more properly belong to the preceding group. They are usually smooth, but may also be reticulated, or, as always in the Hesperini, ribber. 
The tiarate eggs are very beautiful objects, often reminding one of a miniature sea-urchin without spines, and are characteristic of the Lycaenidae, though some of them incline toward the hemispherical form, and all, without exception, are reticulate. In these the surface is never ribbed, but generally covered with a heavy network of deep pits, whose bounding walls are rather coarse and rough. The eggs of the Parnassians resemble them closely.

Finally the hemispherical egg's, generally more than half as high as broad, and with a slight flattened summit, are smooth, and comprise only the Pamphilini, if we except the reticulated Heodes, which possibly belongs here as much as with the turban-shaped eggs.

As an architectural form, the egg of a butterfly is exquisitely patterned. With all the variation in sculpture and contour, every curve and every detail of chiseling is in subordination to a central feature - all lead up to a distinct culminating area, the micropyle, or little rosette of cells of the most exquisite delicacy, which crowns the summit of the central vertical axis. Often requiring some of the higher powers of the microscope to discern, the cells are arranged in such definite and regular pat- 
ter'ns that in looking at them we seem to be peering through the circular rose-window of a miniature Gothic cathedral. Sometimes, in the tiarate eggs, this rosette is situated at the bottom of a very deep and narrow well, and can with difficulty be seen. Often their patterns would furnish useful hints to the decorator, and especially for all forms of embroidery. The cells which form the interior of the rosette are the points at which microscopic pores lead into the interior of the egg, and through which it is fertilized. With this in view, we can understand why this rosette should form the goal of movement of every part of the structure.

When freshly laid, the egg's are generally of some shade of pale green. though in the Pamphilini, with their opaque shells, they are nearly chalky white; but during the development of the caterpillar (or of parasites) within, all sorts of colors may be assumed, often of a rich or almost gaudy hue.

The egg's of butterflies are always laid in full view excepting that in a few instances they are prutially concealed by being thrust into crevices. Usually hatching in a few days, they are generally laid upon the very leaves the caterpillar will eat or 
upon the stem close at hand; but when, as in some cases (only known among Lycaeniclae), the egrg remains all winter, the butterfly selects the stem, and, as an additional protection, chooses a spot next a leaf-bud, or other projection, or tucks the egg in some crevice of the bark. It is even stated by Salesbury, according to Rennie, and repeated by European writers, that the egg of the Blackveined White (Aporia crataegi) may last three years and then hatch, but the statement seems to me fairly open to doubt until verified. For ordinarily the eggs of this species are laid in clusters (whether on leaf or twig I find no statement), and give birth the same year to eaterpillars which winter in small cluster's in webs. All butterflies which winter as egg's feed as caterpillars on trees or shrubs, never so far as known on herbaceous plants. As a general rule the eggs are laid singly, but in not a few cases, oftenest found in the Nymphalidae and Papilionidae, they are laid in clusters of from two or three to several hundreds. Sometimes these are rude bunches piled loosely or in layers one upon another; sometimes they are laid in more or less regular single or double rows; sometimes in a single column of three, or four, or even as many as ten eggs, one atop another; or they may girdle a twig like a fairy ring. 


\section{XII.}

PSYCHOLOGICAL PECULIARITIES IN OUR BUTTERFLIES

WHEN I first mentioned to a company of friends my intention to write an essay on this subject, a scornful laugh greeted me, as if I were testing their credulity. Yet no one, I fancy, could be a close observer of butterflies without noticing that, while there is no great difference between healthy individuals of the same species, there is as great a variety of temperament between different kinds as there is between different sorts of quadrupeds, to write an essay on whose psychological characters would excite no special comment; for the timidity of the hare, the cumning of the fox, the ferocity of the wolf, and other psychical characteristics of various beasts have become proverbial.

In their relation to man one recognizes a great difference between butterflies as to how companionable they may be. According to some writers, there would seem to be a certain variation among 
the same kinds in different places, just as with other animals, aceording to the frequency with which they come in contact with man. Thus DeCandolle remarks that in the Swiss Alps the butterflies have no fear of man and readily settle on the colored dresses worn by the women, while on the better-inhabited plains they are not known to do anything of the kind. Their fear of man $01^{\circ}$ their boldness is to al certain degree dependent upon their power of flight, as Belt has remarked in his "Naturalist in Nicaragua," the swiftest and strongest flyers allowing one to approach much nearer than those with weaker wings, feeling confident that they can dart away from any threatened danger. Yet entirely apart from this, one may roughly divide butterflies into domestic and feral, according to their habits and sympathies. Thus among the feral tribes should be ranked nearly all the Satyrinae, and especially such forms as the Arctic Satyr (Oeneis jutta), the Pearly Eye (Enodia portlandia), and the Little Wood Satyr (Cissia eurytus), and among the companionalble sorts nearly all the species of Vanessini. Instances of the boldness and even friendliness of the latter are not uncommon.

"While I lingered here [says Abbott, one of our hap- 
piest describers of the habits of beasts and birds] a pretty butterfly, the Red Admiral, alighted upon my knee as I was writing, and seemed wholly at ease in this unusual position. Something upon my clothes was attractive to it, and the graceful movements of its proboscis, and occasional down-dipping of one antenna and then the other, were amusing. I noticed that the right and left wing moved separately down and up, as though to retain the creature's balance, which the wind threatened, and at each such movement of the wings the corresponding antennae likewise dipped. This butterfly occasionally flew to the bushes near by, but never to remain long away, and sooner or later returned and was my companion for a great part of the day."

Instances of the vivacious and inquisitive ways of these butterflies are numerous. The entomologist cannot fail to be aware of them. Seeing one alight upon the tip of a bough near by he strikes at it with his net, only to see it fly off in an apparent paroxysm of terror, while if he but stop a moment he will see the rumaway return, dash about him, and alight again upon the self-same spot in a defiant way, flirting its wings up and down, as who shoull say, "Try it again, will you?" For" there is much that is sportive as well in the ways of many butterflies. One of my favorite modes of showing this characteristic to unbelieving friends 
hats been to toss my ap high in the ail, when these butterHies will often dart, dash at, and play aromd it as it begins again to descend. DeGamo has noticed this characteristic, as witness the following passage :

"One of the most curious features of a butterfly's life is its sportive or playful moods and ways. It was some time before I appreciated the fact that they indulged in such moods at all. Seeing them start vigorously after other insects on the wing, I assumed without investigation that these were movements in self-defense, till all the facts pointed to them as movements in play. This opened a new and interesting field of observation. The spirit of playfulness I found to prevail more towards sundown than in the morning. Only a very few times have $I$ seen any signs of it in the morning and never in the absence of sunshine. I found it far more common among the highly developed four-footed butterflies, as the Graptas, Vanessas, etc., than among the six-footed Papilios. . . The greatest manifestation of fun and frolic was in a group of alopes, some thirty in number, clustered under a tree in the shade. Such wild gambols on the wing I never saw, often in one compact cluster, wings and legs and antennae in a confused jumble, then off in pairs, then in two crowds, with all the marks of 'mirth and jocund din.' Such scenes do certainly appear like an intelligent appreciation of fun, as they clearly have no reference to any necessary 
functions of boly, and seem intended only for gratification."

It is but a short step from these characteristics to that of pugnacity, which is manifested by none of our own butterflies so conspicuously as by the American Copper (Heodes hypophlaeas). Watch one on a hot and sunny day in a favorable place, and you will see the fellow dart at every passing object, be it butterfly large or small, or even a blundering grasshopper. So, too, the Buckeye (Junonia coenia) has been described by Jones as " a most pugnacious little creature, and appears to love a quarrel, for you may see three or four of them ascending in the air and buffeting each other, now rising, now falling, unremittingly continuing their aerial warfare."

How totally different this from the sluggish, lazy, easy-going manner of most of the Satyrids, with their dainty ways, tossing themselves in graceful throws in and out the shrubbery; or the hurried direct way of the species of Argynnis, or better of Eurymus, zigzagging from spot to spot as if on business of the greatest urgency, though not quite certain where it was; or the bustling self-important actions of the larger skippers. Even in the butterflies of wilder spots, less frequently seen, how 
great a difference between the timid Gray-veined White (Pieris oleracea), which, though it feeds upon the produce of the garden, will scarcely let you approach in any near proximity, and the showy Red-banded Purple (Basilarchia arthemis) that will allow you to approach and pick it up with the fingers. What a contrast between the dignified Monarch (Anosia plexippus) moving imperturbably along its own way, undisturbed by the attacks of the smaller butterflies which dash abont it, and the vascillating dainty blues which cannot make up their minds just what to do ; or between the wary artful White Mountain butterfly (Oeneis semidea) and the bold and careless Tiger. Swallow-tail (Jasoniades glaucus). How rarely one sees collected in one spot on a flower or about a moist spot more than two or three American Coppers (Heodes hypophlaeas); they are too vicious and quarrelsome to be companionable. How different the equally active but eminently social Clouded Sulphur (Eurymus philodice) or Red-banded Purple (Basilarchia arthemis), which congregate by hundreds, as do. also the Tiger Swallow-tail (Jasoniades glaucus) and many others. The cunning ways of the White Mountain butterfly (Oeneis semidea) in its rocky defenses are elsewhere mentioned, and a simi- 
lar wiliness appear's in others, sometimes shown in a mock stupidity, as it were, flying, as you cautiously pursue, just beyond the reach of your net, moving with greater and greater swiftness as you increase your speed, all the while against the wind, when suddenly, after a quick movement upward, they open their wings to the breeze and are carried far behind you, thus evading the pursuit which they found becoming irksome, and leaving you heading the wrong way. 


\section{XIII.}

SOCIAL CATERPILLARS

As a general rule, caterpillars of butterflies live solitary lives throughout their entire existence. The mother drops an egg here and there upon a spot suitable for the food of its young, and here the caterpillar takes up its abode with more or fewer wanderings. In two of the four families of butterflies there is scarcely a single exception known to this rule, but in the highest family and in a few instances in the Papilionidae, caterpillars during at least a portion of their lives are more or less gregarious. Whenever the caterpillars are strictly gregarious, the eggs are invariably laid in clusters ; there are, however, some butterflies which lay their eggs in small clusters, whose caterpillars are not properly gregarious; yet all such are closely related to other's whose caterpillars are gregarious, so that we find every gradation from solitary to social. There are also some caterpillars which are gregarious in their early life, but afterward part com* 
pany. In such cases the caterpillar usually hibernates, and its social life lasts to some degree throughout the autumn and winter, the company dispersing at the renewal of activity in the spring. Indeed, in almost all cases, the association is most conspicuous in early life, when the caterpillars feed in rows upon the same leaf in such close proximity that it would seem to interfere with convenience. Sometimes this is the only mark of their social nature; but as all caterpillars spin more or less silk in moving about, a web of greater or less extent generally accompanies a colony, and in some cases the community constructs a close structure within which they retire to rest or to moult. A Mexican butterfly, allied to our sulphurs, constructs a web, first noticed by Hardy, which is nearly as close as parchment. With rare exceptions, all butterfly caterpillars feed upon the outside of plants; but there are a few which live in the interior, and one of these, an Indian species of Lycaenidae, is known to be social, living in numbers within the fruit of the pomegranate.

Among our own butterflies, there is nearly every gradation from brief and partial companionship up to a social life which lasts throughout the entire period of larval existence. The weakest form of 
social life is found in some of the Polygoniate (others being purely solitary), where the egg's being often laid in columns of from two to nine, $\mathrm{Oi}^{*}$ several eggs being scattered by the mother upon one leaf, the caterpillars in earliest life are naturally found feeding upon one leaf. Rarely are more than four or five found in company, and each takes up its independent position upon the leaf and acts as if the others were not present. As, however, it is their habit to remain upon the leaf until it is almost eaten, they naturally leave it at the same or nearly the same time, and, following a similar instinct, are apt to pass together to the nearest leaf, but scatter more or less, so that by degrees as they approach maturity they are found widely separated from each other. Yet even in this weakest form their numbers are often so great upon a single plant that when they leave it for pupation the chrysalids hang almost in company, thirty or forty spimning their silken shrouds in such proximity that they may be pulled down together. A somewhat similar or perhaps weaker case may be found in the Cabbage butterfly (Pieris rapae), which often lays a considerable number of eggs singly upon one plant, and the caterpillars, naturally seeking the interior of the 
cabbage-head, may often be found in close proximity. But this even more than the preceding is a case of mere accident, from the nature of the food-plant upon which they subsist. In all other cases of social life among our caterpillars the eggs are laid by the parent in decided clusters. The slightest of these is probably that of the Blue Swallow-tail (Laertias philenor) the masses being ordinarily confined to a dozen or so. The caterpillars in this case not only feed in company but, in earliest life at least, range in rows along the edge of the leaf they are eating, with their heads toward the eaten portion; and in this way they live during at least the earlier half of their lives, scattering more or less after the third moult upon separate leaves, so that at maturity rarely more than one is found upon a single leaf, though the leaf of their food-plant is exceptionally large.

This alteration of habit from companionship to solitarimess is a natural incident due to growth. $\mathrm{Up}_{\mathrm{p}}$ to the end of the third monlt the size of the caterpillar has not increased enough to make it a conspicuous object, but by the time the third moult is passed the caterpillar is half grown, and during this stage and the next its size becomes an important element in its security; and this alone is suffi- 
cient to account for the fact that mature caterpillar's of butterflies are rarely found in company. It is at this stage, too, that in many instances, the winter season overtakes the caterpillar and it hibernates; and since in the spring it revives when the plants have put forth but tender leaves, impossible to nourish more than one or at most two such ravenous beasts as now come out of their winter quarters, such a change of habit would seem to be compulsory. Possibly the change in habit which generally takes place at this middle period of caterpillar life, even when winter does not intervene, is an inheritance from a common ancestor whose habits were fixed by the necessity of hibernation at this age.

As far as our own fauna is concerned, the great mass of social caterpillars are found in the highest family, the Nymphalidae, and indeed in the sub-family, Nymphalinae, in which this habit is found in most of the principal groups. In some instances, as we have related of the Blue Swallowtail (Laertias philenor), the caterpillars in early life live exposed upon the surface, generally the under surface, of the leaf, ranged side by side, feeding and sleeping in mison. But in most some sort of web is constructed by the caterpillars upon 
or beneath which they live, and to which, should they wander beyond its limits for food, they retire for rest and moulting. Some use this web with certain alterations in its structure as a winter residence, but then invariably leave it on the approach of spring and part company, though often being still found in near proximity. Others leave it at the hibernating season to seek, each for himself, his own hiding-place.

Perhaps of all our caterpillars, although it constructs but a slender web, the Mourning Cloak (Euvanessa antiopa) is the most preëminently social. The eggs are laid in a cluster of greater or smaller size around a terminal twig, which they leave together, and as if by common impulse range themselves side by side in compact rows along a chosen leaf. Even if they are separated forcibly from each other, they come together again and rearrange themselves. When disturbed they will simultaneously strike an attitude of alarm and turn their heads in unison as if worked by a machine. The web they form is simply that which they make as they crawl about, each following hurriedly in the track of its predecessor, and as it moves adding its thread to the carpet upon which it treads: and 
being social throughout their life they are more than usually destructive to foliage, stripping branch after branch, and wandering to the very tips until these are borne down by the weight of the mass. It would seem probable that our Eugonia has the same habits from what we know of its European congener, but if so it is exceedingly strange that in only one instance has the caterpillar been seen in this coumtry, and then but a single one, probably one which was hastening to seek a place in which to pupate.

Although it is not stated whether the caterpillar concerned belongs to a butterfly or to a moth, a very curious and interesting case of strict commensalism has been noted by Fritz Müller in South America, in which a large spiny caterpillar was almost invariably found accompanied by a small hairy caterpillar, so small as to rest securely in a transverse position across the back of its goodnatured host, well concealed among its spines; in proof of its continued existence at this point the skin of the host was hardened beneath the tread of its little guest, so as to have become distinctly more callous than in other parts. Just what advantage this would be to either party, both be- 
ing feeders upon vegetable matter, it would be difficult to say, excepting that the spinous surroundings might well be of assistance in protecting the smaller beast. But this neat observation of Miiller seems to open a field of possible investigation which may have great interest. 


\section{XIV.}

\section{THE FIXITY OF HABIT IN BUTTERFLIES}

The habits of butterflies are of extreme antiquity. They are ingrained into the very texture of their lives. They are older than, or at least as old as, the patterns which adorn their wings. Moreover butterflies have two sets of habits, and these statements are equally true of either. The habits of their earlier life as a crawling caterpillar find no place in their aerial life on the wing, and vice versa; although in some we may find certain common characteristics shared by the two, as in the leisurely ways of the Satyrinae.

That this is true follows from the fact that certain special habits characterize large groups. Thus the mode of flight of the Satyrinae, which toss themselves lazily up and down as they move leisurely from spot to spot, is found to a greater or less degree in all the members of the sub-family; even in our White Mountain butterfly (Oeneis semidea) which inhabits a place and is subjected to external 
conditions so different from the others; but it is not found elsewhere among butterflies. The caterpillars of this same group are universally slow in their movement, there being not a rapid traveler among them. All the caterpillars of the Nymphalini humch themselves, the better to display their largest tubercles. One of the most curious instances we may cite is the habit of rubbing the erect hind wings together shortly after alighting by all or nearly all the Lycaeninae, certainly by members of each of its three tribes, and so far as we know it is done by no other butterflies. The darting, skipping flight of the Hesperidae is another instance, as well as the odd style in which the Pamphilini hold their wings when alighted and alert, the hind wings horizontal, the fore wings vertical or oblique. Peculiarities of nest-building are generally shared by a caterpillar with many allies, perhaps by the whole tribe to which it belongs. Slight tricks of movement, as of the sudden electric flirting of the wings when alarmed, or of the position of the antennae, are shared by many. This is equally true of the manner and place of alighting. Who ever saw one of the Lycaenini settle instantaneously like a Pamphilid? How it doubts whether it has found the best place, 
or whether on the whole it will alight now or not!

So one might go through the whole eatalogue of the ways and lives of butterflies to find that the great majority were ways and lives not of one but of many, - inherited traits, become fixed in their lives by constant repetition. Most frequently they are generie habits rather than specifie, often tribal traits, or even sub-family tricks; this in itself shows that habit as a general thing must be older than the wing pattern. But if anything more were needed to show it, it would appear by the facts of mimicry, where pattern plainly shows a far greater plianey to the summons of natural selection than ean be affirmed of habit; and the numerous cases of protective resemblance tell equally the same story ; here habit has often monlded pattern, or at most they have abetted each the other. As we must invariably discard the slightest notion of anything intentional on the part of the protected form, we cannot say, for instance, that the White Mountain butterfly alights on a gray rock, in preference to the ground or a twig of Vaecinium, in order to gain the protection afforded by the resemblance of the under surface of its wings to the mottled rock, but rather that the protective coloring arose from 
its habit of alighting here, while the secondary habit of tilting the wings to heighten the mimicry arose pari passu with the mottling.

If all this be true, a knowledge of the out-door life of our friends, both as crawling worms and as winged sylphs, may be of the utmost aid in attempts to note the interrelationships of nature: and these as well as features of actual structure must be accorded due weight in our classifications; but neither should be divorced from its fellow. 


\section{$\mathrm{XV}$.}

HOW BUTTERFLIES PASS THE WINTER

One would suppose that nature would have so arranged matters that delicate creatures like butterflies, passing a portion of their lives (the chrysalis) in a quiescent condition, would select the winter as the season in which to pass this state, and not waste in an enforced inactivity the precious moments of a too brief summer, when flowers and succulent plants are abundant as food for butterfly or caterpillar. Yet a very considerable proportion of the butterflies of New England pass the winter in some other state than that of the chrysalis. Some pass it in either of two or more states, apparently as a precaution against the total destruction of the species. Many pass the winter as caterpillars, some as eggs, and not a few as butterflies themselves. Many of the Theclini for instance pass the winter in the egg state, while on the other hand the Vanessini, a group which, whether in Europe or America, may 
be considered as almost characteristically pertaining to the temperate zone, where the winter is pronomeed, pass the winter in the imago state. One reason for this is that there is nearly always an antumn brood of butterflies which disport. themselves in great numbers in the latter part of the year, but have not time to undergo further transformations so as again to reach the chrysalis stage before winter would cut them off; but in some instances some of the chrysalids which should produce the antumn brood do not give ont the butterfly until the following spring. According to Wiesenhuitter such chrysalids of the Mourning Cloak (Euvanessa antiopa) as pass the winter are presumably females, inasmuch as the female, according to his observation, is generally fresh-colored in the spring, whereas the males are always very much battered and worn. So far as we know, in the case of these wintering butterflies, pairing always takes place in the spring.

Those hearing for the first time of the existence of butterflies in winter naturally inquire where the butterflies may pass the winter period. Each species has its own peculiar hiding-places, but in general they may be found beneath piles of rocks, in hollow places in the trunks of trees, especially 
near the roots, beneath the rafters of old buildings, in corded wood in the forest, and even in some instances probably simply hanging beneath the branches of trees. Thus Landois saw the European Peacock butterfly (Hamadryas io) take up its winter quarters in an ivy, hanging from a branch by its hind legs, folding all its other legs on its breast and closing its wings. During a warm spell in the early spring it disappeared, only, when the weather again changed, to return to the same spot and reassume its former position. Woodmen sometimes, in cleaving open a tree, will discover a little colony of hibernating butterflies, as has been done in the case of the Monarch (Anosia plexippus); and Goossens of Paris, in beating small trees over his open umbrella (a favorite mode of collecting) in the cold days of November, twice brought down the Comma butterfly (Polygonia c.-album) which fell upon its feet with closed wings. It would seem that they must therefore have chosen the under side of the branches for hibernation. He made some interesting observations upon these, bringing them home and placing one in an unwarmed apartment, the other in the open air on the northeast side of a window. They did not stir until February, when 
they resumed their activity. The one in the open air had experienced a temperature of at least $-5^{\circ} \mathrm{C}$., and Goossens discovered that numbness only comes on at $-2{ }^{\circ} \mathrm{C}$, for when it was warmer their position showed that they appreciated the difference between day and night. At such a time the hind wings are kept motionless, but in the daytime the fore wings are advanced, so that the inner margin is at right angles to the body; at dusk, the fore wings creep backward and finally pass partly behind the hind wings, nearly filling the empty space between the two wings in this genus, due to their great excision. The process is again reversed in the morning, showing that the butterffies are not completely benmmbed and, however quiet, recognize the distinction between night and day.

One November day a Mourning Cloak (Euvanessa antiopa) flew into my cellar and took up its position on one of the risers of the stairway just beneath the projecting edge of the tread above, the extremity of its wings projecting beyond the tread. Here it remained for three months without moving, except that it shifted its position six or eight times in the course of the winter, some- 
times forward, sometimes backward within the range of about an inch. At first the plane of the closed wings was perfectly horizontal, but about the middle of Jamuary they became slightly oblique, and the morning of the day it left its station the obliquity was somewhat increased. It was watehed daily the winter through, and the wings were always in the attitude taken at complete repose in the summer. When on the last day of February it left its station it took up another, head downward on the cellar wall, near a window where it caught the sun's rays a part of the day, and here it remained motionless for five days more, except for slight shifts as before, and that when the sum struck it its antennae were thrust forward and parted a little instead of being ensconced between the wings.

All hibernating butterflies, so far as known at present, belong to the Nymphalidae and Papilionidae, and almost exclusively to the Vanessini and Rhodocerini, neither Lycaenidae nor Hesperidae being known to hibernate in the perfect stage. Almost all the Vanessini of Europe as well as the Brimstone butterfly (Colias rhamni) are known to hibernate in the imago state, and in our own 
country Anosia plexippus, all the Polygonias, Eugonia j.-album, Euvanessa antiopa, Aglais milberti, all the species of Vanessa and Junonia coenia, as well as Hypatus bachmanii, and among the Rhodocerini Callidryas eubule and Xanthidia nicippe. 


\section{XVI.}

THE OLDEST BUTTERFLY INHABITANTS OF NEW ENGLAND

THAT a vast sheet of ice once covered New England has been so long known as to be common intellectual property. The great mass of drift which covers the entire face of the country is too conspicuous to be overlooked by any observing person. That we have indications of a former ice period in the present inhabitants of the district is perhaps not so well known by all. That such should be recognized among the butterflies appears at first blush surprising; yet a careful investigation of the butterfly fauna of New England, and its comparison with that of neighboring parts of the country, show that the nearest allies of no inconsiderable portion of our butterflies now exist in the far north, in regions where the summer still retains the retarding influence of the frozen zone, or they may be found still feeding close beside the existing glaciers of aretic lands. To mention only the 
most conspicuous instances which we have, we would recall the two butterflies before referred to, as now found exclusively upon the barren summits of the White Mountains, and at no other point in or near New England.

The most striking feature in their occurrence is the fact that the genera into which these two butterflies fall have an altogether special interest of great significance in this connection ; for they are exclusively or very largely arctic, and there are but three other such genera known in the whole butterfly world. These others are Erebia, of which there are some examples in subarctic America and in the Rocky Mountains; Agriades, which hardly comes nearer to us than Labrador, and is found again in the high mountains of the western half of our continent; and Eurymus, which is less exclusively arctic than the others, having representatives also over almost the entire globe, excepting in tropical countries, and of which we have three species in New England, one of them subarctic. Oeneis, the genus to which one of our Mt. Washington forms belongs, occurs elsewhere only in high mountain regions, and, with but one or two exceptions, beyond forest limits, whether toward the pole or the zenith. Several species occur 
among the mountains of our west, one is found in the Alps of Switzerland, and one in the Himalayas. Brenthis, however, the other White Mountain genus, while occurring as far north as butterflies are known (two or three species having been found by the very shores of the Arctic Ocean, in Greenland and Grimnell Land), is represented more largely by species occurring in the temperate zone, and we have in New England itself two of such species. In keeping with this distribution of these genera, the White Mountain Oeneis is not only confined to the barren summits of the range, but even, as we have found, to the higher parts of this region, although its food-plant, Carex, is found everywhere above the forest. The White Momtain Brenthis, on the other hand, very rarely occurs in the same district with Oeneis, being almost wholly confined to the lower half of the barren region. Its food-plant, though not known, is presumed to be violets, which are found in scanty numbers in the strictly alpine district, a single species being found in favorable spots ; but they are sufficiently abundant in the subalpine zone.

These two butterflies, then, may be looked upon as the oldest inhabitants of New England, which followed the retreating ice-sheet in its progress 
northward, and whose brethren, thought by some to be even forms of the same species, still cling to the borders of the ice region of the north. They were the first of their tribe to fly over the barren fields of New England when the earliest verdure began to follow the withdrawing ice, and, moving with it step by step, were at last, some of them, beguiled by the local glaciers which remained in the White Mountain region long after the main glacial sheet had left these mountains far in its rear, and until connection with the main body was finally cut off. As one of our writers, Grote, has expressed it :

"Return became at length impossible. They advanced behind the deceiving local glaciers step by step, up the mountain side, pushed up from below by the warm climate, which to them was uncongenial, until they reached the mountain peak, now bare of snow in the short summer. Here, blown sidewise by the wind, they patiently cling to the rocks; or in clear weather, on weak and careful wing, they fly from flower of stemless mountain-pink to blue-berry, swaying from their narrow temure of the land. Drawn into the currents of air that sweep the mountain's side, they are forced downwards, to be parched in the hot valleys below. Yet they maintain themselves; they are fighting it out on that line." 
It may here be remarked that botanists have not yet distinguished two zones of life above the trees in our White Mountains, but only between those plants that are found exclusively in that region or in the high north, and those which, while found there in greatest abundance, are also found decidelly out of it. But my own casual observation of the comparative abundance of certain flowers over the districts I have distinguished as upper alpine and lower alpine leads me to believe that a careful survey of the field would bring one to the same conclusion as I have drawn in the case of the butterflies. Moreover, Agassiz noted many years ago certain distinctions, as the following extract from his "Lake Superior" shows:

"Above this level the mountain is naked, and many fine plants make their appearance which remind us of the flora of Greenland, and many of which grow on the northern shores of Lake Superior, such as Arenaria groenlandica, Vaccinium caespitosum, uliginosum, etc. The summit of the mountain, at the height of six thousand two hundred and eighty feet, produces several plants which have no representatives sonth of Labrador. Such are Andromeda [Cassiope] hypnoides, Saxifraga rivularis, Rhododendron lapponicum, Diapensia lapponica."

The phenogamous regetation of the whole dis- 
trict is indeed pretty well known, but it would be well to prepare full catalogues of the plants found in every distinct centre of alpine vegetation, with their comparative abundance at each place. Thus in the immediate vieinity of Mt. Washington we should have separate comparative lists of plants of the elevated plateaus, of the borders of the Lakes of the Clouds, the base of the southerly cliff of Mt. Monroe, the boggy area above the Fall of the Thousand Streams, the neighborhood of the snow-field in Tuckerman's Ravine, the Alpine Garden, etc., with special notes upon the heights at which they are found as nearly exact as possible. The study, too, of the other insects of this region is just as instructive as is that of the butterflies or the plants. Thus among the moths of the genus Agrotis alone, Mr. Grote finds no less than three species, imperita, islandica, and carnea, which occur, besides on these lofty summits, only in Labrador and in Lapland or Iceland, while a considerable number of other moths and of Coleoptera are also lnown, inhabitants otherwise only of the high north.

It will naturally be asked how it is possible that insects, and especially such delicate organisms as butterflies, can maintain themselves in such a bleak 


\section{INHABITANTS OF NEW ENGLAND 151}

and inhospitable region as the summit of the White Mountains, where a Greenlauder would find it impossible to live in comfort, inasmuch as he would be exposed not merely to the cold to which he is no stranger, but to the fiercest and most biting winds, with an amount of humidity accompanying them which would seem to be almost fatal to existence. In the case of our two bntterflies it is tolerably certain that both of them pass the winter in the caterpillar stage, concealed in crevices of rocks beneath the mantle of snow, so that they are free from the sweeping wind, and have nothing but the rigors of the extremely long and cold winter to encounter. For protection during the brief existence of the butterfly life itself, there is a very plain provision on the part of nature in the protective colors of the wings. Especially is this the case with the Oeneis which, on alighting (which it ordinarily does on the bare gray rocks), invariably closes its wings back to back and settles upon one side as if reclining, the point of the wings away from the wind, where it clings to the roughnesses of the rocks, and is seldom blown from its foothold. In this position the peculiar gray mottling of the under surface of the exposed portions of the wings so closely resembles the gray rocks 
themselves, flecked with minute brown and yellowgreen lichens, that it is almost impossible to discover one in its resting-place unless one has seen it alight. The resemblance is of a very marked character, and is unquestionably a great means of protection.

With regard to the Brenthis, we have here again a case of protective resemblance, though to a less extent; for in the brilliant red and ashy checkered surface of the under wings, seen when the insect is at complete rest, we have contrasted colors frequently to be met with in the subalpine region in the latter part of the season when frosts have begun their work. But whether these protective resemblances are very necessary in a district where so few birds are found - hawks and snow-birds being almost the only persistent inhabitants - may perhaps be doubted, and the markings which we find on these insects may be only their ancestral inheritance, useful on the arctic barrens where birds are more various and plentiful. The Brenthis indeed seems really doomed to destruction. In the scanty numbers that one may find upon the mountain slopes, one sees the sign of their early departure; for, in the many years that I have searched for them with special pains, I have nerer' 

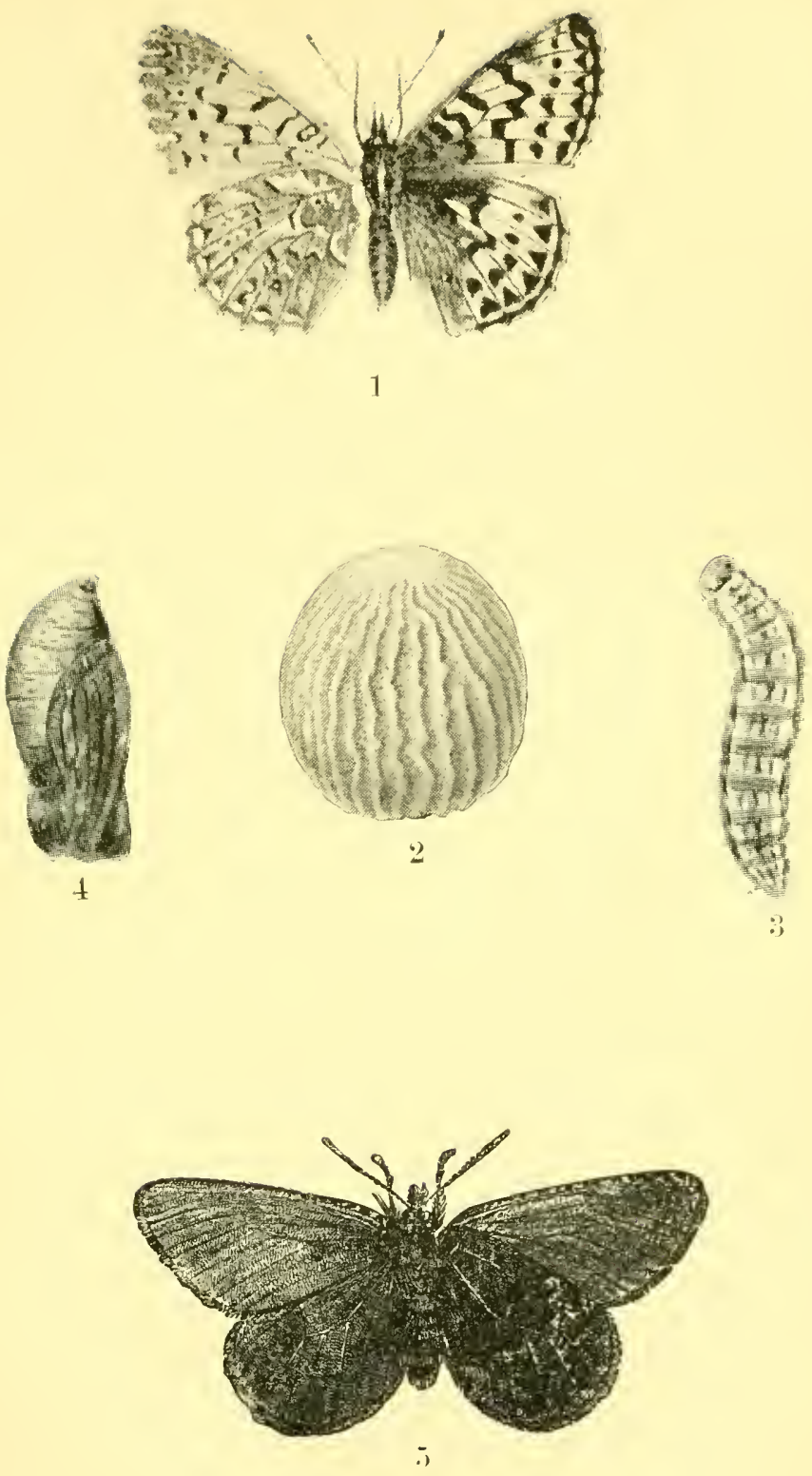

OLDEST N. E. BUTTERFLIES 

seen more than a dozen or two specimens in a single day. Yet this is not at all true of Oeneis, and one hardly need to be anxions, in our generation at least, concerning its persistence, for the butterfly is as abundant in its native haunts in proper season as almost any of the more favored inhabitants of lower levels. 


\section{XVII.}

PROTECTIVE COLORING IN CATERPILLARS

Considering mimicry in butterflies, we pointed out that it was not the least among the strange elements of that phenomenon that these extraordinary departures from a normal type should be gained purely for protection during the final days of a life, the earlier periods of which were subject to far greater dangers than the later.

When, however, we come to examine the earlier stages themselves, though we shall find, as far as I am aware, no cases of parastatic mimicry, we do find that protective colors and markings, if not striking, are at least very general; so general, indeed, that it might be questioned whether there exists a single one of the caterpillar's of our butterflies whose markingss do not serve in some special way for its protection.

Lubbock and. Weismann have pointed out that caterpillars of Lepidoptera generally are green in their earliest stage. This, however, is not univer- 
sally true. Within the narrow scope of our own butterflies we have many instances in which this is not the case. The caterpillar of Oeneis macouni is even brilliantly striped ; those of several species of Papilioninae are almost black with a white saddle, and there are many others, like Eurymus and Basilarchia, which, though having certainly a g'reen tinge, are nevertheless so obscured by other' color's as to have a dusky effect which is at most only greenish. But the fact remains that as a very general rule caterpillars of butterflies as well as of moths are when hatched nearly of the color of green leaves, and the various modifications which we find in the mature form of our different caterpillars are gained during growth.

This change of coloration and of markings which takes place during life is oftenest assumed after the second ecdysis, and, what is noteworthy, it is just then that the size of the caterpillar itself becomes materially enlarged. At the end of its second stage the little caterpillar is rarely more than two or three times as long as at birth, while the rate of growth subsequent to that is so great that in its mature condition it is ordinarily twenty or more times as long as at birth, and its bulk increases in a far greater ratio. The change of 
color and of markings has, therefore, direct relations to its visibility, and it is in this later period, even more than in the earlier, that we see how completely colors which are protective have established themselves. It is now that those oblique strealss upon the sides of the body are apt to show themselves, which, as Lubbock has pointed out, diverge from the general line of the body at much the same angle that the nervures of a leaf part from the midrib. Often the color of these streaks is graduated into the ground color in a manner which closely resembles the shadows of a raised vein upon a leaf, but it is only when we examine such objects in free nature that we see how perfect the deception becomes.

As Lubbock has pointed out, longitudinal stripes are very common markings, and are most common and indeed almost universal upon such caterpillars as feed upon grasses and other elongated forms of vegetation, while they are comparatively rare upon such as feed upon broad-leaved plants. This is well exemplified by a comparison of the caterpillars of our Satyrinae and Pamphilini with those of most Vanessini, in the latter of which, though longitudinal markings are not unknown, they are almost invariably broken up or confused with 
mottlings so as to lose much of their force. The green color of all our Rlodocerini and Pierini also, notably of the Little Sulphur (Emrema lisa), which feed upon broad-leaved plants and lie exposed upon the surface beside the midrib or prominent vein, conceals them almost completely from view even when the eye is fastened upon them. The long and slender form of Anthocharis with its striking longitudinal stripes would seem to render it a conspicuous object, but if seen upon the lank vegetation upon which it grows beside the long drawn seed pods, it would hardly be noticed. Caterpillars like our Argynnids, which conceal themselves upon the ground, are almost black, and can hardly be distinguished excepting when in motion. Even the color of the huge caterpillar of the Tiger Swallow-tail (Jasoniades glaucus) is such an exact imitation of that of the leaf upon which it rests, whose sides it has so turned up that no profile view may be had of it, that it does not readily catch the eye.

The few exceptions we have among our butterfly caterpillars, where striking and conspicuous color's obtain, are perhaps not easily explained. In some, doubtless, the colors may be regarded as warning colors, indicating the unpalatable nature 
of the creature, as in the case of the Monarch (Anosia plexippus). But there are others, such as the Variegated Fritillary (Euptoieta claudia) and Harris's butterfly (Cinclidia harrisii), where we know no reason for holding such a view; and it is a little perplexing when we come to examine the large, naked, and exposed caterpillars of our Papilioninae, as of the Blue Swallow-tail (Laertias philenor) for instance, its black body with projecting orange points set off vividly against the deep green of the Aristolochia, or the gay bodies of Iphiclides and Papilio with their transverse stripes of brilliant orange, green, and black, - it is perplexing, I say, to assert that these are warning colors given to show the inedibility of the caterpillar, possibly indicated also by the nauseous odor of the osmateria, when in two other of our own genera, Jasoniades and Euphoeades, with the same osmateria, we have protective colors of no mean importance. They may, however, be explained, at least in part; for the caterpillars of Laertias conceal themselves beneath the broad leaves of Aristolochia so as not readily to be found but for the marks of their presence in their droppings; and although one finds it difficult to look upon the colors of the Black Swallow-tail 
(Papilio polyxenes), the more striking of the other two mentioned, as in any sense protective, it is nevertheless true, as pointed out by Poulton with regard to the similarly colored species, the Swallowtail of Europe (P. machaon), that the protection afforded by the coloring of these insects is "very real when the larva is on the plant, and can hardly be appreciated at all when the two are apart."

Poulton, therefore, distinguishes between general protective mimicry, which, he says, is "such an appearance in an organism that the artistic effect of its surroundings is sufficiently reproduced in it to prevent attention from being attracted when the one is seen in the midst of the other," 111 fact simply a general harmony with its surroundings; and special protective mimicry, where protection is gained by the acquisition of a special appearance. Slater has urged that gaily colored protected caterpillars feed upon poisonous plants like Euphorbiaceae, Asclepiadaceae, Aristolochia, etc.; perhaps experimentation might show how much value there is in this suggestion.

One further point may be alluded to. It is well known that the caterpillars of many species of Lepidoptera are dichromatic in their later life, some of the forms being brown and others green. 
This has nothing whatever to do with sex or with food, and Poulton argues that in these cases both colors are protective, and that the species (though in no way either dichromatic form) is advantaged because when once discovered by an enemy others of the same color would then be more easily found by this enemy (a reason which would appeal to every field entomologist); so that while one form might suffer the species would be saved through the escape of the other. Weismann believes that this change has been brought about by natural selection, but Semper urges that selection "could not possibly effect any alteration in the pigment, but could only operate after such a change had actually occurred." Closely allied to this is the well-known fact that, in a number of our caterpillars and particularly in those of the Papilioninae, an entire change of color takes place just previous to pupation. The period of pupation is probably the most hazardous for an insect, as far as its active external foes are concerned, it being absolutely helpless in this period and in a very sensitive state. The time required for the change is nuch greater in any one species than for ordinary eclysis in the same species; and whatever the purpose of the change in coloration may be, it will hardly fail 
to be noticed that in general all vivid colors are subdued and entirely neutral tints assumed.

There are many instances among other caterpillars where most extraordinary resemblances are assumed, very probably protective in their nature. Incleed, in some of our own swallow-tails the markings of the front part of the body may very likely serve to alarm a foe about to attack, as they are really of a very striking nature, especially when the creature assumes the attitude which it does when disturbed. We have, moreover, some caterpillars which possess features of a very surprising character, doubtless for the sake of protection; one of the commonest of which is the striking contrast between creamy white and black, or some other dark tint, which makes the creature resemble the vermiform dropping of a bird! This is true of all our species of Basilarchia, of the Green Comma (Polygonia faumus), and, especially in their middle stages, of several of the Papilioninae, such as the Green Clouded Swallow-tail (Euphoeades troilus) and the Giant Swallow-tail (Heraclides eresphontes).

All these mimetic colors are of advantage only as against their vertebrate enemies. M'Lachlan has pointed out, what every observer must discover, 
that they give the insect no exemption whatever from the attack of ichnemmons, - a fact which is perfectly in accord with our knowledge of the physiology of insect-vision. But as regards their more highly organized enemies, it may indeed be doubted whether there is a single one of our butterfly caterpillars which is not protected by means of its color, either to prevent its being seen or to render it conspicnons. Indeed, we are inclined to say with Drummond that "mimicry is not an oceasional or' exceptional phenomenon, but an integral part of the economy of nature. It is not a chance relation between a few objects, but a system so widely authorized that probably the whole animal kingdom is more or less involved in it." 


\section{XVIII.}

\section{AROMATIC BUTTERFLIES}

Fritz Müller, a naturalist who has done much by his researches in various fields to bring new evidence in support of Darwin's theory, astonished the entomological world some years ago with a long list of odor's emitted by butterflies and moths. It had been known for a long time that certain butterflies had peculiar odors, but no one imagined the extent and variety of this peculiarity. And indeed this is not altogether strange, since the cases known up to the present time are largely drawn from tropical butterflies, and the odor is always lost after death, and in many cases is exceedingly faint and fleeting. The study of the apparatus through which the odors are emitted shows that three classes of organs are involved in their production, and the variation in intensity of odor in different creatures leads to the very reasonable belief that the identical organs found in an immense number of butterflies where 
we can perceive no odor are also scent-producers, even though their odors may be too ethereal for human senses.

The odors prodnced by butterflies are very largely confined to the male sex, evidently for the delectation of their mates, and the organs through which they are produced may be divided into three classes: extensible glands, situated upon the abdomen; tufts or pencils of hairs, found upon varions parts of the body, even including the legs and wings; and scales or scale-clusters, confined entirely to the wings. In the first class, that of extensible glands, we have the case of Anosia and its allies, the males of which can protrude from the terminal segment of the body a sac-like finger, bristling with hairs, which upon withdrawal are closely compacted into a pencil. The odor emitted by this organ is said by Fritz Miiller to be rather disagreeable when the processes are fully protruded, and as being rather faint in our species. I have never myself experimented with it. Similar organs are found in the allied Euploeinae, of some species of which de Nicéville says: "The males .. may often be observed patrolling a small aerial space, with the end of the abdomen emrled under the body toward 
the thorax, and with the two beautiful yellow anal tufts of long hair distended to their fullest extent at right angles to the body." So, too, in the Heliconinae similar organs exist, and that in both sexes, and the otor is described as of a disgusting nature. The females of Melete and Callidryas, genera of Pierinae, have similar organs in the female, possessing a peculiar odor, and the males of some speeies of Morphinae "are able to protrude from the end of the abdomen a pair of hemispherical bodies covered with short hairs which produce a very distinct odor." So, again, both sexes of a species of Didonis, one of the Nymphalinae, protrude from the dorsal side of the abdomen, between the fourth and fifth segments, hemispherical protuberances which have a rather disagreeable and strong odor; and what is the more remarkable, in addition to this, the male of the same species has a second pair of similar protuberances, between the fifth and sixth segments, which are white and "emit an agreeable odor, comparable to that of heliotrope."

With the second group, where the odors have their origin in tufts or pencils of hairs, the odors at once change in general from a disagreeable to a pleasant nature. In the Ithomyini, Fritz Mül- 
ler found a pencil or tuft of long hairs near the front margin of the hind wings of the males which emits a distinct and agreeable vanilla-like odor. The same organs with the same odor are occasionally found in some of the females, but the organs are never so large nor the odior so strong. In Prepona, one of the Nymphalinae, there is a tuft of black hairs on the hind wings of the males which possesses a distinct odor. The same odor of vanilla comes, according to Wood-Mason, from the scent-fans of a species of Thammantis, a genus of Morphinae, where they are situated in various positions upon the upper surface of the hind wings near the base. Similar tufts of hairs on the wings of the males of a species of Catopsilia are said by the same writer to smell like jasmine; while Muiller reports that in some of the higher Hesperini he perceived a very faint odor issuing from certain peneils of hairs which are found on the hind tibiae of the males when they were expanding, the pencil being ordinarily hidden in a furrow on the ventral side of the body between the thorax and abdomen. So, too, he found in the males of a species of Melete, one of the Pierinae, already referred to, a pencil of hairs not retractile, protruding from the ventral side of the 
tip of the abdomen, which emits "a rather strong' odor," but whether agreeable or not he does not state. In addition to these, there are not a few instances known in which the statement regarding the source of the odlor is somewhat vague, a gland being referred to when the only specification of such an organ is a collection of scales of peculiar character. On this account, and because in certain instances the odlor of such collections of scales is plainly due to the scales themselves and not to the pouch in which or the surface upon which they may occur, I prefer to class all these instances in the third group.

This includes odor's emitted by scales or clusters of scales. In all instances, so far as known, these are confined to the male sex, the scales themselves or the patches being similarly restricted. Thus we find a species of Antirrhea, one of the Satyrinae, in which, according to Fritz Miiller, the males emit a strong odor from a collection of scales on the hind wings at the anterior base of the upper surface, covered by the fore wings and specially protected by a curving mane of pale buff hairs. In a genus of Morphinae, Stichophthalma, Wood-Mason perceived a pleasant odor emitted by a patch of modified scales 
and an erectile whisp of hairs on the hind wings of the male. This, he says, comes from a fluid secreted by these scales or hairs, the only instance in which such a secretion has been noted; but this pleasant odor, he adds, is so faint "as barely to be perceptible in the presence of a much stronger odor (resembling that of sable fresh from the furrier's shop) which is common to the two sexes," but which is not localized. In the neighboring group of Brassolinae, spots of peculiar scales are very often present on the hind wings, and Mïller observed that very distinct odors were emitted from these spots in several different genera, particularly in Dasyophthalma. So, too, he noted that a rather strong odor was given off from a species of Ageronia, one of the Nymphalinae, by two large brown spots situated between the wings where they oppose each other, though in other allied species of the same genus neither the odor nor the patch could be detected. A most curious instance is that of the species of Didonis, already mentioned, where abdominal glands ocenr in both sexes and even a second pair in the male, one with agreeable and one with disagreeable odor, a butterfly which is still further beperfumed, since Mïller was able to retect a 
musk-like odor produced by a black spot of seales near the base of the under side of the front wings. Another member of the same sub-family, the European Charaxes, is said by Girard to have a strong odor of musk, especially just after its eclosion, though he does not state in which sex it arises, or from what point of the body it originates. In our own fama we have a striking instance of this odor in the scent emitted by the scales clustered along the median nervules of the upper surface of the fore wing in the Mountain Silver-spot (Argynnis atlantis), scales which have a distinct odor of sandalwood, so strong that it is hardly possible to handle living specimens without recognizing it, and which I have known to be retained for many weeks after death, when the insect had been inclosed at capture in a paper envelope. This is the more remarkable because I have never detected the same or any odor in the allied species of Argymnis of New England, which nevertheless possess precisely the same scales and in the same position. Finally, in this highest family of butterflies, we have the instance of the Monarch (Anosia plexippus); the scales found in the little ponch upon the upper surface of the hind wings next the lower median nervule emit 
a slightly honeyed odor over and above the carroty smell which all the scales possess.

In the next family, the little discal spot of scales upon the upper surface of the fore wing of the males of a large number of Theclini is well known, but it has never been noted by any one except Fritz Miiller that this patch of scales occasionally has an odor of greater or less distinctness. In the allied group of Lycaenini, the males of which possess scales of peculiar battledore form scattered over the upper surface of the wings, we find in one of our own species, the Spring Azure (Cyaniris psendargiolus), an exceedingly delicate odor, which I can only describe as that of newly stirred earth in the spring or of crushed violet stems.

Among the Pierinae, Müller mentions several instances of odoriferous scales, which in some instances are collected into patches and in others not. Thus in Leptalis he finds on the portions of the front and hind wings which conceal each other a patch of scales emitting an odor of greater $\mathrm{Or}^{\circ}$ less strength according to the species; an odor, he remarks, which is "disagreeable to human noses." So, too, in the males of several species of Callidryas, he discovered in the patch of scales in the 
same position on the hind wings a musk-like odor of varying degrees of strength according to the species. He adds that our own Cloudless Sulphur (Callidryas eubule) emits a faint musk-like odor, but this has been more earefully and independently determined by Miss Murtfeldt of Missouri as a slight violet odor'; she was unable, however, to locate the spot from which the odor originated. Again, according' to Müller, a "very delicious perfume" is produced on the upper side of the wing of the male of the species of Melete already referred to, a perfume which is rather faint, but which may be rendered distinct by keeping the animal alive with the wings closed, when the odor may be perceived on opening them. Another instance in which two closely allied species may vary in regard to their odor is found in our species of Pieris, the males of the Cabbage butterfly (Pieris rapae) being only faintly orlorous, while those of the Gray-veined White (P. oleracea) have a more distinct but still faint odor of syringa blossoms; so, too, the Green-veined White (P. napi) of Europe is said by different writers, de Selys Longehamps, Perkins, Weismann, to have the odor of thyme, verbena, orange, or balsam. The only one of our Papilioninae in which 
there are any such scales peculiar to the male sex is Laertias, which has the inner margin of the hind wings reflected, concealing scales of a peculiar character; I have never taken a living male, and so have been mable to detect any odor there, but Edwards speaks of the butterfly as having a strong and disagreeable smell which probably originates here; for Müller has found in other allied swallow-tails odor's which arise from exactly this source, the reflected margin being expanded, he says, when the wings are moved strongly in a forward direction, and allowing the odor to escape. Indeed, Müller asserts that in one species there appear to be "two sets of males, emitting equally strong but quite different odors," a case which would be very similar to that of dimorphism in color or markings, - diosmism we might eall it. The odors which he discovered from the different patches of this sort were in some cases agreeable and in some disagreeable.

According to Aurivillius, both male and female of Oeneis norna of Enrope have a musky odor, and as he can discover no odor in either sex of the Large Cabbage White (Mancipium brassicae), a species in which the male possesses large androconia, he looks askant at the so-called scent scales 
deseribed by Fritz Müller. But if the species of Oeneis named possesses this odor in both sexes, it is probable that it does not arise from the scent scales but from some other source, probably from some abdominal excretory organ, such as Müller has described in many other butterflies. I have been unable to detect any odor in three other species of Oeneis examined alive by me, and they, like Mancipium brassicae, are merely some of many instances in which our senses camnot perceive an odor presumably emitted. Lelièvre, again, found that both sexes of Thais polyxena had on eclosion, when handled, an odor similar to that of its food plant Aristolochia, the odor arising from a fluid which was left upon the hand that had seized the insect. The European Swallow-tail (Papilio machaon) is also said to sometimes exhale a distinct odor of femnel, upon which, the larva feeds. All these, however, are plainly means of defense, if they have any purpose, and have no relation to the odor's of scent scales. Nor does it appear that any organs for their production have been noted.

The statement by Miiller that the fragrant odors emitted by butterflies are in some cases produced by peculiar scales found in the male sex, and which he terms scent scales, was received with a great 
deal of incredulity, and rightly, because the wing of an insect was looked upon, at least after the butterfly had flown awhile, as an almost completely dead organ. But the fact that any one may experiment with our own butterflies, and in several cases prove to himself the exact location of an odor, removes in the first instance any possible doubt as to its origin; and Weismann, in defending Miiller, has clearly shown that there is a living tissue in the wings of butterflies which would allow of the production of an odor through local active scent glands.

It seems, therefore, to be clearly proved that very many butterflies emit odors either of an agreeable or of a disagreeable nature, and that those which are pleasing to us are in large measure confined to the male sex, and are emitted through microscopic canals which course through microscopic scales to microscopic glands at their base within the wing membranes. Now it is quite plain that, since these insects emit odors, they must also be able to perceive them. That this is the case has always been known to be true of moths, since the males of certain species, especially among the Bombycidae, will of an evening enter in great numbers an open room within which a female 
of the same kind has been disclosed from its cocoon entirely out of sight of and often at a great distance from her visitors. It is plain that in instances of this sort, known to every entomologist and too numerous to mention, the sense of smell - must be the sole directing agent; and since in many of these instances no odor is perceptible to human sense, it is plain that there may be many odors emitted which, though imperceptible to us, may be all-sufficient for them. This abundantly explains the many cases of organs from which we can perceive no odor, when in allied insects identical organs are perceptibly fragrant.

Moreover, we have in certain specific structures in the enlarged antennal club of butterflies what are plainly sense-organs supplied with nerve-endings; and inasmuch as there is no structure found in them which could subserve the purpose of hearing, or indeed of any other of the senses known to us excepting that of smell, it is the belief of physiologists that here are situated the organs of smell in butterflies. The under surface of the antennae of butterflies is invariably naked to a greater $\mathrm{Or}^{\circ}$ less degree, and, more plainly in some joints than in others, little dimples can be readily seen. It is in these little pits that are situated the organs of 
smell; each consists of a sac-like cavity, the opening into which is often protected by cuticular processes, and at the bottom of which in the hypoderm is situated a fusiform body with a delicate conical ending extended free into the centre of the sac, its other extrèmity being in direct continuation of a nervous thread.

For myself I am inclined to attribute to butterflies, as to moths, an exceedingly delicate and high perception of odor's. Any one observing their action with this in view will find numerous instances in which this sense certainly seems to come in play, particularly as it appear's highly probable from recent researches that the sight of these creatures is far less distinct than was formerly supposed. The mere fact that the egg's of butterflies are invariably laid upon or in close proximity to the food plant of the caterpillar can be explained, as I have already suggested, only on the supposition that the creatures have the power of distinguishing such plants by their odors. If one will watch a butterfly bent upon laying eggs as it flits in and out among the herbage, he camnot fail to perceive the brief visit it makes to plants which seem quite closely to resemble the food plant of the caterpillar, and how quickly it settles upon the desired object, as if it 

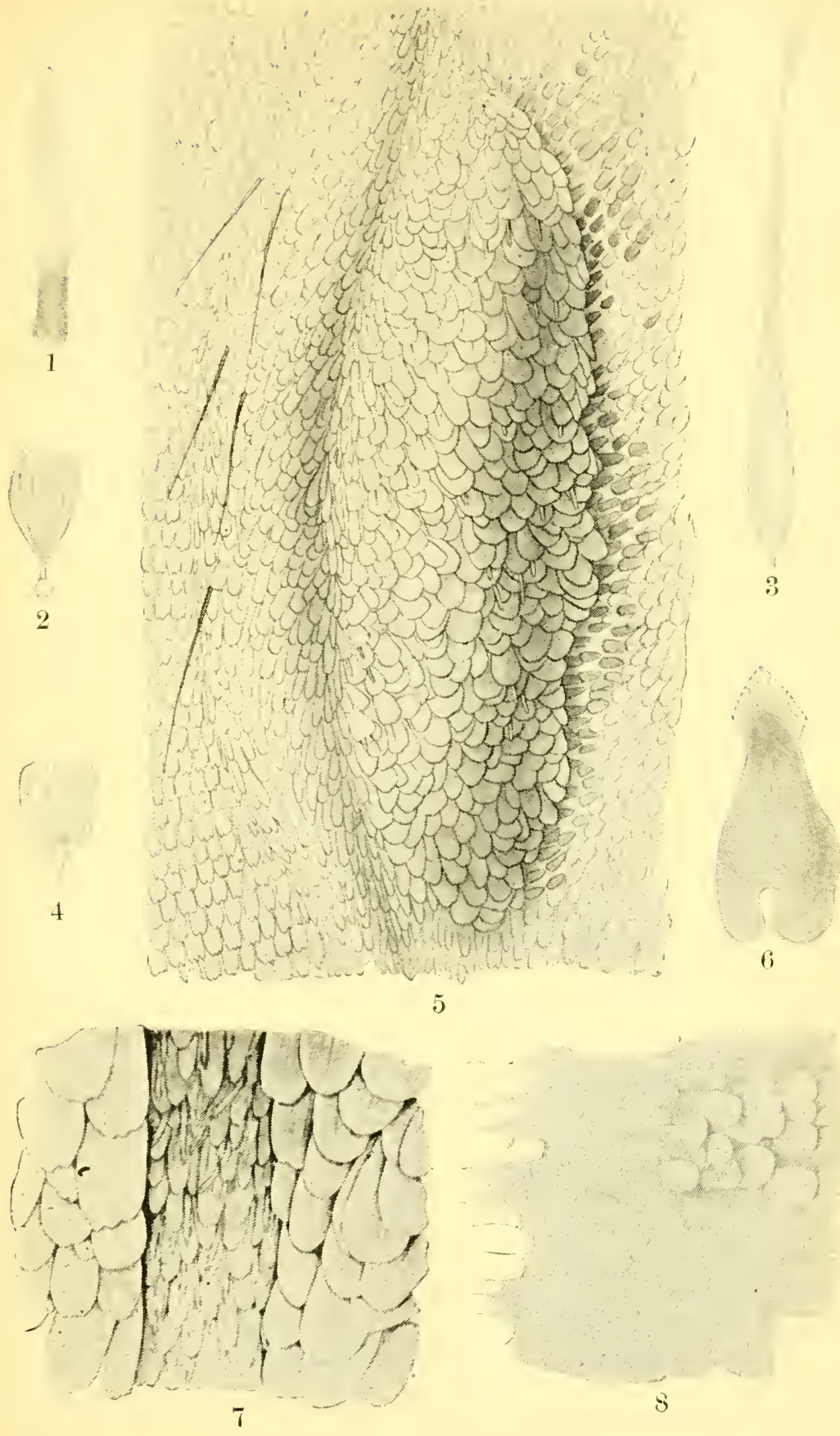

were recognized in an instant. More than this, how merringly it discovers the plant it is in search of, even if hidden beneath a canopy of entangled obstacles. It acts in every way as if it were scenting out the object of its quest.

So, too, the very high development of scent scales of varied patterns and character among butterflies indicates a direct sexual use, which. is the more easily understood when we consider that the greater variety and brilliancy of the color's of butterflies as contrasted with moths has, in all probability, no sexual significance whatever. Brilliant masculine colors may possibly have arisen in birds through sexual selection, but such an origin is impossible in butterflies; since, therefore, the males cannot be attractive to their mates by seductive color's, they resort to odors, and vie with each other in the production of sweet-smelling garments. 


\section{XIX.}

\section{THE PROCESSION OF THE SEASONS}

No one can observe butterflies in most casual way without having forced upon him the constant fluctuation of forms that greet his eye. At one time he will be struck by the abundance of kinds and of individuals; then by the small number he will neet, mostly of two or three sorts. One common kind he will fancy he has lost sight of, only to have crowds of them burst on him later in the season. He will look for the re-occurrence of others in vain. And each succeeding year he will note the same phenomena in the same order, varied only by the greater abundance or scarcity of one kind or another.

This supplanting of one species by another is in wonderful adaptation to the parallel changes going on in the vegetable world, especially among the flowers. I do not know that any of our naturalists or artists have written of the harmony between the prevailing tints of a New England landscape at 
different times of the year, and of the insect world at the same seasons. Our common butterflies, which nature has been at such pains to adorn, show a shifting panorama of form and color from early spring to the time of frost. First in the sombre leafless woods come the various dusky wings, brown and black, skipping softly in and out among the gray rocks and over the dry leaves and dark pools of melting snow, or suming themselves on dry sticks athwart the sum. Hard upon these, in the time of early violets and hepaticas and frequenting the spots most loved by them, follow the little blue butterflies, scarce larger than the flowers. Then, as spring fairly bursts upon us with its fresh and varied hues, come crowds of queenly swallow-tails, lustrous with metallic gleam, or striper and belted with gay colors; and the banded and spotted purples that court the quiet forest road and the brink of the mountain brook; the soft white butterflies, that look too pure for earth, less retiring than the last, float abont our gardens, alas! on sad intent; while the brisk little tawny and black skippers everywhere bustle and whisk about. Summer, with its blazing sun and diversified blossoms, brings us the hot-looking coppers, and all that dappled band of 
fritillaries and angle-wings, blocked in red and black above, and often variegated by odd dashes and spots of burnished silver, or by peacock eyes beneath. How they crowd about the spreading thistle blossoms, or on the many-flowered umbels of the milkweed, and fan themselves with content at their sweet lot! As autumm approaches and the leaves grow dull, the grain ripens in the meadow and the pastures parch with drought, then come the satyrs or meadow-browns, lazily dancing by the roadside and over the thickets which skirt the fields; in the time of goldenrods and yellow and blue asters the great throng of yellow and orange butterflies appear; some of them are with us throughout the season, companions of the buttercup, the dandelion, and the rudbeckia; but now they swarm, flitting busily in zigzag courses over upland pasture and lowland meadow, by marsh and brook, in field and fen, crowding around the open flowers, or dancing in pairs in mid-air. 


\section{XX.}

\section{THE WAYS OF BUTTERFLIES}

Trie butterfly is a daughter of high noon and of the sun. Rainy days see none astir. A few will venture out on a dull day, but it needs the full blaze of the sun to marshal all the hosts; indeed, there are few butterflies abroad in New England before seven or eight o'clock of a summer's day, and long before nightfall, with closed wing's, and antennae snugly packed between, they are quietly resting beneath some leaf or clinging to some grass-blade. 'The morning seems to be the favorite time for changes, at least with us, whether it be for depositing eggs, their hatching, the eclyses of the caterpillar, or the assumption of the pupal and imago states. In the tropies, according to Distant, many species have a definite period of the day for their flight, and the esmeralda butterfly, by Wallace's statement, even prefers showery weather for its activities. In resting at night each species has its own peculiar haunts, from which it may be 
easily stirred. Driving one morning within an hour after sumise across the sandy plains of Nantucket, along a road fringed with a row of stunted pines some fifty feet from the track, a continuous stream of Blue-eyed Graylings (Cercyonis alope) arose, stirred from the low tops of the bordering pines by the rumble of our wagon-wheels; none were to be seen either before or behind us, but on either side they constantly arose as we reached them, and, wafted by the wind, sank drowsily to the earth. Just before nightfall, at the proper season, one may readily discover the American Copper (Heodes hypophlaeas) or the Clouded Sulphur (Eurymus philodice), clinging head upward and with drooping wings to any common herbage; or watching the Spring Azure (Cyaniris pseudargiolus) as it rests on a bough may observe it, as a heavy cloud obscures the sum, drop fluttering to the ground to alight upon a blade of grass in some concealed spot beneath the shrub it had left. Gosse states that in Jamaica the Heliconians (Apostraphia charithonia) assemble in a swarm before sumset and huddle together on the stem of a certain plant for the night; is it not possible, however, from what we now know of this butterfly, that these were simply males assembling about a chrysalis of a female? 
But we are sending our friends to bed before ever they have busied themselves with the day! Their first thought appears to be of honey, and off they go, probing every flower they meet, and spending the greater part of the time in this employment.

Some butterflies are less greedy than others, and spend long hours in sumning themselves, resting upon the leaves of herlos or trees, or perhaps upon the ground, gently half opening and shutting their wings; many kinds are of a lively and even pugnacions disposition, and perch themselves upon the tip of a twig or on a stone or some such outlook, and dash at the first butterfly that passes, especially if it be one of their own species; then the two advance and retreat, forward and backward, time and again, circle around each other with amazing celerity, all the while perchance mounting skyward, until suddenly they part, dash to the ground, and the now quiet pursuer again stations himself on the very spot he quitted for the fray. But they are not always particular to choose one of their own kind for this combat. Toss your hat in the air, and almost any of our Angle-wings will dash at it and circle around it as it rises and falls; and the little American Copper, one of our smallest butter- 
flies, will dart at every bulky grasshopper that shoots across its field of vision.

Some butterflies are as fond of water, or even of ordure, as they are of the sugared sweets of flowers. Every one must have noticed at the brink of roadside pools left by a recent rain, how the yellow butterflies will start up at one's approach, flutter about a few moments, and then settle down again to their repast. On favorable occasions, you may find them ranged by hundreds along the edge of a puddle, with wings erect, crowded as closely as they can be packed. The little azure butterflies congregate in the same way about moist spots in the roals through woods; but as they choose less frequented places, this is not so common a sight. Our Tiger Swallow-tails throng about lilac-blossoms, and become so intoxicated that on one occasion a friend of mine caught sixty of them at once between his two hands; and Baron tells the story of two kinds of swallow-tails in Madagascar which evidently suck moisture from the ground for the mere pleasure of the thing, alighting by a stream of water and ejecting the water behind as fast as they take it in in front; on one occasion about a saltspoon of what was apparently pure water was caught from the abdominal flow in about five minutes! 
The butterflies I have mentioned show an appanent fondness for each other's company, apart from the attractions of the flowers or the muldy road; indeed, there are very few hutterflies which, at the time of their greatest abundance, do not show a tendency to congregate. The Monarch or Milkweed butterfly (Anosia plexippus), for example, may be seen quite by himself, sailing majestically over the fields, until late in the season, when, having multiplied to excess, vast swarms are found together; together they mount in the air to lofty heights, as no other butterfly appears to do, and play about in ceaseless gyrations; and sometimes they crowd so thickly upon a tree or bush, as by their color to change its whole appearance; occasionally we hear of the migrations of butterflies in swarms, but they are of rare occurrence, and have mostly been observed in the tropies. Mr. W. Edwards, however, relates how, from the top of Pegan Hill, in Natick, Massachusetts, he saw such a moving swarm flying steadily for hours in a single direction. They passed too high for recognition, although, by his description of their size and their mode of flight, it was probably the same butterfly which we have just mentioned.

The movements of butterflies on the wing are 
as different as the flights of birds, and just as an ornithologist may distinguish many birds by their. mode of flight when their form and colors are indistinguishable, so the observant entomologist may often determine a butterfly from a considerable distance. In the case of the entomologist, however, the decision is more difficult, since there are such rapid replacements of one species by another throughout the summer that direct comparison of the flight of similar species is often impossible. 


\section{XXI.}

\section{BUTTERFLIES AT NIGH'T AND AT SEA}

Butterflies are ereatures of the land and of the day. No aquatic stage is known, or one that is aquatic in any stage of its existence. They love the sun and warmth, being essentially tropical animals, every one of the larger groups decreasing in representatives in passing from the tropics towards the poles. They rarely undergo their transformations other than above the ground, and mostly in midsummer. They fly by day, and generally by brightest day and in clearest weather. Yet there are some groups which love the forest gloom, and a few which, in tropical countries, favor the twilight. There are a few, too, which venture to make their homes in the frigid zones, and on high and bleak mountain summits. There are, however, exceptions to nearly every general rule, and a few of them may be related here.

About fifteen years ago, I was spending the summer on the island of Nantucket. The under- 
keeper of the powerful flash light at Sankaty Head brought me one day a tin box full of "moths" which had been fluttering around his lantern in great swarms the night previous. On opening it, I discovered a dozen living specimens of the Compton Tortoise (Eugonia j.-album). Hundreds of them had flown into the lantern the preceding night, and had given him a great deal of trouble. This is the first instance, so far as I can learn, in which butterflies have been known to fly by night, and it was the more surprising because this butterfly had never before and has never since been found by me upon the island of Nantucket. Nor do I think there are enough plants there upon which its caterpillars would be likely to feed to support any considerable brood. Since then, Miss Murtfeldt of Missouri has stated that after ten o'clock one August evening a specimen of Chlorippe celtis entered the open window of her sittingroom, attracted by the light, and was captured in a butterfly net. Another specimen was taken earlier in the evening, but after the lamps were lighted. A hackberry-tree, Celtis, on which the larva feeds, was near the window. An instance still more nearly approaching our first is stated to have been mentioned at a meeting of the Brooklyn Entomo- 
logieal Society in October, 1885; Dr. C. Hart Merriam was quoted as having mentioned that a light-house keeper on Lake Ontario had been greatly annoyed by the large swarms of the Monarch (Anosia plexippus) that flew against it and obscured the light. These are the only instances that I have been able to find, either in this country or elsewhere, of the attraction of butterflies to ordinary light; but since the introduction of electric lights into our cities, entomologists have made use of them for the capture of insects, many nocturnal animals being attracted from all the surrounding country by the brilliancy of the light, and among them, according to Mr. Hemry Edwards and others, several species of butterflies. Most of them, like the preceding, were members of the highest family, Nymphalidae, viz., Anosia plexippus, Vanessa atalanta, V. cardui, V. huntera, and Euvanessa antiopa; and, besides these, Cyaniris pseudargiolus and Euphoeades troilus. As all these instances, excepting that mentioned by Miss Murtfeldt, were cases of exceptional brilliancy and magnitude in the light, it is hardly to be presumed that we shall change our opinion that butterflies, as a rule, are insects of the day, although, as is well known, there are certain groups, especially of 
the Satyrinae, which in the tropies are accustomed to fy by twilight and even in the rain.

My attention was early called to the occurrence of butterflies far out at sea by seeing, on my first natural history expedition nearly forty years ago, a specimen of the Mourning Cloak (Euvanessa antiopa), which visited our vessel on the $26 \mathrm{th}$ of February, while off the coast of North Carolina and some twenty or thirty miles from land, making us a short and flighty visit. One of the most remarkable instances, however, is that related by Darwin in his "Naturalist's Voyage around the World":

"One evening [he says], when we were about ten miles from the Bay of San Blas [northern Patagonia], vast numbers of butterflies, in bands or flocks of countless nyriads, extended as far as the eye could range. Even by the aid of a telescope it was not possible to see a space free from butterflies. The seamen cried out 'It was snowing butterflies,' and such in fact was the appearance. More species than one were present, but the main part belonged to a kind very similar to, but not identical with, the common English Colias edusa. Some moths and Hymenoptera accompanied the butterflies; and a fine beetle (Calosoma) flew on board. . . . The day had been fine and calm, and the one previous to it equally so, with light and variable airs. Hence 
we cannot suppose that the insects were blown off the land, but we must conclucle that they voluntarily took flight."

Observers in India and other tropical regions have noticed on many occasions vast swarms of Pierinae moving in a line along the sea coast, and occasionally such swarms have been seen in similar situations in temperate regions; thus Dr. Schulte relates that in a dearl calm off Nordeney in the Baltic Sea, he steamed for three hours and a distance of thirty miles through a continuous flock of the Cabbage butterfly (Pieris rapae) from ten to thirty miles from the main land and only five miles less than that from the nearest island; afterward the shore was foumd strewn with their dead bodies. And on our own side of the ocean we have a curious instance related of the Little Sulphur (Eurema lisa) by Mr. J. M. Jones, who states that early one October morning several persons living on the northern side of the main island of Bermuda perceived what they thought to be a cloud coming from the northwest, which turned out to be "an immense concourse of small yellow butterflies, which flitted about all the open grassy patches and cultivated grounds in a lazy manner, as if fatigued after their long voyage over the deep," and fisher. 
men out that morning stated that their boats were literally covered with these butterflies. Other instances are recorded by Caldcleugh and Cornelius. I have elsewhere recorded ${ }^{1}$ the tendency of the Monarch (Anosia plexippus) to swarm along the water edge as if preparing for a great flight, and also the fact that this butterfly must have flown vast distances over the Pacific Ocean to have tenanted the scattered islands where it is now found. Also that it was seen by one naturalist in the south Pacific five hundred miles from the nearest island, and on the Atlantic Ocean "hundreds of miles from land." There is further a single record of the occurrence of Pieris rapae on one of the transatlantic steamers, when more than a thousand miles from land. This last might perhaps be accounted for on the supposition that the insect had emerged from a chrysalis on board, which had matured during the passage. But a still more striking instance of the occurrence of Lepidoptera far out at sea, on account of the number of species concerned, is given in "Science," where Mr. Lucas records that while in latitude $25^{\circ}$ south and a thousand miles from the nearest portion of the coast of Brazil, his party

1 See The Life of a Butterfly. New York, 1893. 
"encountered several light squalls of wind and rain, during one of which two butterflies were driven past. 'The weather continued squally all night and for part of the next day, the wind coming from the westward. The following morning it was found that quite a number of Lepidoptera had been blown on board, and ensconced themselves in various places sheltered from the wind. They were mostly, if not wholly, nocturnal species of small size, although one large hawk-moth was among them. About twelve or fifteen specimens, representing nearly as many species, were captured, and others seen; so that not less than twenty or thirty individuals must have reached our ship."

This number of specimens at so great a distance is certainly very remarkable and shows that the occurrence of butterflies at sea must not be looked upon as excessively rare, and explains without doubt one means by which the natural distribution of butterflies from one region to another may take place. 


\section{XXII.}

SONE SINGULAR THINGS ABOUT CATERPILLARS

Some one has said that it is the unexpected that always happens. So, to one who may be tolerably familiar with the structure of caterpillars, some new and unexpected feature often presents itself and will then appear in the same or in some modified form through a long series of different species. $\mathrm{Or}$ the arrangement or disposition of parts with which he is perfectly familiar may suddenly be found to follow certain laws which he can formulate but not explain, and which he had before overlooked.

One of the most fundamental facts in the structure of caterpillars, as of all arthropods, is the repetition of similar parts along the several rings of which the body is composed. But there are in caterpillars, at least, two disturbing elements which modify this law; one, considering that the metamorphoses of insects are conceded to be an acquired characteristic, is readily explained, and that is the 
difference between the structures found on the thoracic and the abdominal segments. Thus, on account of the development of the future wings, the spiracles of the second and third thoracic segments are omitted, and the legs found upon the thoracic and abdominal segments are very different in character, those of the abdominal segments being a temporary expedient for the long trailing abdomen, while those of the thoracie segments are more highly developed. But these exceptions, which have a direct relation to the future needs of the animal, cannot explain certain other features which show similar differences. In general terms, the entire surface structure of the upper part of the animal is practically identical on the thoracic and abdominal segments, but there are certain differences which appear, to which no explanation is readily given.

For instance: By the transverse creases which simulate the incisures between the segments, each segment is ordinarily divided into two or more transverse sections. Now these sections, at least when there are more than one or two, invariably differ upon the thoracic and abdominal segments, the abdominal segments having a system of their own, distinct from that of the thoracic. The first 
thoracic segment, indeed, is the subject of great specialization and differentiation, and often differs widely in its divisions, as also in the appendages it bears, from the other thoracic segments; but this is not true, or is true in an extremely limited sense, as regards the other thoracic segments, which to all practical purposes are identical in general appearance with the abdominal and would seem to have much the same office to fill. Yet, if we examine carefully the dermal appendages of these segments, we shall note some curious features distinguishing them from those of the abdominal segiments. Thus, the spines, bristles, filaments, or other special developments of the skin, are ranged in most caterpillars of butterflies in longitudinal rows when they have any regular disposition whatever. There may be one or two or more upon each segment in a single row; all the spines of one row will be found at corresponding points of the different segments, either on the middle or back or front, as the case may be. Yet with scarcely an exception among the caterpillars of butterflies, those series which extend along the abdominal segments will either stop altogether at the thoracic segments or slightly change their direction at this point, so that often we may readily distinguish the 
thoracic from the abdominal segments without looking at those parts which characterize them distinctively, such as the legs or spiracles. Thus, even in the mere disposition of the spines along a caterpillar's back, the future separation of the thorax and abdomen is foreshadowed. This is wholly independent of the larger amount of space upon the thoracic tract due to the absence of spirarles; for, when the spines are well developed on the first thoracic segment, which bears an umusually large spiracle, they are aligned with those of the other thoracic segments and not with those of the abdominal segments.

This, like the absence of spiracles from the second and third thoracic segments, might be explained on the theory that the transformations of the insects are an acquired characteristic, a development backward from the imago. But this will not explain another peculiarity which one observes in the general arrangement of the spines and other dermal appendages on the back of caterpillars, a feature which is extremely common, though perhaps not universal, with all vermiform creatures. I refer to what might be called the polar or antithetic arrangement of these appendages, which shows itself in a multitude of ways. As a general 
rule the hairs, spines, filaments, or what not, are highly developed upon the thoracic segments, sometimes increasingly so from the hindmost forward, the series culminating in lofty bristles or long appendages upon the first thoracic segment. When this occur's, it is an almost invariable rule that a similar but reversed arrangement and extension of the same class of appendages is found upon the terminal abdominal segments. Or if, as is frequently the case, the second or third thoracic segment is independently enlarged or its armature specially magnified, a similar but generally lesser development will be found to occur on one of the preterminal, though not the terminal, abdominal segments. A case in point is easily seen in the caterpillars of the genus Basilarchia, where the second and third thoracic segments are mammilate, and the second is crowned by a pair of stout, thorny tubercles. So, too, in a less degree, the seventh and eighth abdominal segments are slightly humched and the corresponding tubercles at that point are noticeably enlarged, especially on the eighth segment.

Many other similar features might be pointed out even among the limited series of our own caterpillars, as in all the young Papilioninae, and this 
symmetrical polarity seems quite akin to what I once pointed out in the markings of the wings of butterflies, where corresponding ocelli are found upon the wings in antithetie positions as related to the vein structure beneath. Another instance of this polarity is seen in many of the caterpillars of the Satyrinae, in all of which the terminal segment ends in a fork of greater or less dimensions, in some instances taking the form of a long, pointed spine on either side, directed backward. When this is the case, and especially when it is most developed, the head also is crowned with a similar pair of pointed spines, and at rest the head is bent downward, so that these spines are thrown forward and the body ends at each extremity in a pair of long pointed spines. In this instance, at least, a purpose might be seen in such an armature, for it would appear as if the head bearing these long pointed spines would present a formidable appearance to some of its enemies, especially as it is able to present these organs at any point with great force and rapidity. If an enemy, alarmed at the front aspect, sought to assail the creature in the rear and were to find a similar pair of spines, it might well be conceived that he would presume that these also could be used with equal offen- 
siveness. Possibly this will explain many other eases.

If we examine the arrangement of the spiracles upon the sides of the body, we shall find that the first thoracic and the last abdominal pair are invariably much larger than the others, which are equal among themselves. The explanation of this is easy. The respiratory tube of each has to feed a very much larger field, the head and second thoracic segments being fed by the tubes finding their outlet at the first thoracic segment, and several of the hinder abdominal segments of the body being equally dependent upon that of the eighth abdominal segment. The spiracle of the first thoracic segment is also sitnated on a higher level than the ordinary abdominal spiracle, and this is a consequence, in part at least, of the ordinarily smaller size of this segment; yet it is also true in those forms in which the first thoracic segment is greatly enlarged. But what is curious is that in certain gromps, the Lycaeninae in particular, and the Hesperidae to a less extent, the spiracle of the eighth abdominal segment is also situated at a considerably higher level than those of the other abdominal segments. This seems another instance of the polar arrangements of parts to which we 
have alluded, but the explanation here is less obvious, since it is a characteristic only of certain groups, and even here is not invariable; for in the caterpillar of Feniseca, one of the Lycaeninae, the eighth abdominal spiracle is quite on a level with those in advance of it, just as it is in the bulk of butterfly caterpillars. The only reason for this elevated position in these cases would seem to be the particular form of the termination of the borly, for in all the Lycaeninae, excepting Feniseca, and in all the Hesperidae in which this occurs, we find a flattened subonisciform shape, one which, indeed, throws the spiracles of all the abdominal segments a little higher relatively to the base of the body than is common among caterpillars in general.

Besides the spines, filaments, bristles, etc., which form so noticeable and common a feature among butterfly caterpillars, there is another still more common and of a very similar nature; that is, the short hairs or pile with which the body is provided, always supported by little papillae and distributed with great regularity, in which a transverse is more often seen than a longitudinal direction, sometimes dispersed indiscriminately all over the body. When a trimsverse arrangement obtains, it is usually related closely to the sections into which 
the segments are divided. The use of this clothing for the body is tolerably clear, since this pile must prevent the too rapid evaporation of the heat from the surface of the body; for, although caterpillars would be classed among the cold-blooded animals, they nevertheless have an internal heat above that of the surrounding atmosphere, which originates from the activities of the organs and the respiratory function, and which they would lose more rapidly but for this investing pile.

But there are two other series of structures, always arranged in longitudinal rows, the use of which is wholly unknown. One of these is a universal characteristic of all caterpillars in their earliest stage, excepting probably the larger part of the highest family, and is common to the later stages of some of the lower families; and that is the special papilla-mounted bristles, which are furnished with an expanded trumpet-mouthed tip and are the ducts leading from glands at their base secreting a transparent fluid, which, after secretion, is borne in a little globule in the mouth of the trumpet, and sometimes kept in its place by a few microscopic bristles which surround its rim. 'That these have some protective function is highly probable, but what its nature may be, or low it acts, 
is quite unknown. 'That they may be odoriferous seems highly improbable, for, though we can easily eonceive that their insect enemies might perceive an odor from them, did such exist, which would be imperceptible to our senses (as we have the best reason for believing is the case with minute odoriferous organs of the perfect insect), yet we have not a particle of evidence to this effect, since in not a single instance have we been able to perceive any odor whatever from them. In the case of the organs of the mature forms, we conclude them to be odoriferous because in a few instances we can perceive an odor, and may fairly argue that entirely similar structures in others from which we can perceive no odor emit, nevertheless, some scent. Such evidence is absolutely wanting with regard to the present structures, and their use is therefore a subject for research. On experimenting, however, with some of the caterpillars of Pierinae which bear them when full grown, I have found the globule at the summit to be visibly increased when the creature was disturbed.

There is still another structure only recently made known, the purpose of which is obscure. These are the crateriform, chitinous annuli, which are ranged in longitudinal rows along the abdomi- 
nal and sometimes the thoracic segments. They are found only in eertain groups, but appear to be a universal characteristic of the earliest stage of the Lycaenidae, and have the appearance of spiracles, only they are ordinarily quite circular, while spiracles are generally oval, and they present no opening in the centre, but only, as far as I have been able to observe, a simple pit of more delicate structure than the chitinous amnulus itself. They are found also in some Hesperidae in their earliest stage and sometimes also thronghout life. But for the tenuous structure of the pit in the centre, they wonld have all the appearance of suppressed spines, and, indeed, the central pit seems sometimes to be wanting, and we have simply a shining lenticle, similar to those which are so common in the Papilioninae. But whether they should be looked upon as structures on their way to some use, or as effete structures, degenerated spines so to say, we have no facts at present to show, and an explanation of their purpose is still to be sought.

The discussion of these odd structures and curions arrangements of parts in caterpillars may already have been extended to too great length, but I should like to draw a moment's attention to two other special points in the structure of caterpillars 
which are still enigmas. One is the purpose or cause of the excessively constricted neck of the caterpillar's of Hesperidae, a universal characteristic and one that is widely different from the frequent enlargement of this segment, as we find it in the Papilioninae, and to a much greater extent in the Lycaeninae. Another is the curious swollen vesicle which hangs like a bag, a blunt, conical, or transverse structure below the first thoracic segment in advance of the legs. Various suggestions have been made with regard to this. It is a very common occurrence, perhaps not universal, with caterpillars, but very much more highly developed in some than in others. In those in which it is most highly developed, we have found no habit or peculiarity which would explain its purpose. It is ordinarily covered with gritty tubercles of a special structure, but as far as I have been able to see, contains no openings whatever. Many other singular things about caterpillars needing explanation could be given, especially as regards their coloring, but these will suffice to show that there is yet a wide field open, even among our commonest forms. 


\section{XXIII.}

WHERE DID THE BUTTERFLEES COMMON TO THE OLD AND THE NEW WORLD ORIGINATE?

If we bear in mind the continuity of land between South America and North America, we shall not be surprised at finding, at least along the borders, some butterflies which are found on both continents; but considering what wide oceans separate on either side the Old World and the New, and that their points of contiguity are in extreme northern latitudes, we might expect a greater absence of Old World forms in North America. Yet if we separate from the bulk of butterflies of this continent those which are found south of the Canadian border and east of the Rocky Mountains, we shall find, out of the somewhat less than two hundred and fifty species occurring therein, not over a dozen which may be fairly considered identical with butterflies found in the Old World, whether in Europe or in Asia. The identity of some of these, many writers have questioned; about some there is no 
doubt whatever, while there are others which approach in appearance those of the Old World so closely that naturalists are still in dispute concerning them. Let us consider a few of these separately, that we may gain some idea as to the nature of their peculiar distribution.

In the first place there is one species, the Cabbage butterfly (Pieris rapae), whose introduction into the eastern part of our continent is a matter of history, and of whose immediate European origin there is therefore no question. There are three other's, the Mourning Cloak (Euvanessa antiopa), the Painted Lady (Vanessa cardui), and the Red Admiral (V. atalanta), which do not vary in the slightest degree from the same species in the Old World, although some writers have at times thought that they could pick out the American and European forms when mixed in the same collection. Euvanessa antiopa is very widely distributed, covering almost the entire North American continent excepting arctic and subarctic lands, and even here it extends within the latter to Alaska. In the Old World it has an equally wide distribution, being found over the whole of Europe excepting southern Spain, and over all of northern Asia. It is an insect of strong flight, and being found upon both 
sides of Bering Strait, could unquestionably pass from one continent to the other at this point of their nearest approach. In which continent the species originated must be judged rather from the abundance and variety of its nearest allies on the one continent and on the other. In America there is but a single additional species of the genus occurring, and that so rare that I am not aware that more than one specimen has ever been found, occurring as it does in the mountains of Mexico. In the Old World several species occur in southern Asia, but in addition there is a very closely allied genus, Hamadryas, which occurs in Europe but not in America, and it is therefore in the highest degree probable that the origin of the species should be looked for in the Old World. As to the two species of Vanessa, we have shown in our New England Butterflies that the genus is divisible into two sections, into one of which cardui falls, into the other atalanta; and that the immediate congeners of cardui are found altogether in the New World and those of atalanta in the Old. The distribution of these species in the New World is more restricted than that of E. antiopa, so that there is no probability of any recent transfer of forms between the two continents, and we are left 

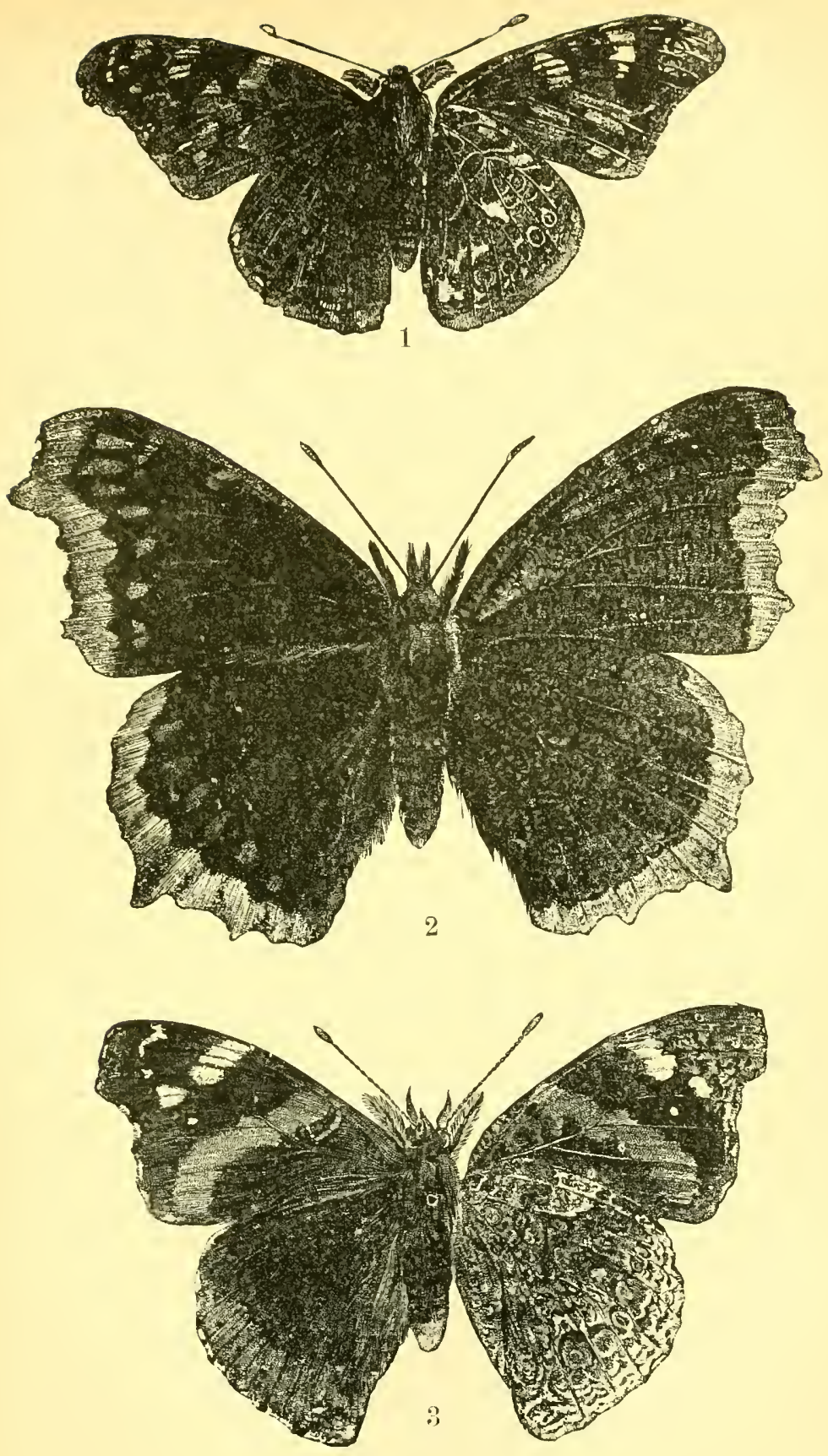

entirely to the consideration of their allies to judge in what part of the world they originated, and on this basis there ean be no question whatever that cardui originated in Anerica, and atalanta in the Old World.

Two other species are in nearly the same category as the last as regards their distribution on this continent. These are the Spring Azure (Cyaniris psendargiolus) and the American Copper (Heodes hypophlaeas), which many writers are inclined to consider identical with argiolus and phlaeas of the Old World. There can be no doubt of their exceedingly close affinity, nor, on the other hand, of the fact that whether species or variety, the forms existing in the New World can be separated from those of the Old. With regard to Heodes, there is but a single species of the genus, in its restricted form, in either hemisphere. In each it extends from ocean to ocean, although not found in the high north, and inasmuch as the genera nearest to it are also represented by species in each hemisphere (more abundantly in the Old Wrorld than in the New), it is difficult to form any proper judgment concerning its place of origin, though it would appear more probable on general grounds that it originated in the Old World. ' The same general 
statements are true to a large extent as regards the species of Cyaniris. There is a single form on each continent which extends across its entire width, but is not found in the high north. As in Heodes also, its immediate relatives are found in greater abundance in the Old World than in the New; but on the other hand the development of varietal forms within the species is so greatly in excess in America that we must conclude it probable that its life on this continent has been longer than on the Old.

There remain only those species which occur within our district, but which belong more properly to high boreal regions. Among these we have first a species of Oeneis (Oeneis jutta, the Arctic Satyr), which is unquestionably identical on the two continents. Its distribution on this continent is probably much more extensive than known, as it has been found at widely distributed localities. The genus to which it belongs is a characteristically alpine and arctic group, and is so widely developed on both continents that here again it is extremely difficult to decide as to the probability of its origin. Often living close beside the ice, it has undoubtedly been a companion of the terminal moraine throughout the ages. One indication 
might at first lead us to suppose that the life of the genus may have been the longer in Enrope. This is the fact that in the Alps of Switzerland there is a species very clearly distinct from any found in the north, while on our own high mountain-tops the White Mountain butterfly (O. semi(lea) is considered by many writers as identical with a species found in Labrador. But both are waifs left by the glacial epoch. Still, the bulk of genera to which the satyrids of Europe are referred belong to the section with ribbed eggs, in which Oeneis falls, while the contrary is true of the American forms. It would seem, therefore, as probable (though highly uncertain) that Oeneis originated in the Old World.

All the other species, in the opinion of most critical entomologists, are different from those of the Old World, but in all cases they approach so closely to them that many writers have considered them as identical. The Green Comma (Polygonia faunus) is a case in point. It has been considered as identical with one of the forms of the variable Comma butterfly (Polygonia c.-album) of Europe ; but the facts in the case would seem to show that, whereas the species of the Old World are few and variable, those of the New are numerous and 
closely allied, and at the same time frequently dimorphic or even polymorphic. The excess to which variability has extended in this country would therefore seem to indicate this as its older abode. The opposite is probably true of Eugonia, represented in this country by a single species; this is considered by many as identical with Eugonia van-album of Europe, which has there for its companion many very closely allied species. The Gray-veined White (Pieris oleracea), almost our only native species of Pieris, considered by many as the same as the Green-veined White (Pieris napi) of the Old World, has also many allies in the Old World, and therefore, like Pieris rapae, probably originated there. Finally, Pamphila, represented in this country by only a single species, the Arctic Skipper (P. mandan), widely separated from all its allies, strong of flight and extending to Alaska, belongs to a genus represented in the Old World with its immediate allies by several peculiar types, which range across the entire breadth of the continent; we must therefore look upon this species as one introduced from the Old World, but at a period of time so long ago as to have become fairly distinct from the primal stock.

If now we turn our attention to the butterfies 
found north of our boundary and not extending into it, we shall find a considerable assemblage of species, from twenty-five to thinty in number, belonging to as many as thirteen genera; and we shall at once be struck by the fact that in every case these genera are represented either by the same or by allied species in the Old World; and what is more, that in all cases but one they are more, often much more, bountifully supplied with distinct forms in the Old World than in the New. Thus we find several species of Oeneis, two of which oceur in Europe, four of Erebia, and two or three of Coenonympha, all considered distinct from those of Europe, and confined to the western half of our continent; five species of Brenthis, of which three are looked upon as identical with those of Europe, and one of Lemonias; one each of the lycaenid genera Cupido, Agriades, and Epidemia, all distinct from the European species, five or six species of Eurymus, of which at least two are found in Europe, one of Pontia, two of Parnassius, one of which is found in Europe, the same of Papilio, and finally one of Erynnis, which also occur's in Europe. This last genus is the one to which we referred as being far more developed in America than in Europe; indeed, the European species, the 
Pearl Skipper (E. comma), is only known upon our continent by a varietal form occurring in Labrador.

Of the above thirteen genera we further notice that the species of no less than five of themErebia, Coenonympha, Lemonias, Cupido, and Parnassius, including a dozen of the species - are altogether confined to the western half of the continent, and show a distinct geographical relation to Alaska. While on the other hand, not one of the genera is confined to the eastern half; and besides this not any genus of American butterflies not found in Europe, with the sole exception of Phyciodes and Basilarchia (by a single species in each case), shows any special tendency to extend its domain toward Alaska. The avenue of migration is thus clearly marked.

It would seem, therefore, very clear that the identity or intimate resemblance which occurs in certain species between the butterflies of Europe and America is due altogether to their boreal character ; that their occurrence on the two continents, looked at from a broad point of view, must be regarded as the consequence of a continuity or close proximity of land during later tertiary times, when a warm climate prevailed in the high north; and 
that the distinction between them, and even the representation of the same genus on the two continents by clearly different species, is due to the subsequentseparation of the two regions in glacial and post-glacial times, and the variations which isolation, a difference of climatic conditions, and their general environment have brought about in the lapse of time. 


\section{XXIV.}

ANTIGENY; OR SEXUAL DIVERSITY IN BUTTERFLIES

IF male and female butterflies of the same species always resembled each other more than either resembled the same sex of an allied species, the work of the systematist would be easy, and we may perhaps add, - stupid. No such simplicity, no such stupidity, is in store for him. Nature is constantly perplexing him, piquing his curiosity, testing the sharpness of his wit, and leading him on from one comparison or one conclusion to another, till he finds himself confronted with questions of deepest interest and wide purport. It matters little what branch of zoölogy a student may follow; modern science, with its new questions born of evolution, will not leave the mind to stagnate.

By secondary sexual diversity, or antigeny, as it may be more briefly termed, is meant all such accessory peculiarities of one sex or the other as are not directly connected with generation. They are 
multiform and multitudinous. The lines of erect hairs on the upper surface of the wings of some Satyrinae and Argymnini, the gland-like spot at the base of the wings or the powdery band at the margin in some Rhodocerini, the little oval disk near the middle of the front edge of the upper surface of the fore wings of most Theclini, the pocket beside the first median nervule of the hind wings of Anosia, the umschlag or fold of the front edge of the fore wings in many Hesperini, and the velvety dash in the middle of the fore wings of nearly all the Pamphilini, always confined to the males, these are all accessory sexual peculiarities found on the wings alone, and are quite on a par with the characteristic plumage of the males in many birds. Or, if one seek something still closer, he may find it in the bristling front of the head of the Theclini.

So when we come to color, and, to a certain very limited extent, to its distribution in definite arrangement upon the surface of the wing, we find the same thing. Here we may pass from the simplest imaginable distinctions to those which are quite extraordinary. In the Painted Beauty (Vanessa huntera), for example, a slender, short, transverse stripe near the apex of the upper wings is white in 
one sex and orange in the other; nothing could be simpler than this, and the distinction is so slight it might be readily overlooked, yet it is the only difference one can find, and there is nothing analogous to it in the allied species, the Painted Lady (V. cardui). On the other hand, the two sexes of the Spring Beauty (Erora laeta) have so different an appearance that it is not strange that they were originally described by the same person as two distinct species; and the difference is still more marked in the Chrysophanini, where it may possibly be said to affect also the pattern of coloration. In one species, the Purple Disk (Epidemia epixanthe), the female, besides lacking on its upper surface the brilliant and peculiar lustre of the opposite sex, is also marked by the presence of a row of blackish spots, which is quite wanting in the male. In another, the Bronze Copper (Chrysophanus thoe), the male has the upper surface of a deep coppery hue, with a narrow black border; while the female has a deep orange color with a broad black margin and a transverse row of distinct black spots near the middle of the outer half of the wing, which appear in the male only through the diaphanous nature of the wings, the same row occurring in both sexes upon the under surface. 
This strikes us as the more remarkable since, in the two New England genera which are most closely allied to it, and with one of which it is usually directly associated, no such sexual distinction is found. A somewhat similar example occurs in the Black Swallow-tail (Papilio polyxenes), the male of which presents upon the upper and under surfaces of all the wings, a little distance beyond the middle, a transverse series of yellowish or orange spots, which are equally distinct on the under surface of the female, but partially or sometimes wholly obsolete above. In the Whirlabout (Thymelicus brettus) we have even a more conspicuous example. The female is very dark brown, almost black, with two little yellow spots in the middle of the front wings; while the male differs totally, being tawny, with indented brown borders and an oblique black dash in the middle of the front wings; at first glance no one could suppose them identical. In Semnopsyche diana the male is a rich dark brown, with a very broad fulvous margin upon all the wings, marked on the front wings by one or two rows of black spots. The female, on the other hand, is a rich purple black, with no trace of fulvous, but with the space where it belongs occupied on the fore wings by three rows 
of white spots and dashes, and on the hind wings by two belts of blue, broken into spots, one of the belts narrow, the other exceedingly broad. ${ }^{1}$

It is not a little remarkable that in all these examples, and indeed in very nearly all that have come under my notice, this sexual diversity is displayed only upon the upper surface of the wings, and almost invariably upon the fore wings, ${ }^{2}$ a mark of ancestry and of the lower position of moths, in which the hind wings are covered by the front wings in repose, and are as a rule less ornamented by diverse patterns. We might perhaps anticipate the restriction of the characteristics to the fore wings, since upon the upper surface the complication of colorational design in butterflies is greater on these than on the hind wings; yet this same reasoning makes their restriction to the upper surface the more striking, since the under surface of the hind wings of butterflies is usually more variegated than any other part.

1 Here, however, as is shown elsewhere, the difference is really due to another disturbing element, mimicry.

2 De Nicéville states that in Ergolis, a genus of oriental Nymphalidae, the males have a large patch of glistening scales on the under surface of the fore wings (Butt. India, ii. 8 ) ; and what under the circumstances is curious, these butterflies always settle with expanded wings. 
Now in all these cases of colorational antigeny, it is the female and almost never the male which first departs from the normal type of coloring of the group to which the species belongs. Occasionally the feminine peculiarity has been transmitted to the male, and, by this means, a new type of coloration established in the group; I recall among our butterflies but one ${ }^{1}$ case where the male alone departs from the general type of coloring peculiar to the group. This is precisely the opposite conclusion to that which Darwin reached. He gives several examples on the authority of Bates, which certainly favor his conclusion, but may, at the same time, be explained from the opposite point of view. He gives other examples from the European blue butterflies, which not only do not support, but even oppose, his general statement.

Take the case of Semn. diana, than which we could hardly find a stronger, since the group (Argynnini) to which it belongs is remarkably uniform, exhibiting in all its numerous members the same characteristic play of fulvous and black markings. The male of $\mathrm{S}$. diana is indeed very

1 The Spring Azure (Cyaniris psendargiolus), in which both sexes are ordinarily blue upon the upper surface, but in the south the male is sometimes brown. 
unlike most other fritillaries, but it retains, nevertheless, abundant traces of the same style of ornamentation, and has precisely the same colors; while the female departs widely from the characteristic features of ornamentation in the group, and in addition loses every trace of fulvous, so that no one at first glance would recognize it as a member of the Argynnimi. Or, if it be objected that a case of variation through mimicry should not be used here, take the Clouded Sulphur (Eurymus philodice), and its allies. In some Eurymi, indeed, there are only pale females; but in others all, or most of the females, are yellow or orange, like the males; and any one who knows how yellow and orange tints prevail throughout the group of Rhodocerini will acknowledge that the color of the males is normal. So, too, with the blues (Lycaenini), which Darwin himself quotes; in almost all of them, both males and females are of some shade of blue; in comparatively few, the males are blue and the females brown; in exceedingly few, both sexes are brown; and the very fact that they are familiarly known as "blues" is a popular recognition of the prevailing color. In the group of skippers to which Thymelicus brettus belongs (Pamphilini), the 
prevailing colors, at least in the temperate zones, are certainly tawny and black or brown; the latter, marginal. This is the case with the male of the Whirlabout (T. brettus), while the female diverges from the type in becoming wholly brown. In the Tiger Swallow-tail (Jasoniades glaucus), where we sometimes have a black female, it is more difficult to decide what should be considered the normal color, owing to diversity of view upon the relationship of many of the swallow-tails; but to judge only from those agreed by all to be most nearly allied to it, there can be no question whatever that the striped character prevails.

It will also be noticed, in this last case and others given, that wherever partial antigeny $\mathrm{or}^{\circ}$ dimorphism is confined to one sex, it is nearly always to the female; Cyaniris seems to furnish our only exception to this rule. In these instances, on my hypothesis, half of the females depart from the type; on Darwin's, half of the females, and all of the males. But if, on Darwin's theory, sometimes one half and sometimes three quarters of a species has diverged from the type, why does it so rarely happen that only one fourth of the species diverges?

The instances given by Darwin, which strongly 
sustain his view, are drawn from specimens of the South American gemus Epicalia, found in the rich cabinet of $\mathrm{Mr}$. Bates. The facts, as stated by him, are these: There are twelve species of the genus discussed by him; of these, nine have gaudy males and plain females; one has plain male and plain female; and two have gaudy males and gaudy females. The plain females, he adds, "resemble each other in their general type of coloration, and likewise resemble both sexes in several allied genera, found in various parts of the world." To examine this case fairly would need a large collection of exotic butterflies. If we confine ourselves to Epicalia, we evidently cannot say whether the gaudy or the plain coloring be normal; there would be less variation from the standard on the supposition that the gaudy were the normal type, and in this case it is the female which has departed from the type; but the difference is not enough to form an objection. It is only when we look at the allies of Epicalia that judgment seems to lean toward Darwin's side; but, from the unfortunate want of material, I cannot fairly discuss this point.

Take, however, another case, which appears to be equally complicated, - our native coppers 
(Chrysophanini.) We have one species in which both sexes are fiery red marked with black; another where both are fulvous marked with black; others where both sexes are brown; and several where the male is brown, marked with fulvous, and the female fulvous, marked with brown; others where the male is wholly brown, and the female fulvous, spotted with brown; and again others with fiery male and brown female. We have nearly every possible variation, but the prevalent feature is a dark male, often with more or less metallic reflections, which sometimes increase so as to give the insect a fiery copper hue; and a fulvous, spotted, and margined female. I do not see how we can possibly discover, with any certainty, from within the limits of the group of coppers, what should be considered the normal type. Nor are we much better off in an examination outside the group; there the prevailing tint is either brown or blue; and I am inclined to think that brown, tending strongly to copper, should be considered the normal type; in which case the males are normal, and the species generally antigenic. 


\section{XXV.}

\section{LETHARGY IN CATERPILLARS}

OnE of the most inexplicable phenomena in the life-history of butterflies is the fact that during the only period of activity in the preparatory stages, a period when all the energies seem to be concentrated on eating and growing, there should occasionally intervene a lethargic period when all activities are suspended, the creature partakes of no nourishment, moves at most only by its own length to secure a position more to its liking, as a drowsy sleeper turns in bed, and that this period should last for weeks or even months.

There are lethargic periods in the life of every caterpillar, when it has gorged itself to the full and rests quietly to digest its meal; but these last at most but a few hours. For those that feed exclusively by day, or by night, as the case may be, there is also that slightly longer diurnal period when they enjoy a period of quiet shared with a great body of their fellow creatures, including our- 
selves. There is further that much longer period of inactivity which comes to those that must pass the winter in the caterpillar stage, a period we call hibernation, and which is immediately related to low temperature and absence of food.

The period of inactivity termed lethargy is directly connected with this last, although neither of the provocative causes are present. It is a period of greater or less duration, lasting from a few days to a few months, generally as much as two or three weeks, often in the very heat of midsummer, when the food-plant of the caterpillar is superabundant and low temperatures are at farthest remove. In some instances it extends from midsummer to winter and so may be called premature hibernation. In nearly, if not quite, all cases it affects only a portion of any given brood of caterpillars, the remainder of the brood continuing on in the regular course. Even the portion which is concerned in it may be mequally affected, some arousing from the torpor at the end of a few weeks and proceeding regularly thereafter with their transformations, others continuing torpid to and through the winter. This shows its direct relation to hibernation. The same phenomenon occurs in the chrysalis state, where sometimes 
early in the season a portion of a brood will disclose the butterfly, while another portion will retain the inmates until the succeeding spring. But its occurrence in the active larval stage is far more unexpected.

This lethargy in caterpillars was first observed by a French naturalist named Vaudoner more than sixty years ago, but his statements lay a long while nearly unnoticed. According to this observer (a full account of whose observations is given in my New England Butterflies), one of the European species of Brenthis upon which he experimented flies in May and again in July and August. The caterpillars from the second summer brood are half grown when winter comes, hibernate in this stage, and in time produce the spring brood; the caterpillars of the spring brood, when they have reached the hibernating age, late in June, act in a precisely similar manner, and some of them do not arouse until the succeeding spring, when, with the caterpillars of the summer brood, they produce a new spring brood; but other caterpillars of the spring brood, which became lethargic, awaken from their torpidity after a time, resume eating, undergo their transformations, and emerge as butterflies in July and August. 
This same feature occurs in some of our own species of Brenthis as I have several times observed. It is also found in some of the Melitaeini, and I suspect also in the genus Argynnis, from the fact that there are in some places two apparent broods of the butterfly, months apart, but only one period of egg-laying. Since in these cases the winter is passed in the larval condition, the caterpillar just from the egg, it would appear probable that lethargy makes its appearance in the spring and early summer among the growing caterpillars, or else, what seems less likely, the period passed in chrysalis is very mequal.

It is possible that to this list should be added those Theclini and Chrysophanini which ostensibly pass the winter in the egg state. If, as is probable, these eggs mature during the hot season in which they are laid, and not in the succeeding, cooler, early spring when the caterpillar escapes, then the only difference between these caterpillars and those of the Argynnini is that one passes the winter within, the other without the egg-shell; and their refusal to escape in the warm weather points to premature hibernation, begimning in a kind of lethargy.

The cause of this strange feature in butterfly 
life must be attributed, like all other points in their history, to the struggle for the perpetuity of the species. Should disaster befall the advance guard who have not halted by the way, the sluggards can take up the work; the chances of sur. vival are, not doubled perhaps, but greatly increased. Nature seizes upon some phenomenon in the life of each species and turns it to its advantage; thus in the European Brenthis, it seizes on the caterpillar's habit of hibernation when half grown, and forces the spring brood of caterpillars at that point in their growth to premature hibernation, in which some continue throughout the hot weather and until the following spring. Do not all these strange phenomena, invariably looking toward the surer survival of the species, point to something superior to the mere forces of evolution, controlling and directing them? Surely, if hibernation be the pure result of physical causation - and nothing seems simpler than that where are the physical causes that first produced premature hibernation in midsummer? If it be said that this is subsequently induced through inheritance by the habit of the alternating brood, we may ask: Why does not this occur in Basilarchia, which winters in the same stage, and 
in whose eaterpillars of the spring brood no such premature hibernation or sign of lethargy occurs? No, the deeper we look into these phenomena, the surer seem to be the signs that the forces provoking the changes and characteristics observed are doing their work in no blind fashion, but rather under the impulse of some controlling and thoughtful power. 


\section{XXVI.}

A BUDGET OF CURIOUS FACTS ABOUT CHRYSALIDS

Examre any butterfly chrysalis you please, and you will find on either side of the head, close to the base of the antennae and partially overlapped by them, a smooth crescent-shaped belt, which generally contrasts rather strongly with the roughened surfaces about it. It corresponds closely in position with the curving row of simple ocelli found on the head of the caterpillar, where it is generally marked by a distinct impression; it also lies across the middle of the convexity which marks the position of the compound eye of the inclosed butterfly; the convex case of the rest of the eye is rough and coarse like the chrysalis skin generally, but this curved ribbon is smooth and thin, and regularly embossed, each gentle elevation apparently corresponding to the centre of a facet of a compound eye. Now it has been suggested that this belt is a window through which the prisoner may look abroad; what end this would serve is not ex- 
plained ; nor have the structure, form, and position of the belt been taken into consideration. No underlying structure, as far as I am aware, has been found related to it alone; and as an external covering of an eye its structure is midway between that of the caterpillar and the perfect insect. May it be a relic of the past, the external sign of what once was? Are we to look upon this as one hint that the archaic butterfly in its transformations passed through an active pupal state, like the lowest insects of to-day, when its limbs were unsheathed, its appetite unabated, and its daily necessities required the use of a compound eye, such as would result from the multiplication and conglomeration of simple eyes within the normal ocellar field of the larva? This, it is true, is merely speculation; but whatever explanation of the structure of this glassy band is given must account for its form and its relation to the larval row of tubercles.

There is another peculiarity in the head of certain chrysalids which demands our atrention and an explanation of its cause, since it is found in some groups and not in others. On either side of the front of the head there is often a roughened angulate or conical projection, bearing no relation 
whatever to the parts beneath, but looking like a pair of clumsy horns or ears projecting forward; other chrysalids have the front extremity prolonged in the middle, while the sirles of the head are quite smooth and regular; others again have the same smooth and bluntly rounded head which generally characterizes the pupa of moths. Since these projections are mere extensions of the pellicle and quite hollow, it might be presumed that they indicated some variation in the life of the chrysalis; and such, at least generally, is indeed the fact. Many ehrysalids are protected by some sort of a cocoon, and these have perfectly smooth and rounded heads; so, too, have those which, though exposed, are girt immovably to the object they have chosen as their support. Other chrysalids are attached by the tail and loosely bound about the middle by a girth which allows the borly to sway from side to side; while still others hang freely by their hinder extremity. In these two latter cases the chrysalids may be blown hither and thither by every breeze and are liable to injury from neighboring objects; as in all cases the tail is fastened, their point of greatest motion is of course the head, and this, therefore, is guarded by projecting roughmesses. In those 
which hang freely there are some exceptions to this rule, as is the case especially with the Satyrids, but even here some angulations or little conical tubercles may be discovered; and, besides, the chrysalis stage of such species is invariably passed in midsummer, and therefore is very brief. So far as I am aware, every chrysalis which lives through the winter, and whose body hangs at the mercy of the wind, has its head protected as I have described; those which hang freely have always the two frontal projections; those which are also loosely girt about the middle sometimes have the same, or they may have the single extension in front. It is, indeed, only by exception that any of our pendant chrysalids pass the winter at all. So good an observer as Rambur, whose observations were made in Spain long ago, remarked : "Je ne connais, du reste, aucune espèce dont la chrysalide soit suspendue, qui passe l'hiver en cet état.'

It may also be noticed that chrysalids with extraordinary projections or ridges in other parts of the body all belong to the same free-moving groups; the greater the danger to the chrysalis from surrounding objects, the greater its protection by horny tubercles and roughened callous ridges; the greater the protection possessed in other ways, 
as by firm swathing or a safe retreat, the smoother the surface of the borly and the more regular and rounded its contours. We have thus a complete explanation of all the angularities in the surface of the body, with the sole exception of certain horn-like protuberances on the front of the head in some Pamphilini, which may possibly be of use in keeping the body from too great movement in the cocoon-like inclosure in which the chrysalis is protected.

There is a further peculiarity in our chrysalids which strikes one as orld when first noted, though it is not confined to them alone. In certain instances the chrysalids of neighboring groups very nearly resemble cach other, while the caterpillars from which they came differ strikingly; and the reverse is equally true. No better instances can be given than in our genera of swallow-tails. The chrysalids of Jasoniades and Papilio, for instance, are very much alike, and would often be mistaken for each other did the size agree; while the caterpillars from which they come differ in the most striking manner, not only in color and markings - a difference of special importance in naked caterpillars — but also in form. To reverse the picture, the caterpillars of Jasoniades and Euphoe- 
ades are of precisely the same form and color, on a first view, differing only in some minor points of markings, while their chrysalids seem made on quite a different plan.

One finds the same thing true in certain groups, if the other stages of life are also examined. $\mathrm{It}$ only serves to show that selection has seized upon every available point of structure at each stage of life, and quite independently; so that it is only by the summation of characteristics of all the stages that we may arrive at a true conception of their actual relationships. In some groups selection has apparently found nothing in one stage to seize upon to answer its ends, and all the members of that group show then a dull uniformity which would seem to indieate no great antiquity, or in other words a very intimate relationship between its different members; when, if another stage be studied, we find at once where selection has been employing her forces, and can only regard the differences here as marks of an immense lapse of time since the common ancestor of all flourished upon the earth.

But to leave these general considerations and to return to our chrysalids. We have pointed out some common features of interest about their struc- 
ture. Can we find anything worthy of remark in the life of such apparently lifeless things? Certainly ; we may fairly call a chrysalis a most fickle object, a most uncertain creature. Has it not been mentioned over and over again in recent works on butterflies that while one brood may follow another with tolerable regularity, broods are apt to be uneven in their numbers, because some chrysalids fail to disclose their inmates at the expected time but wait a little or a longer time? That there should be some little variation due perhaps to conditions of temperature might be expected; but that the continence of the chrysalis should be precisely enough to have it just skip a brood is certainly reason for wonder, for here meteoric conditions can often have clearly nothing to do with it. Some instances, indeed, are on record where, when normally a single winter would mark the duration of a chrysalis, it has lasted two winters ind, of course, the intervening summer. All these variations seem to be provisions of nature to guard against destruction of the species under adverse circumstances. Nature seems always on her guard.

$\mathrm{O}_{1}$ take a kindred fact. It is well known to the aurelian that the males of a given brood almost 
invariably make their appearance before the females, sometimes only a lay or two, sometimes as many weeks. It seems only another instance, so many of which are known in both animal and vegetable kingdoms, of a device to secure fertilization. Now, Mr. Edwards, with his umivaled experience in breeding butterflies, tells us, what all of us have seen on a smaller scale, that when bred in confinement, not exposed to all the vicissitudes of the weather, the females appear quite as early as the males. What subtle influence then is it which earlier awakes the male under wholly natural conditions?

We owe to Wilhelm Müller (a brother of Fritz Miiller, who has made so many neat observations in the natural history of tropical animals) a curious fact in the lives of the free hanging chrysalids of tropical Nymphaliclae. Every naturalist knows how rarely these chrysalids are discovered in free nature; most of our knowledge of them eomes from those raised in confinement; for the caterpillar nearly always seeks an obscure place in which to change, or else imitates in its color and perchance in its form, surrounding objects. Now Miiller has discovered that many of them are directly sensitive to light and will respond, slowly 
indeed but effectually, to its presence. To experiment upon them he devised an arrangement by which the light - not the direct rays of the sun, but merely its light - could be thrown upon them from one direction or another without tonching them, and he found them capable of changing their position, some of them from side to side, some from a pendant to a horizontal position, through an angle, varying in the species, of from $45^{\circ}$ to $70^{\circ}$ or even $90^{\circ}$, in order to present as little surface to the light as possible, to get, as it were, in the shade; some responded to changes as frequent as a dozen in six hours. The experiments were made with a number of species; one of them was an Ageronia, which, pendant when in the dark, in the light hugged the horizontal surface from which it hung so as to assume the attitude of a girt Papilionid, whence arose, Miiller believes, the error of Lacordaire and others, who asserted Ageronia had a girt chrysalis. As not a few of the chrysalids most frequently experimented on died or produced crippled butterflies, Mïller believes that too much light is injurious to them, and reasoned that this movement was therefore one of protection. But he found one very strange exception to the rest in a species of Catonephele, which responded to his 


\section{ABOUT CHRYSALIDS 241}

experiments in an exactly opposite manner, bending to receive on its side the fullest amount of light and reversing its position when the light was transferred to the opposite quarter. Surely we have much yet to learn from apparently lifeless chrysalids. 


\section{XXVII.}

\section{DIGONEUTISM IN BUTTERFLIES}

In all plural brooded butterflies with an extensive distribution in latitude, the number of generations varies with the length of the season, and this will account for the apparent waste we often see as winter approaches, for such changes must be gradual, and in intermediate districts irregular, dependent upon the season. Where, as is sometimes the ease, some chrysalids of each brood live until the following spring, it manifestly makes little difference how short the season may be, or how suddenly and effectually any brood may be cut off ; these chrysalids, and so the species, will survive. That this feature is more common than is generally supposed is shown by the increasing number of proofs brought forward of lethargic tendencies in caterpillars and of persistent torpor in many midsummer chrysalids. It is also indicated by the variation in the numerical proportions of different broods; the winter is the severest season, and con- 
sequently the spring broods are ordimarily, and under simple conditions would always be, less numerons than the summer or autumn broods; generally the broods go on increasing in individuals as the season advances; but in some it is not so, and it may be presumed that these are species which have not long enjoyed the privilege of a second brood, or, in other words, those in which a part of the chrysalids fail to persist until the following spring. In the case of our Tiger Swallowtail, which is found from Alaska to Florida, we have a butterfly which is single brooded in the north and double brooded in New England; but the second brood is much less abundant than the first, and the change as we go north is probably effected by the lingering development of some caterpillars and the disposition of chrysalids to winter early. Wherever in a double brooded butterfly the second brood is less abundant than the first, it is probable that the butterfly is partly single and partly double brooded - that is, that the early broor of a given year is made up of the direct descendants of each brood of the preceding year.

Occasionally, the difference in the number of broods affects the mode of hibernation. The Black 
Swallow-tail, for instance, is triple brooded in the south, and hibernates as a butterfly and perhaps also as a chrysalis; in the north it is double brooded, and hibernates only as a chrysalis.

Digoneutism or polygoneutism, then, is either a device of nature for the better perpetuation of the species, by varying the conditions of its existence at any given time, and so multiplying the chances of successfully meeting opposing or unfavorable agencies; or it is simply taken advantage of by nature as a means thus to vary the conditions. The particular problem difficult of solution which it carries in its train is this: In some speciesand it would appear to be no very uncommon occurrence, and to be found among moths as well as butterflies - the result of summer dormancy in the caterpillar or prolonged life in the chrysalis is that, by some unexplained common impulse, the caterpillars or the chrysalids that arouse after lethargy, and do not hibernate, more frequently than otherwise do this at such a time that the resulting butterfly flies with its nephews and nieces instead of with its brethren and sisters, i. e., it bridges over with considerable accuracy the interval between two generations in midsummer, just as happens from easily perceived causes when winter 
intervenes. Who solves this problem will win deserved renown.

What may be the exact climatic features which determine the number of generations of a butterfly has not yet been studied; but there are some curious difficulties in the way of understanding them. The Painted Lady (Vanessa cardui), for instance, is double brooded in New England, both in the districts where the contrasts of heat and cold, moisture and drought, are excessive, - that is, where the climate has those peculiarities which are termed "continental;" and also on islands such as Nantucket in southern New England, where a much greater evenness prevails and the climate partakes of an "insular" character" yet in the valleys of Switzerland, where perhaps of all places in Europe the climate presents the greatest and most sudden inequalities, and therefore is most similar to that of New England, and certainly more "continental" than that of Nantucket, this butterfly is single brooded. We have exceedingly few identical butterflies in Europe and the United States, and this apparently is the only one of them that differs in its broods in the two countries; but there are several of our butterflies which are represented by rery closely allied species in Europe, 
and in half a dozen or more of these we find quite similar disparities, all of which are in the same direction.

The European Tortoise-shell (Aglais urticae), for example, is generally double brooded; occasionally a triple brood is mentioned; it is one of the commonest of European butterflies, and reaches from the North Cape to the Mediterranean; our congeneric species, the American Tortoise-shell (Aglais milberti), is rarely found south of the northernmost parts of the United States, and yet it is triple brooded in all parts of Canada. Even the Dappled Fritillary (Brenthis montinus) of the White Mountains is probably double brooded, while all the mountain species of Europe are single brooded. Everes amyntas, again, occurs throughout Europe, with the exception of certain northern and northwestern portions, and is double brooded; our Tailed Blue (Everes comyntes), named for the resemblance to its European congener, and by some careless authors considered irlentical with it, is also a widespread insect; but even in New England, which is at the northern limit of its eastern range, it is triple brooded. The widespread European Bhes, Rusticus argus and R. aegon, the Silver-studded Blue, are usually 
placed among monogoneutic insects, and the latter certainly has only a single brood in England (where it is the only one of the two found); Meyer Diir is in fact almost the only author who claims these species as digoneutic; both of them occur in southern Europe; our Pearl-studded Violet (Rusticus scudderii), closely allied to these and an insect hardly known south of the Canadian border, is double brooded. Our Chequered White (Pontia protodice) is triple brooded, and the European Bath White (P. daplidice) only double brooded, while our common Clouded and Orange Sulphurs (Eurymus philodice and E. eurytheme) are triple brooded in the north, perhaps polygonentic farther south, and the closely allied European species only single or double brooded.

But the most striking example of all will be found in the species of the gemus Iphiclides. The European I. podalirius is confined to the Mediterranean region, while our Zebra Swallow-tail (I. ajax) belongs to the southern half of the United States; the regions are therefore fairly comparable; yet we find no mention of more than two broods of I. podalirius, while Mr. Edwards believes that, even as far north as the Appalachian valleys of West Virginia, I. ajax has four and sometimes five generations during the year. 
These cases might perhaps be multiplied, and it should be added that there is no reversal of the rule: among all the butterflies properly comparable on the two continents, there is no single instance where the European butterfly has more broods than the American.

This result of the comparison of the annual histories of similar European and American butterflies thus furnishes but another instance of that intensity which seems to characterize all life in America. The expenditure of nervous and vital energy, against which physicians vainly inveigh, which superannuates our merchants, lawyers, clergymen, and other professional men, is not induced by the simple passion for gain, place, power, or knowledge, but by an uncontrollable restlessness, a constant dissatisfaction with present attaimments, which marks us as a hurrying, energetic, enterprising people. My own experience has been that studies of precisely the same nature and undertaken under similar external conditions are accompanied by a very different mental state on the two continents. In Europe we are content to plod industriously on, unconscious of the need of relaxation; in America we bend with nervons intensity to our work, and carry the same excitement into the 

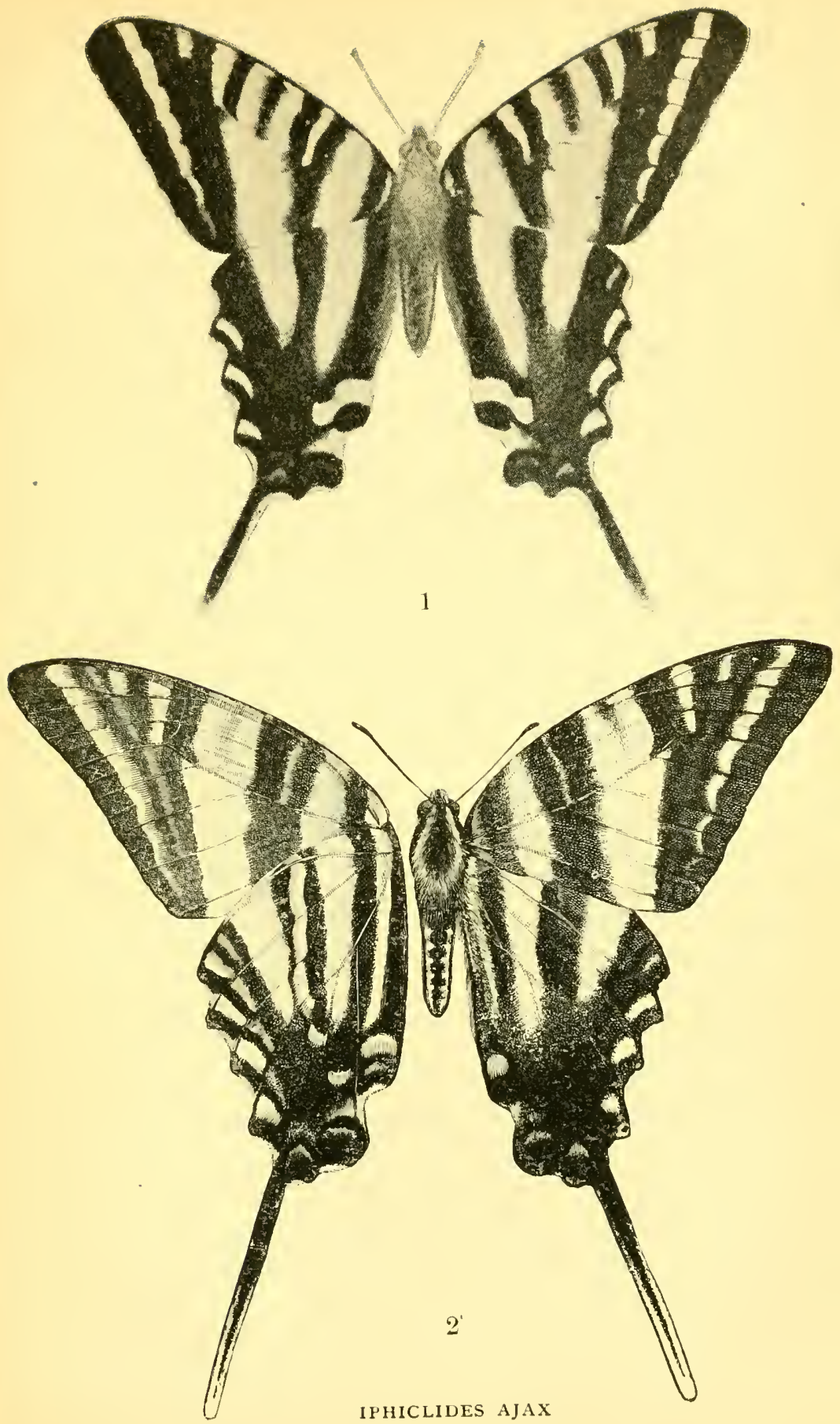

relaxation which such a life inevitably demands. After a long absence in Europe, a keen observer may even be directly conscious of this quickened life.

Now to what shall we ascribe such peculiarities in animal life? Naturally we look to climatic influences, and our attention is first attracted by the well-known fact that if we compare two places in Europe and America having the same mean annual temperature, the extremes of variation will prove much greater on this side of the Atlantic. For example, while the mean anmual temperature of New York is about the same as that of Frankfort, the summer temperature of the former is that of Rome and its winter that of St. Petersburg. Moreover, the changes from summer to winter and from winter to summer are more immediate in America; or, in other words, the summers and winters are longer by about three weeks. Such long and hot summers are of course favorable to the multiplication of broods in butterflies whose history allows a repetition of the same cycle more than once a year; the length of the winter is of slight consequence, as long as the insects can survive it; and it can have no influence upon the number of broods, unless there be species (of which 
we know nothing) able to resist a cold winter only in certain stages of existence, and a multiplication of whose broods might require some pliability in this respect. Not only, too, are our summers longer and hotter, but they enjoy a marked preponderance of sumshine, as compared with European summers; and this alone would almost seem capable of producing the variation we have noticed in the number of broods.

In an extremely interesting article on the effect of our climate on manners and customs, written by the Swiss naturalist Desor, who resided several years in the United States, this writer attributes everything to the far greater dryness of the climate, when comparing eastern America and Europe. This produces, according to him, a nervous irritability, the recognition of which has compelled a measure of self-restraint, and the exercise of this has gone far to make the development of our political institutions possible! What a future is before the coming inhabitants of our arid plains !

Differences will be foind in all other climatic phenomena of the two continents. "From Europe as a standard," says Blodgett, "the American climate is singularly extreme both in temperature, humidity, quantity of rain, wind, and cloudiness or 
sensible humidity. The oscillations of the conditions are greater, and they vibrate through long measures above and below the average. All the irregular as well as regular changes are of this sort, and the European observer defines the climate as directly antagonistic to that he has left." These differences, however, as Humboldt and others long ago pointed out, have a broader bearing than the above statements would imply; for they are characteristic of the eastern shores of both worlds as opposed to the western, the meteorological phenomena of the eastern United States being almost precisely paralleled by those of northern China, where great excesses of temperature occur, with wide variability, long summers and winters, and rapid transitions.

Perhaps on these grounds we can most simply accomnt for the difference in the number of broods in certain butterflies on the two continents; but, if so, then it follows that we ought to anticipate similar differences between the broods of some of the species found both in Europe and in eastern Asia ; a point about which we can assert absolutely nothing, for want of data. These grounds, however, will certainly be insufficient to account for the differences to which we have alluded in man; 
for what contrast could well be greater than that existing between the national character of the Chinese and that of the Americans! We are rather forced to believe that the causes of the distinction between the European and the American, if these are due to physical agencies, must chiefly be sought elsewhere. 


\section{XXVIII.}

PERIODICITY IN THE APPEARANCE OF BUTTERFLIES

Every year we read in the pages of our entomological journals something about the rarity or abundance of this or that insect. Particularly is this the case with those insects which are agricultural scourges, since here the observation of their comparative abundance or scarcity is quickened. It is none the less true, however, of other insects, and among them of butterflies. Indeed, there are comparatively few butterflies which appear in similar numbers every year. There is always more or less fluctuation in this regard, but we notice it only when their excessive abundance, especially with such swarming butterflies as the Monarch (Anosia plexippus) and the Painter Larly (Vanessa car(lui), or their great rarity causes general comment, at least among entomologists. Sometimes we can directly tell the cause of a scarcity, rarely that of a superabundance; for in the for- 
mer case, the scarcity may involve several species, and the plain cause some excessive or exceptional meteorological condition.

Now though the massive meteorological conditions which we term climate have undoubtedly very much to do with the distribution of butterflies and determine, indeed, in very many cases, whether or not a given kind shall or shall not live in a certain place, the indirect results of meteorological conditions have undoubtedly more to do with the abundance or scarcity of a given butterfly in a given season. For the very existence of the butterfly shows its capability of withstanding the excesses of meteorological conditions in the spot in which it lives, and the greatest stresses under which it lives are those more active forces, like insectivorous creatures and parasites, which find their own life dependent on taking its life, or its neighbor"s. The activity of these is governed largely by temperature and storm conditions, and hence the indirect influence of meteorological conditions on the life of the butterfly may be more important than the direct. A caterpillar which could withstand any amount of cold or of warmth in itself considered might not be able to battle against the foes which a mild winter kept in unusual activity and need of sustenance. It does 


\section{APPEARANCE OF BUTTERFLIES 255}

not appear that ou butterflies suffer particularly from an exceptionally cold or long winter, but rather from unusual warmth, sufficient to arouse insects from torpor at times when hibernation should be expected; or, in the fair season, directly from long continued storms and moisture.

The fluctuation therefore in the numbers of our butterflies is probably due in large measure to the activity or inactivity, the abundance or rarity, of their active enemies, and especially, considering how extensive their depredations, to the abundance or otherwise of their parasites. It is the striking of the balance which exists between a creature and its enemies in the struggle of each for its own existence. Let some event, untoward to it, decrease the ratio of the parasite, - the butterfly flourishes; but its very consequent superabundance the following year only gives a better pasturing ground to the parasite, reduces the butterfly below the normal, and causes the parasite to abound inordinately, only to find its food supply eut off by its own voracity and ineontinence and the scales again to be turned. It is then this perpetual warfare, this unending, inexorable struggle for existence, testing the fitness to survive, which is the prime eause of periodicity in the abundance of a given species. 


\section{XXIX.}

COLOR PREFERENCES OF BUTTERFLIES, AND THE ORIGIN OF THEIR COLOR

DARwis has maintained, as every one knows, that the beanty of flowers depends very largely, perhaps entirely, upon insects, the purpose of the gayly colored corolla being to attract the insect to the spot necessary for it to reach to effect fertilization in the plant. The broad fact that flowers fertilized by the wind are never gayly colored, while there are others habitually producing two kinds of flowers, one open, colored, and provided with nectar to attract insects, the other closed, uncolored, destitute of nectar, and never visited by insects, seems to render this very clear. But we still need to know how color originated in the equally or more gayly colored butterflies which visit flowers, which the poets have been wont to compare to flowers afloat. The prevailing opinion has been that this was due in the first instance, as in the case of the birds, to sexual selection, 
that male being chosen which surpassed in beauty. This is the view held by Darwin; but recent discoveries in physiology and histology make it tolerably elear that butterflies have themselves no power of clear vision. They may see masses of color, but not definite pattern or form, and as, apparently, the disposition far more even than the brilliancy of color goes to make up the beauty of butterflies, this can in no sense be looked mpon as a true cause.

That butterflies have some perception of color in mass is unquestionable. It has often been remarked that white butterflies alight by preference upon white flowers, yellow butterflies upon yellow flowers. Direct observations have shown that this vague opinion is founded clearly upon fact, and several instances which show this and at the same time show the lack of power of perception of form have been published. Thus Christy observed in Manitoba one of the swallow-tails "fluttering over the bushes, evidently in search of flowers. As I watched it," he says, "it settled, momentarily and exactly as if it had mistaken it for a yellow flower, on a twig of Betula glandulosa bearing withered leaves of a light yellow color." Aibert Müller records seeing the blue 
alexis of Europe fly toward a very small bit of pale blue paper lying upon the grass and stop within an inch or two of it as if to settle, doubtless mistaking it for another of its own kind. Plateau has observed the Small Tortoise-shell (Aglais urticae) of Europe fly rapiclly toward a cluster of artificial flowers, and a species of Pieris toward a white calla which could offer it no sweets. And Jenner Wier has noticed how the white butterflies settled on the variegated leaves in his garden.

Such examples as these seem to indicate that butterflies may perceive color in mass, but in no case indicate any further visual powers; and since the difference between the sexes is generally rather one of disposition of colors than of variety in the color's themselves, though the latter is by no means wanting, the theory of sexual selection proposed by Darwin cannot be rightly claimed to cover the general ground. Wallace, moreover, has adduced strong reasons for doubting the value of this theory, even in those animals against whose powers of sight no such stricture can be made, believing, as he does, that all differences between the sexes can be explained from the fact of the greater vigor of the male, and the intensity 
of that vigor in the breeding season. This theory, too, would at most hardly do more than explain the differences one now finds between the two seres, and could not take into account, except in a very secondary way, by transmission, that wonderful variety and brilliancy of color found throughout whole groups of butterflies and common to both sexes.

Wallace has pointed out that, in general, color is proportionate to integumentary development, that no insects have such widely expanded wings in proportion to their bodies as butterflies and moths, that in none do the wing's vary so much in size and form, and in none are they clothed with such a beautiful coating of scales. In support of the physical theory of the production of color, he maintains that numeron color changes must have developed in such long continued expansion of the membrane, - color changes which have been checked, fixed, ntilized, or intensified, according to the needs of the animal, by natural selection; and by this alone would he explain all the variety which we find in the whole tribe of butterflies. And this indeed seems to be the best explanation that can be offered, and one that is in better accordance with our knowledge of the distribution of 
color generally in the animal lingdom, with the heightened colors that we find in the tropics, with other features of the geographical distribution of colors, and with that biological distribution throughout great groups in the animal series. Some color's may therefore be looked upon as of great antiquity. The prevalence of yellow and orange in the Rhodocerini, of white in the Pierini, of white and green and orange in the Anthocharini, of coerulean blue in the Lycaeninae, of silver spots in the Argymnini, of browns in the Satyrinae, and of other colors in other groups, all indicate that these colors have in each instance held control dming all the changes which have followed the development of these types from a common ancestry.

A very large proportion of the colors and patterns upon the wings of butterflies, far larger, I believe, than is generally conceded, must be looked upon as protective and to have originated in the simplest possible manner through natural selection. Surely if the wonderful mimetic changes we have before recorded have been brought about through natmal selection, and that, too, in comparatively recent time, we must allow its power to accomplish very much in the modification and distribution of pattern. It seems in any event probable that we 
shall have to concede to the same laws of development which have moulded the structure and form of all organized beings, the power to develop that wonderful clisplay of color and pattern on the wings of butterflies which appeals so powerfully to the aesthetic sense of every human being.

Yet plainly natural selection, as such, cannot aceount for everything in color, any more than it can in structure. Infinite variety and multiplicity of patter'n may be due to its aetion; but what shall we say of infinite harmony? of a harmony which appeals to savage and to sage? There has yet to be brought forward one single line of evidence to show that natural selection or any other purely natural, law-constrained force can, uncontrolled, produce or even sustain that harmony of tint and design which each of the whole tribe of butterflies displays on its individual surface; a harmony so infinitely extended when comparisons are begun that the eternities would not suffice to exhaust them; a harmony pervading the utmost minutiae, which the unaided eye cannot pereeive; a harmony appealing at every point to the aesthetic sense of the highest creature we know, doubtless also to many a lower one whose physical and psychological acquirements permit it. The untrained child but rarely and ac- 
cidentally touches a chord upon the piano; so the undirected play of natural forces with color would oftenest be misdirected; and where is the selection that shall bring about the survival and perpetuation of the harmonious? Nay, that has done it: Every part of the animal frame, the entire economy of the animal kingdom, the aesthetics of the animal universe, past and present, point to an infinite and eternal directive force, guiding all forces ; to an infinite, uplifting power, which we may trust. 


\section{XXX.}

THE FRIENDS AND ASSOCIATES OF CATERPILLARS

ONE of the most surprising statements which have been made regarding the caterpillars of butterflies is that they are sometimes accompanied by ants, which seem to guard them with great jealousy, running about them with nervous activity, and rushing with open jaws at any creature that approaches. This phenomenon, first observed. more than a century ago, has been repeatedly witnessed by others, but owing to the fact that the caterpillars in question are very small, usually of the color of the leaf or flower upon which they may be feeding, slow in movement and of a flattened form, they are among the least known of our caterpillars and rarely are seen by the casual observer. For the only caterpillars which are thus accompanied are, as far as known, those which belong to the sub-family of the Lycaeninae, and indeed to the tribe of Lycaenini or Blues, minute butterflies whose caterpillars rarely attain a length of an inch. 
The cause of this friendship and association is not far to seek, for a slight observation of the action of the ants will show that they have a reason for their devotion to the caterpillars. They tend these as they tend plant lice, becanse each of them has the power of exuding, from special glands near the extremity of the body, a droplet of fluid having a saccharine character, and thus attractive to ants, whose fondness for sweet things is well known to every housekeeper. In the butterfly caterpillars, as may be found in any description of these forms, this gland is situated in the middle of the borly on the seventh abdominal segment, and now and then, at the solicitation of the ants, by the stroking of their antemnae, is evaginated and a droplet of fluid exposed, which the ants greedily lap np.

Now, although the only caterpillar's attended by ants belong to the blue butterflies, the gland which secretes the sugary fluid is not confined to the caterpillars of these butterflies, but is also found in many of their immediate allies, namely, in most of the Iair-streaks or Thechini, and in one at least of the Coppers, Tomares ballus of Europe. Two explanations readily offer themselves: one, that in caterpillars so little known as are these, it may 
well be true that the association of the ants with the caterpillars lias escaped notice; or, on the other hand, that in these instances the glands secrete a fluid which has no saccharine ingredients. The advantage that it may be to the caterpillar to secrete a sweet fluid attractive to ants is obvious, since the ants undoubtedly keep off many ichneumon flies and other enemies of the caterpillar, and the mutual benefit conferred by ant and caterpillar is unquestionable. It is doubtful if in the other cases the gland ever secretes a fluid having an offensive quality which might equally serve as a protection against intruders; since this means of defense is probably found, in caterpillars of this group, in organs of a very different character upon the snceeding abdominal segment, and it is hardly to be presmued that two organs, distinct in their position and structure, shouk arise in one and the same animal for precisely the same object. The use, therefore, of the median gland presumably not possessing a saccharine character is very problematical.

It should not be overlooked in connection with this subject that these caterpillars are themselves fond of saccharine matters. They, and only they, of all our butterfly caterpillars, attack flowers where 
honey is secreted, and we have at least one form which has come to have an entirely carnivorous diet, feeding upon plant lice bodily for their juices, very likely for the same reason that the ants seek their secreted fluids in detail. So, too, and possibly for the same reason, these creatures not unfrequently show a cannibalistic tendency, feeding upon the bodies of their own brethren when they are in a helpless condition, as previous to pupation. All these subjects are closely related to one another, and need to be investigated more carefully in order to a complete solution of their meaning.

It is a curious thing that among the Lycaenini these glands are found on some species while not found upon others closely allied; their occurrence in many members of the other two tribes of the Lycaeninae, together with the impossibility of their independent origination in different genera, render it probable that these glands first arose as long ago as before the differentiation of the three tribes of Lycaeninae. The brotherhood of the ants and the caterpillars may therefore be of great antiquity. 


\section{XXXI.}

BUTTERFLIES OF THE PAST

FossrL butterflies are the greatest of rarities. They oceur only in tertiary deposits, and out of the myriads of objects that have been exhumed from these beds in Europe and America less than twenty specimens have been found. The great body of these deposits is of course of marine origin, but at least thirty thousand specimens of insects have been recovered from those beds which are not marine. Over fifteen thousand insects from the one small ancient lake of Florissant, high up in the Colorado Parks, have passed through my hands, yet I have seen from there but eight butterflies. Each of these belongs to a genus dis. tinct from the other's, as is also the case with all, or all but one, of the butterflies found at Radoboj, at Aix, and at Rott in the European tertiaries. With two (European) exceptions, each represents an extinct genus, and these two exceptions, Eugonia and Pontia, are genera found to-day both in 
Europe and America. The species, however, are all extinct.

One would hardly anticipate that creatures so delicate as butterflies could be preserved in a recognizable state in deposits of hardened mud and clay. Yet not only is this the case, but they are generally preserved in such fair condition that the course of the nervures and the color-patterns of the wings can be determined, and even, in one case, the scales may be studied. As a rule they are so well preserved that we may feel nearly as conficlent concerning their affinities with those now living as if we had pinned specimens to examine; and generally speaking, the older they are the better they are preserved.

There is, to be sure, no great difference in their age. Aix and Florissant are probably both oligocene, and in any case can differ but slightly in age. One of the butterflies from Aix, Coliates, comes from beds a little lower than the others and may be looked upon as probably the oldest butterfly known. These two oligocene localities share between them a dozen butterflies, not to mention a caterpillar from Aix which has been considered that of a butterfly. Rott, the next oldest (lower miocene), has furnished but one butterfy; and Radoboj (middle miocene) the remaining three. 
Three of the four families of butterflies are represented in this meagre little collection, the smaller butterflies of the family. Lycaenidae being unknown in a fossil state in the rocks, though it is rather vaguely reported that they have been found in amber. The largest number (ten) are Nymphalidae, the next (four) Papilionidae, while the Hesperidae have only two representatives. All but one of the eight American species, however, belong to the Nymphalidae; that exception to the Papilionidae.

These meagre statisties may have a certain interest; but it is of more importance to inquire how far the fossils differ from existing forms, and what they teach us. For this purpose let us briefly examine the European and American forms separately, turning our attention first to the European species, but omitting the caterpillar from Aix, which is thought to be one of the Satyrinae, to which sub-family two of the five Aix specimens belong:

To begin at the top of the series, we have first these two Satyrids, Neorinopis and Lethites, a group now represented by the dark brown butterflies of our meadows and groves; the nearest allies of both of these are now restricted to the Indo- 
Malayan region, and are much more gayly attired than the present sombre representative of the subfamily in Europe. Their food in the larval state has invariably been found to be either grasses or, occasionally, with the more arctic or alpine forms. sedges. In the Aix deposits, as in the Indo-Malayan region to-day, these plants are numerically unimportant, so that if we may form any opinion from such meagre data, we find that while oligocene Aix had a European proportion of Satyrids, they were composed of species of an Indian aspect and fed upon plants characteristically temperate, but, as in tropical countries, numerically unimportant.

The remaining Nymphalid is the Eugonia from Radoboj. This is more nearly related than any other to the mass of the Florissant fossils. It belongs to an existing genus, represented to-day equally in Europe and North America, but with a fuller development of neighboring genera in the New World, showing that its affinities are rather with the New than with the Old World; its food in early life was probably some species of elm, willow, poplar, or birch, and species of all these genera have been found in the same beds.

Passing to the Papilionidae we find three Pierinae and one of the Papilioninae; two of the three 
Pierinae are allied to our common Brimstone-yellow butterflies, and the third to our White-spotted Cabbage butterflies. The former, however, Mylothrites and Coliates, belong to distinctly tropical types, referable again to the Indo-Malayan or Austro--Malayan regions; their larvae doubtless fed on leguminous plants, which have been found in abundance both at $\mathrm{A}$ ix and Radoboj, fiom which these species come. The white butterfly belongs to the existing genus Pontia, whose present geographical relations are almost precisely those of Eugonia mentioned above, though the genus itself is far better represented to-day in Europe than in America ; their larvae feed generally on Cruciferae, but these are plants of a nature hardly almitting of preservation in a fossil state and are excessively rare in the European tertiaries; none have been found at Radoboj, whence this butterfy comes, the most closely allied being a species of Terminalia.

The Papilionid is an interesting insect belonging to a striking and rather aberrant group. From. its affinities to the existing Thais, it is called Thaites. Thais is confined to-day to the Mediterranean district, within which Aix, its place of deposit, belongs. It probably fed on Aristolochia, and while this genus of plants has not yet been 
found at Aix, it is found in other Emropean tertiary deposits, and according to the late Marquis Saporta, the principal student of the fossil plants of Aix, "Ce genre devait y exister."

There are left the two Hesperidae, - a family not represented in the American rocks. One of these, Thanatites from Rott, belongs to the tribe Hesperini and is closely related to Thanaos, a genus found in the north temperate zones of both hemispheres, but rastly more developed in the New IVord, which has at least four times as many species as the Old, some of them extending into the sub-tropical regions; the adjacent genera are purely American, although tropical or sub-tropical, and therefore Thanatites looks toward sub-tropical North America for its prevailing affinities. Entirely the same is the case with Pamphilites of Aix, a butterfly belonging to the other tribe of Hesperidae. The food plant of both these butterflies was very probably Leguminosae, which occur in abundance both at Rott and at Aix.

The allies therefore of nearly one half of the European fossil butterflies are to be looked for in the East Indies: of one third of them in America, and especially sub-tropical America ; of the remainder, at home; but, as among other insects and 

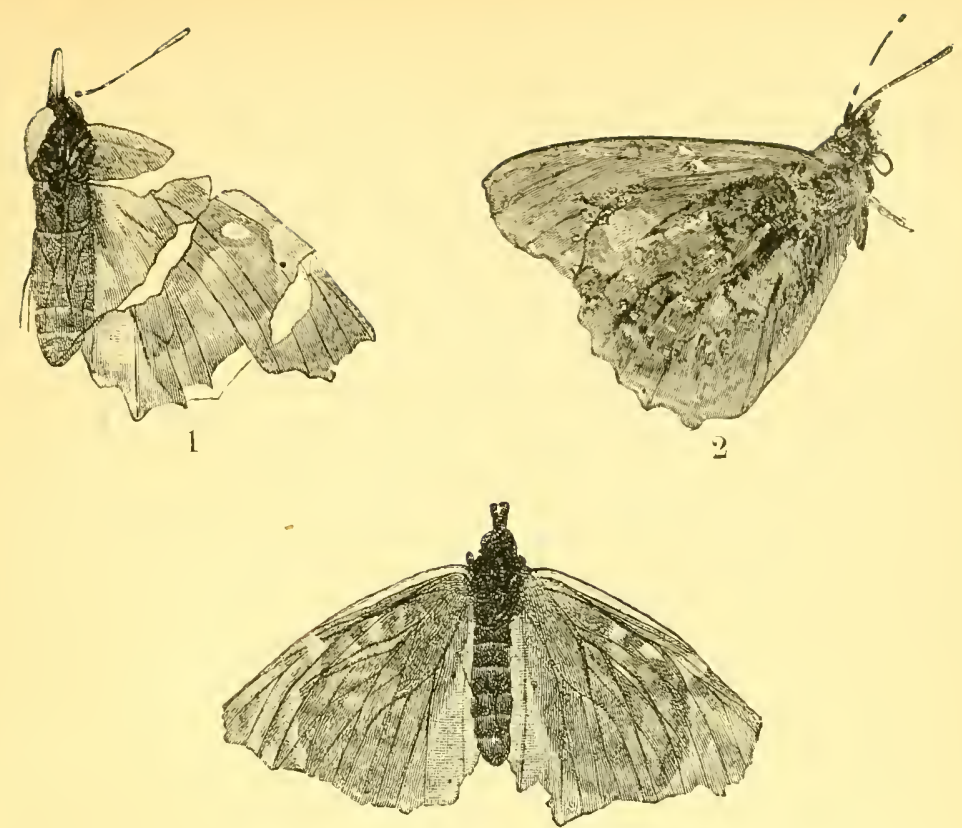

3


i

FOSSIL BUTTERFLIES 



\section{(IF THE PAST}

among the plants, there is a growing likeness to American types as we pass upwarl through the tertiaries.

The American fossil butterflies, fewer in number, less varied in character, and all from one locality, Florissant, are more quickly reviewerl. They all belong to extinct genera. Seven of the eight belong to the Nymphalidae, and all but two of these to a single tribe, Vanessini, of the subfamily Nymphalinae.

Of these, three, Prodryas, Jupiteria, and Lithopsyche, form a group by themselves, more closely allied to one another than to any living forms, but having distinct affinities to certain butterflies of Central and generally subtropical America. A fourth, Nymphalites, is related to them, though not very closely, and it, too, finds closer relations among Central American butterflies. The fifth, Apanthesis, is still farther removed, and is related, as closely as to anything, to a tropical American group of butterflies geographically isolated, all of its immediate relations being East Indian. Of none of the butterflies to which all of these Nymphalinae are allied is the food plant of the caterpillar known.

The other Nymphalids, Prolibythea and Barbarother, are of special interest, for they belong to 
the curious sub-family Libytheinae of which only a dozen species are now known, and these scattered all over the globe. No group of butterflies exists with so many anomalies of structure; none, so far removed from its nearest neighbors, which is anywhere nearly so poverty-stricken in forms. It is a clear case of a waning type; and that ont of the paltry dozen or two of fossil butterflies two should be found to belong to a group which cannot number one tenth of one per cent. of living forms is indeed a surprise. It has a further interest, for the existing Old Workl forms of this group and those of the New are separated by characters which are unmistakably combined in these fossils, thongh on the whole their relations are closer with the Old World than the living New World type, and specially with a form from West Africa. The group as a whole is distinctly tropical and sub-tropical and widespread, so that the sub-tropical aspect of the previously mentioned Florissant forms is not disturbed. The food of the caterpillar, as far as known, is exclusively Celtis, and it is therefore interesting to note that Lesquereux has found among the fossil plants of Florissant, in the same beds with these fossils, two perfectly well preserved leaves of a very fine Celtis, whose generic 
relations are unquestionable: with them were also found fragments of flowers which could have been readily armitted as of the same species. It is therefore highly probable that Prolibythea vagabunda and Barbarothea florissanti fed on Celtis maccoshi.

The last American fossil is Stolopsyche, one of the Pierini, more nearly allied to Pieris than to any other, but not very closely allied; wherein it departs from it, it approaches some sub-tropical forms. Little can be said of it, and nothing can safely be sumised of its food plant.

The aspect of the Florissant butterfly fama is therefore distinctly southern; and while tertiary America does not fully return the compliment tertiary Europe seems to pay it, there is a certain Old World aspect in the representatives of that gypsy-type, the Libytheinae.

There are one or two points further in our American fossil butterflies which it is interesting to note. In two or three of them the structure of the front legs can be determined, and we are able to note that in this oligocene time, among the earliest butterflies that have come down to us, we have the same structure of the fore leg in the female Libytheinae that we have to-day; while at 
the same time the atrophy of the male fore leg's is shown to have reached in Nymphalites the same stage which it now possesses. In other words, the developmental plane of butterflies appears to have been the same in those days as now.

On the other hand, there are some marks of a lesser degree of development in one of our fossils, in the character of the ornamentation; for Prodryas has fore wings which in form, proportions, and markings would be taken at once for those of an Hesperian, the lowest, rather than of a Nymphalid, the highest, of butterflies; the markings of the hind wings are, however, distinetly Nymphalideous, though some tropical American Hesperidae have some features nearly resembling them. A greater simplieity of markings than is common to their existing relatives is also seen in Neorinopis and Apanthesis. 


\section{INDEX TO NAMES OF INSECTS}

Acanthosoma nebulosa, 80.

Acraeinae, 16.

Ageronia, 52, 88, 92, 93, 94, 95, 168, 240.

Aglais milberti, $39,42,43,76,81,143$, 246.

Aglais urticae, 66, 63, 90, 246, 258.

Agriades, 146, 213.

Agrotis carnea, 150 .

Agrotis imperita, 150 .

Agrotis islandica, 150 .

Aimblyscirtes samoset, 79 .

Amblyscirtes vialis, 79 .

Anosia, 116, 217.

Anosia plexippus, $10,19,41,125,141$, $143,158,169,185,189,192,253$.

Anthocharini, 260.

Anthocharis, 157.

Antirthea, 167.

A panthesis, 273, 276.

A poria crataegi, 119.

A postraphia cliarithonia, 182.

Argynnimi, 38, 43, 48, 98, 157, 217, $221,222,229,260$.

Argymuis, 124, 169, 229.

Argymis atlantis, $76,81,169$.

Barbarothea, 273.

Barbarothea Horissanti, 275.

Basilarchia, 9, 22, 41, 44, 155, 161, 198, 214.230.

Basilarchia archippus, 9, 19, 74, 80, $81,106$.

Basilarchia arthenis, 73, 81, 125.

Busilurehia astyamax, 10,20 .

Basilarchia eros, 19.

Bibio femoratus, 80 .

Bombycidae, 174.

Brassolinae, 168.

Brenthis, 53, 85, 89, 95, 147, 152, 213, $228,229,230$.

Brenthis bellona, 76,81 .

Bienthis montinus, $82,84,246$.

Brenthis myrina, 76,81 .

Callidryas, 165, 170.
Callidryas eubule, 144, 171.

Callophrys rubi, 97, 93.

Calosoma, 190.

Catonephele, 241.

Catopsilia, 166.

Ceratinia, 51.

Cercyonis alope, 44, 123, 182.

Charaxes, 169.

Chlorippe celtis, 188.

Chlorippe elyton, 43.

Chrysophanini, 77, 218, 225, 229.

Chrysophanus, 48.

Chrysophams thoe, 218.

Cinclidia, 105.

Cinclidia harrisii, 41, 42, 76, 77, 158.

Cissia eurytus, 121.

Coccinella, 61.

Coenonympha, 213, 214.

Colias edusa, 190.

Colias rhamni, 143.

Coliates, $268,271$.

Cupido, 213, 214.

Cyaniris, 77, 210, 223.

Cyaniris argiolus, 209.

Cyamiris psendargiolus, $77,80,81,170$, 182, 189, 209, 221.

Dasyoplithalma, 168.

Didonis, 52, 165, 168.

Dircenna, 51.

Enodia portlandia, 121.

Epicalia, 224.

Epidemia, 213.

Epidemia epixanthe, 218.

Erebia, 85, 86, 146, 213, 214 .

Ergolis, 220.

Erora laeta, 218.

Erymmis, 213.

Erymis comma, 214.

Eneides, 64.

Eugonia, 133, 212, 267, 270, 271.

Engonia j.-album, $43,75,80,81,143$, 188.

Eugonia vau-album, 212.

Eumica, 92. 


\section{INDEX TO NAMES OF INSECTS}

Euphoeades, 158, 237.

Euphoeades palamedes, 111.

Euphoeades troilus, 40, 44, 161, 189.

Euphydryas, 105.

Euphydryas phaeton, 76, 77 .

Euploeinae, 13, 18, 37, 164.

Euptoieta claudia, 158.

Eurema lisa, 157, 191.

Eurymus, 61, 85, 86, 124, 146, 155, $213,222$.

Eurymus eurytheme, 44, 247.

Eurymus interior, 78.

Etirymus philodice, 77, 125, 182, 222, 247.

Euvanessa antiopa, 42, 58, 75, 81, 86, $91,92,101,131,140,142,143,189$, $190,207,208$.

Everes amyutas, 246.

Everes conyutas, 246.

Feniseca, 201.

Feniseca tarquinius, 77.

Grapta, 123.

Hamadryas, 208.

Hamadryas io, 91, 141.

Heliconii, 4.

Heliconinae, 3, 165.

Heodes, 117, 209, 210.

Heodes hypophlaeas, 77, 124, 125, 182, 183, 209.

Heodes phlaeas, 209.

Heraclides cresphontes, 161.

Hesperidae, 40,41, 49, 50, 85, 86, 136 , $143,200,201,204,205,269,272,276$.

Hesperini, 40, 49, 102, 109, 111, 116, $166,217,272$.

Hypatus bachmanii, 40, 14 .

Ichneumonidae, 68 .

Incisalia niphon, 81.

Iphiclides, 158.

Iphiclides ajax, $70,247$.

Iphiclides podalirius, 247.

Ithomyia, 3, 5, 51 .

Ithomyini, 165 .

Jasoniades, 48, 158, 236, 237.

Jasoniades glaucus, 40, 51, 78, 81, 125, $157,223,243$.

Junonia coenia, 39, 124, 144.

Jupiteria, 273.

Laertias, 158, 172.

Laertias philenor, 39, 41, 43, 130, 131, 158.

Lemonias, 213, 214.

Leptalides, 3, 14.

Isptalis, 170 .

I,ethites, 269.

Libytheinae, 274,275 .
Limochores taumas, 81.

Lithopsyche, 273.

Lycaenidae, 49, 96, 100, 117, 119, 128, $143,204,269$.

Lycaeninae, 45, 48, 97, 136, 200, 201, $205,260,263,266$.

Lycaeniui, 48, 77, 85, 86, 136, 170, 222, 263,266 .

Maucipium brassicae, 66, 172, 173.

Mechanitis, 51 .

Melete, 165, 166, 171.

Melitaeini, 39, 40, 43, $66,85,86,110$, 229.

Morphinae, 165, 166, 167.

Morpho, 91.

Mylothrites, 271.

Neorinopsis, 269, 276.

Nephila, 5.

Notodonta, 28.

Nymphalidae, 42, 49, 64, 93, 99, 115 , $119,131,143,189,220,239,269,273$, 276.

Nymplalinae, 18, 48, 52, 76, 98, 131, $165,166,168,273$.

Nymphalini, 76, 136.

Nymplialites, 273, 276.

Oeneis, $85,86,146,147,151,153,173$, $210,211,213$.

Oeneis jutta, 121, 210.

Oeneis macomii, 155.

Oeneis norna, 172.

Oeneis semidea, $81,83,125,135,137$, 211.

Ornithoptera, 114.

Pamphila, 212.

Pamphila mandan, 78, 212.

Pamphilini, 40, 48, 49, 60, 103, 109, $114,117,118,136,156,217,223$, 236.

Pauphilites, 272.

Papilio, 123, 158, 213, 236.

Papilio machaon, 159, 173.

Papilio polyxenes, 159, 219, 243.

Papiliondae, 49, 119, 127, 143, 269, 270, 271.

Papilioninae, 46, 48, 116, 155, 160, 161, 171, 198, 204, 205, 240, 270.

Paruassini, 117.

Parnassius, 85, 86, 213, 214.

Paruassius apollo, 93.

Phyciodes, 214.

Phyciodes batesii, 76.

Phyciodes tharos, 52, 76, 81 .

Pierinae, $3,49,69,70,77,100,115$, $165,166,170,191,203,270,271$.

Pierini, 157, 260, 275.

Pieris, 171, 212, 258, 275.

Pieris napi, 171, 212. 
Pieris oleracea, 78, 124, 171, 212.

Pieris rapae, 66, 78, 81, 129, 171, 191, $192,207,212$.

Polygonia, 39, 80, 110, 129, 143.

Polygonia c.-album, 1+1, 211.

Polygonia faunus, $39,74,75,81,92$, $10 \%, 161,211$.

Polygonia gracilis, 75, 81 .

Polygonia interrogationis, 81 .

Polygonia progne, 43, 75 .

Pontia, 213, 267, 271.

Pontia daplidice, 247.

Pontia protodice, 247.

Prepona, 166.

Prodryas, 273, 276.

Prolibythea, 273.

Prolibythea vagabunda, 275.

Rhodocerini, 49, 143, 144, 157, 217, $222,260$.

Rusticus aegon, 246.

Rusticus argus, 246.

Rusticus scudderi, 247.

Satyrinae, $38,43,48,53,110,111,116$, $121,124,135,156,167,190,199,217$, $235,260,269,270$.

Semnopsyche diana, 20, 37, 219, 221, 222.
Speyeria, 115.

Stichophthalma, 167.

Stolopsyche, 275.

Strymon titus, 40.

Tasitia berenice, 19 .

Thais, 111, 271.

Thais polyxena, 173.

Thaites, 271.

Thanaos, 272.

Thanaos icelus, 79, 81 .

Thanatites, 272 .

Thammantis, 91, 166.

Theclini, 48, 77, 110, 139, 170, 217, 229,264 .

Thymelicus brettus, 219, 223.

Thyridia, 51.

Tomares ballus, 264 .

Vanessa, 39, 123, 144, 208.

Vanessa atalanta, $41,59,86,98,102$, 104, 122, 189, 207, 209.

Vanessa cardui, 58, 86, 104, 189, 207, $209,218,245,253$.

Vanessa huntera, 40, 105, 189, 217.

Vanessini, 48, 68, 69, 89, 94, 121, 139 , $143,156,273$.

Xanthidia nicippe, 144. 



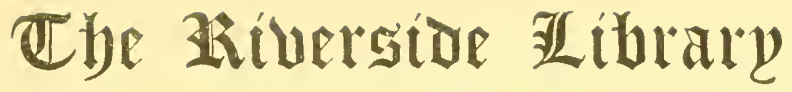

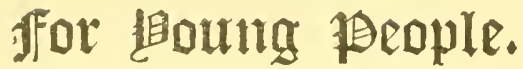

A Series of Volumes devoted to Mistory, Biography, Mechanics, Travel, Natural History, and Adzenture. Each, $16 \mathrm{mo}, 200-250$ pages, 75 cents.

1. The War of Independence.

By John Fiske. With Maps.

2. George Washington: An Historical Biography.

By Horace E. Scudder. With Portrait and Illustrations.

3. Birds through an Opera Glass.

By Florence A. Merrian. Illustrated.

4. Up and Down the Brooks.

By MARY E. BAMFORD. Illustrated.

5. Coal and the Coal Mines.

By Homer Greene. Illustrated.

6. A New England Girlhood, Outlined from Memory.

By Lucy Larcon.

7. Java: The Pearl of the East.

by Mrs. S. J. Higginson. With a Map.

8. Girls and Women.

By Harriet E. Paine.

9. A Book of Famous Verse.

Selected and arranged by AGNes Repplier.

ro. Japan: In History, Folk-Lore, and Art.

By W'illian Elliot Griffis, D. D.

II. Brave Little Holland, and What she Taught us.

By Willian Elliot Griffis, D. D.

12. Photography Indoors and Out.

A Book for Amateurs. By Alfixander Black. Illustrated.

13. Four-Handed Folk.

By Olive Thorne Miller. Illustrated.

r4. Japanese Girls and Women.

By Alice M. Bacon.

15. Frail Children of the Air:

Excursions into the world of Butterflies. By Sanuel H. Scudder. Illustrated. 


\section{Critical fRotices.}

\section{FISKE:S War of Independence.}

John Fiske's book, "The War of Independence," is a miracle. I can neve: understand why, when a perfect literary work is issued, all the critics do not clap their hands! I think it must be because they never read the books. This story of the war is such a book, brilliant and effective beyond measure. It should be read by every voter in the United States. It is a statement that every child can comprehend, but that only a man of consummate genius could have written. - Mrs. Caroline H. Dall, in the Springfield Republican.

The story of the Revolution, as Mr. Fiske tells it, is one of surpassing in terest. His treatment is a marvel of clearness and comprehensiveness; dis carding non-essential details, he selects with a fine historic instinct the main currents of history, traces them with the utmost precision, and tells the whole story in a masterly fashion. His little volume will be a text-book for older quite as much as for young readers. - Christian Union.

\section{SCUDDER'S George Washington.}

Mr.Scudder's biography of Washington is a fit companion volume for Mr. Fiske's little history. It tells the story of the great patriot, soldier, and statesman with simplicity, sincerity, and completeness. It is not too much to say of these books that they ought to be put into the hands of every boy and girl, not only because of that which they contain, but because of the soundness of their form. - Christian Union (New York).

Mr. Horace E. Scudder has executed a difficult task in a praiseworthy manner. In spite of the innumerable lives of the first President, who shall say anything new of his career and paint it in fresh colors? Mr. Scudder has been able to do this, and his book will be welcomed by old and young. - Boston Beacon.

\section{EMERRIAM'S Birds through an Opera Glass.}

A capital text-book of the right sort for young observers of Natural History. By text-book we do not mean a formal school-book, but a book with a clear method, a capital style, and adequate information. This little volume describes all the birds to be found in our fields and woods; describes them, not as an ornithological treatise, but as a keen-eyed and thoroughly interest. ing observer would describe them. Such a volume ought to be the companion of every intelligent boy and girl during the summer.-Christian Union (New York).

The book is deserving of praise for its eminently practical nature. The hints to observers with which it opens, the appendix giving the classification of birds by general family characteristics, by localities, by colors, by song, the books of reference, and the index, all combine to make the book extremely useful. - The Academy (Syracuse). 


\section{GREENE'S Coal and the Coal Mines.}

In the vehicle of the author's terse, vigorous language, the reader is then taken down into the subterranean passages, where he is almost made to see the operations of mining the fuel, so vividly and picturesquely is the information conveyed. Interesting and valuable statistics are quoted, amusing incidents are related, entertaining descriptions and wise suggestions are given and made, and, taken altogether, though dealing largely with what is essentially dry in its nature, the book makes good reading for the old as well as the young. - The Ancrican (Philadelphia).

The exhaustive theme of coal and coal mining is made so concise and simple thit a child can thoroughly comprehend it. The anthor covers the ground of study in a simple and interesting way, and furnishes illustrations to make the words clearer. - New Jork School Journal.

\section{MISS BAMFORD'S Up and Down the Brooks.}

This is a book which it is a pleasure to read and a duty to praise. Miss Bamford tells us of her rambles by the California brookside, and her acquaintances made there; of their habits, their transformations, death and burial, or happier release after a period of observation by the captor. . . . On the whole, we do not know among recent books any more likely to give pleasure to the nature-loving boy or girl, or more calculated to stimulate the taste for healthy recreation and good reading. - The Nation (New York).

A charming book, full of most fascinating details in the lives of little known insects, and opening a rich field of study and interest, accessible to every country child. . . IVe would put the book into the hands of every girl and boy. - Epoch (New York).

\section{MISS LARCOM'S New England Girlbood.}

More than all, as a vivid, tenderly sympathetic yet uncompromisingly truthful picture of phases of New England life, in home and at work, which have now practically ceased to be, the booli has a permanent, one may say an historical value. - Boston Advertiser.

The story is one that will aid other girls to make the most of their oppor tunities, and help them in understanding the real value of life. It is a book that every girl will be better for having read. - Boston Herald.

\section{HARRIET E. PAINE'S Girls and Women.}

I do sincerely hope that all the giris of the day may read it; it is capable of making a splendid generation of them.... I shall be very glad if any words of mine can aid in the least the introduction to notice of such a book as "Girls and Women." It will not need much praise; it will praise itself. - Adeline D. T. Whitney, Milton, Mass.

It fills the place for young women that is filled for young men by Dr. Munger's book, "On the Threshold." . . Miss Chester's words are worth their weight in gold. - Boston Herald.

There are not very many such books written in a manner both instructive and enjoyable, and this will be a valuable addition to any young girl's library, and also a suitable volume to take up and read aloud at home or in social groups when fiction becomes a weariness. - LUCy LARCoN, Beverly, Mass.

An admirable book, the work of a practical woman, of a wise woman, a woman of well rounded character and warm sympathies. - The Evangelis: (New York) 


\section{BLACK'S Pbotography Indoors and Out.}

This is a thoroughly practical book. It is addressed to amateurs who wish to do good work and acquire a real and intelligent mastery of the subject. - New York Indepondent.

He offers here a distinctly useful book. It is a clear, reliable, and convenient manual for the host of amateur photographers who are going all over the world in search of the picturesque. - New York Photografhic Times.

It is easily the best of its class and and takes up the whole subject in a plain, matter-of-fact way, going into details sufficiently so as to leave nothing to be taken for granted, and elucidating difficult processes very distinctly. We have no hesitation in heartily recommending it to all who are yet in the earlier grades of photography and wish to make themselves Masters. Public Ofinion, Nezu York.

\section{MRS. MILLER'S Four-Handed Folk.}

A most fascinating book about monkeys and their kind by a keen observer and a charming writer. Children and grown people alike will be interested and instructed by this entertaining book. - New York Observer.

Animal lovers will extract much enjoyment from these pages, while those scientifically interested will find these intimate studies both valuable and suggestive. - Boston Transcript.

It is a delightful book in both style and substance. - Vew York Independcut.

\section{MISS BACON'S Japanese Girls and Women.}

The author of this volume seems to us to show not alone careful research, but to have treated a delicate subject with uncommon skill. . . V Ve are positive that if carefully read a better comprehension will be had, not alone of the women, but of the condition, of Japan. . . . The quaintness of Japan, the fine sense of honor there, the high breeding, the courtesy of the people, both high and low, and the fascination of it all, can be readily understood by reading the book. - New York Times.

One longs to know some of the quiet, sweet women whom Miss Bacon shows us in this charmingly written book. - Evangclist, Now York.

\section{SCUDDER'S Frail Children of the Air.}

It is to be heartily commended, not only to those who desire to make collections of butterflies, but to all who are interested in the wonders of insect life: for to many readers who come new to the subject the revelations here given of the intelligence and adaptation of the lower order of creation will have all the fascination of a romance. - Boston Beacon.

The expert can but admire it for its scientific interest, while the ordinary reader can but enjoy it for its directness, clearness, and ardor. - Jourmal of Education, Boston.

The result is both interesting and instructive, and opens up a new world of observation to those who cannot go deeply into the study of natural history. - Living Church, Chicago. 


\section{MISS REPPLIER'S A Book of Famous Verse.}

The "Book of Famous Verse," which Agnes Repplier has selected, is primarily intended for children whose enjoyment from poetry, being "far. reaching and of many kinds," she wisely thinks should be obtained from the noblest streams. Accordingly, she has chosen this collection from the rich orchard field of English verse, with the sole purpose of giving pleasure, and with an effort carefully to study the tastes, feelings, and wishes of children. The collection has been made with much intelligence as well as care, and better will be that child into whose hands it falls. - New York Times.

One can only praise the good feeling, good taste, and good judgment shown in the selections which have been made. The child who becomes familiar with these poems may be sure of acquaintance with that which is best in the poetry of our English tongue. - Christian Register (Boston).

The older children of ten clesire a vorime which, without being too bulky, may contain the best of the standard ballads and otler favorite poems. Miss Agnes Repplier has made a collection which will supply this need very well. - The Congregationalist.

\section{DR. GRIFFIS'S Japan.}

In writing of the "history, folk-lore and art" of Japan, Dr. Griffis has found occasion to discuss quite fully the history of both the people and the Government. His opportunities for gaining a knowledge of these subjects were exceptionally good, for he was upon the ground before old Japan had retired from the stage, and he saw much of the struggle between the old order of things and the new. The story of this revolution is of special interest to our people, since it is due largely to the example, the influence, and the teaching of America that new Japan is the furst of oriental countries to try the experiment of constitutional government and of western civilization. ... Most of the volume is occupied with myths that bear about the same resemblance to the myths of the Greeks that Japanese art bears to the art with which we are familiar. . . The explanation of the myths admits us to the world of thought and sentiment in which the people live. - Boston Transcript.

\section{DR. GRIFFIS'S Brave Little Holland.}

This book is a marvel of investigation. It might be thought the writer had spent a score of years in studying musty old folios to gain information. It is packed full of facts which have a most interesting relation to the early settlement of this country, and shows how much Dutch methods and ideas had to do with the formation of American institutions. It must help to a far higher appreciation of Hollandish influences than is commonly enter tained. While it is full of history, the story is told in a charming way. Christian Inquirer (New York).

His book will be read far and wide and greatly enjoyed. It is everywhere bright and interesting to a remarkable degree. - Boston Herald.

\section{HOUGHTON, MIFFLiN \& CO., Boston. \\ I EAST I7TH StREeT, New YORK.}








SMITHSONIAN INSTITUTION LIBRARIES

|| |||||||||||||||||||||||||||||||||||||||||||||||||||||||||||||||||||||||||||||||||||||||||||||||||||||||||||||||||||||||||||||||||||||||||||

$\begin{array}{llll}3 & 9088 & 00721 & 3762\end{array}$ 